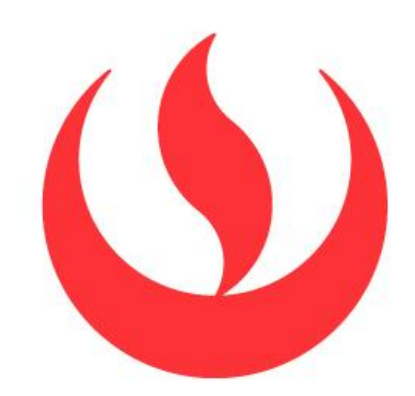

UNIVERSIDAD PERUANA DE CIENCIAS APLICADAS

FACULTAD DE NEGOCIOS

CARRERA DE ADMINISTRACIÓN DE EMPRESAS

\title{
"COMPETENCIAS CRÍTICAS DE LA MUJER EJECUTIVA DEL BANCO SCOTIABANK EN LIMA METROPOLITANA"
}

Tesis:

Proyecto de investigación para optar por el título profesional de Licenciado en Administración de Empresas

Autor:

Bullón Solís, Nadia (0000-0002-2472-7111)

Asesor de tesis:

Gamarra Vargas, Natalie (0000-0002-7289-6462)

Lima, 18 de Julio de 2018 


\section{Agradecimientos}

Mi mayor agradecimiento es para Bruno, quien me motivo y alentó desde que inicie este proyecto a no darme por vencida, sacrificando valiosos momentos para que pueda concentrarme y culminar esta meta.

A Natalie Gamarra, mi asesora, por sus constantes asesorías por no perder la fe en mí y darme la oportunidad de recuperarme y demostrar mi compromiso con la investigación.

A Miguel, quien siempre creyó en mí y me apoyo a seguir creciendo en la empresa y desarrollar mi tesis, por las vacaciones otorgadas en meses seguidos que me permitieron culminar mi fase de entrevistas.

A Oscar, quien apoyo mi tema desde un inicio y me recomendó los libros de Martha Alles, experta en competencias, por orientarme tanto en el trabajo como en la tesis y por alentarme a seguir creciendo en Scotiabank.

A Elvis, por apoyarme desde que inicie mis estudios y por sus valiosas recomendaciones que enriquecieron este trabajo.

A todas las entrevistas que participaron de esta investigación, la calidez de su recibimiento y por compartir sus experiencias personales y profesionales de crecimiento. Su especial colaboración ha sido muy valiosa para el presente estudio. 
Dedicatoria

Este estudio, está dedicado a todas aquellas mujeres que formaron parte de él, y a todas aquellas que aspiren crecer profesionalmente dentro de la banca comercial.

A Dios por guiar mi camino y a mis padres y hermano por ser la motivación de mi crecimiento personal y profesional. 


\section{RESUMEN}

El presente trabajo de tesis tiene como objetivo identificar las competencias críticas que tienen las mujeres ejecutivas del banco Scotiabank en Lima Metropolitana.

En el primer capítulo, se presenta el marco teórico que permitirá comprender la situación actual de las mujeres ejecutivas, las barreras que enfrentan para su desarrollo profesional y sus competencias críticas. En el segundo capítulo, se realiza una investigación cualitativa basada en el estudio del caso que permitirá identificar las competencias críticas que las mujeres ejecutivas de scotiabank han desarrollado. En el tercer capítulo, toda la información obtenida se analiza para responder cada una de las preguntas de investigación. En el cuarto capítulo, se detallan cada hallazgo encontrado de la investigación.

Finalmente, se presentan las conclusiones y las recomendaciones finales sugeridas a partir de los resultados obtenidos en la investigación.

Palabras Claves: competencias críticas, mujer ejecutiva, Scotiabank,

\section{ABSTRACT}

The present paper aims to identify the core competencies that executive women from Scotiabank in Lima possess. In the first chapter, the theoretical framework will allow to understand: the current situation of executive women in banking, the barriers they face and their core competencies. In chapter two, a qualitative investigation is carried out based in the case study research that will allow to identify the core competencies that executive woman in Scotiabank have developed. In the third chapter, all the information collected will be analyzed and an answer is given to each one of the research questions.

In chapter four, the findings of this research are detailed.

Finally, in the last chapters the conclusions and recommendations for this study are presented, which are the result of the process that led to the findings.

Keywords: core competencies, executive women, Scotiabank. 


\section{TABLA DE CONTENIDO}

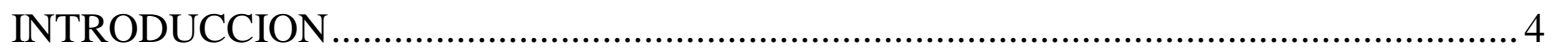

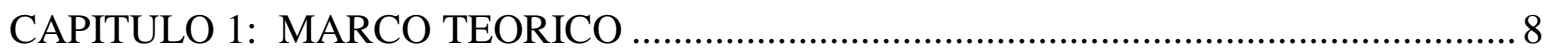

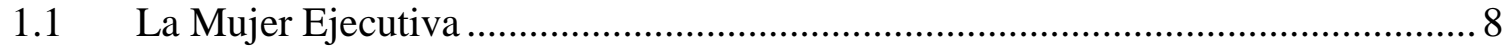

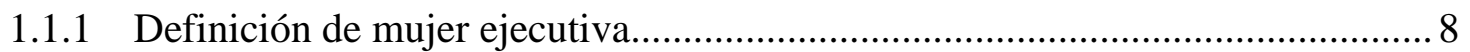

1.1.2 Perfil de la mujer ejecutiva en Latinoamérica ................................................. 9

1.1.3 Barreras que enfrentan las mujeres ejecutivas..................................................

1.1.4 Situación actual de la mujer ejecutiva ............................................................ 12

1.1.4.1 Situación actual de la mujer ejecutiva internacional ................................ 12

1.1.4.2 Situación actual de la mujer ejecutiva en Perú .......................................... 14

1.1.4.3 Normas legales de apoyo para mujeres en Perú ....................................... 15

1.1.4.4 Situación de la mujer ejecutiva en la banca comercial internacional ........ 15

1.1.4.5 Situación de la mujer ejecutiva en la banca comercial en el Perú............. 16

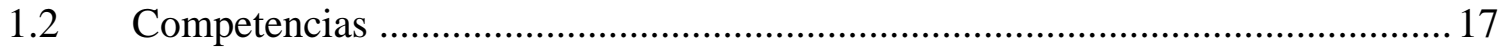

1.2.1 Definición de competencias....................................................................... 17

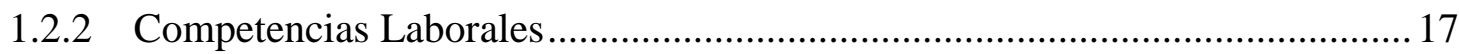

1.2.2.1 Componentes de una competencia laboral .............................................. 18

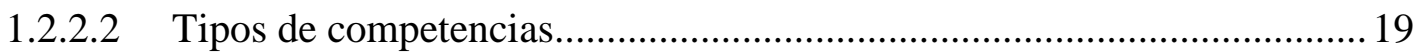

A. Competencias Cardinales ......................................................................... 19

B. Competencias Específicas Gerenciales ........................................................ 20

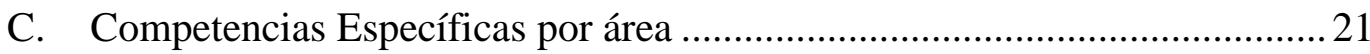

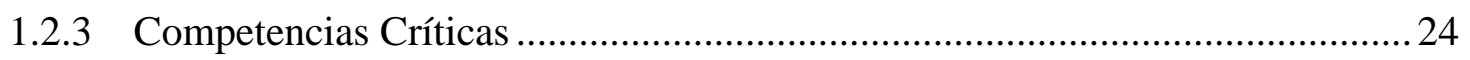

1.2.3.1 Definición de competencias críticas .........................................................24

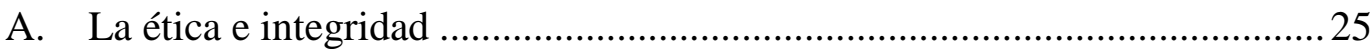

B. La orientación hacia el cliente interno y externo..............................................27

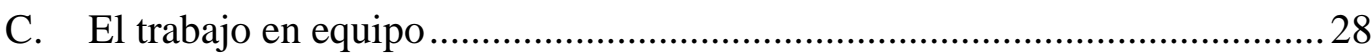

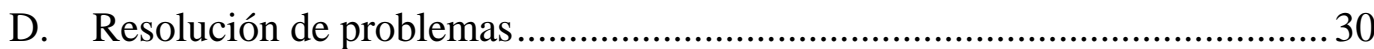

1.2.3.2 Importancia de las competencias críticas ................................................... 30

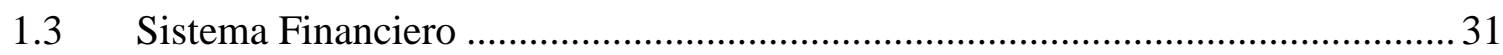

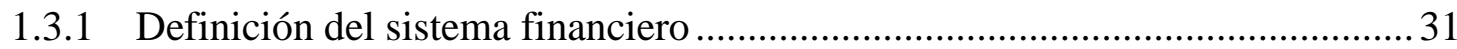


1.3.2 Definición de la banca comercial ................................................................... 32

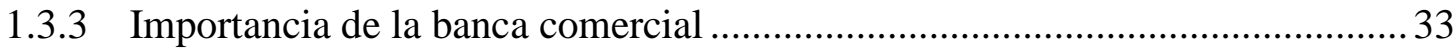

1.3.4 Situación actual de la banca comercial............................................................... 34

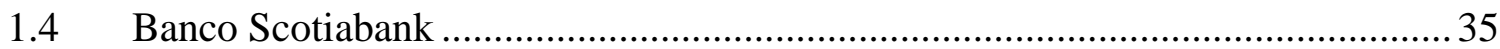

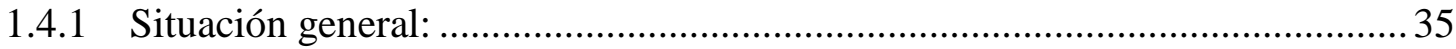

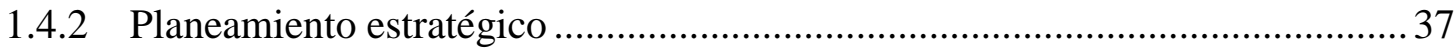

1.4.3 Posicionamiento dentro de la banca comercial en el Perú................................... 38

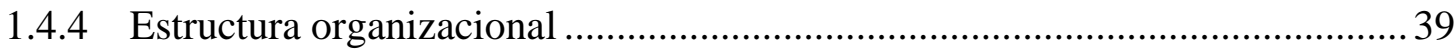

CAPITULO 2: METODOLOGIA DE INVESTIGACIÓN ................................................... 42

$2.1 \quad$ Planteamiento de la investigación ...................................................................... 42

2.1.1 Propósito de la investigación:.......................................................................... 42

2.1.2 Tipo de investigación ................................................................................. 42

2.1.3 Preguntas de la investigación: ........................................................................ 43

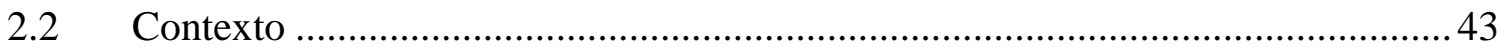

2.2.1 Descripción del contexto interno y externo ........................................................ 43

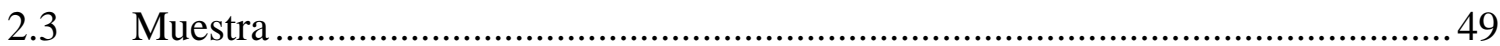

2.3.1 Descripción de la muestra: ............................................................................. 49

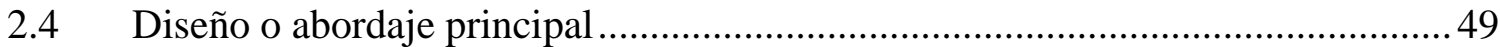

2.4.1 Identificación de la estructura de la entrevista. ...................................................49

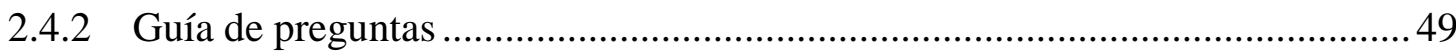

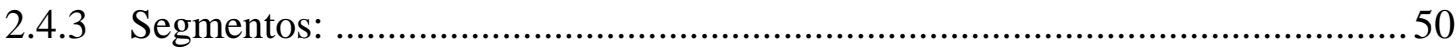

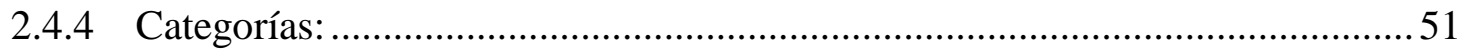

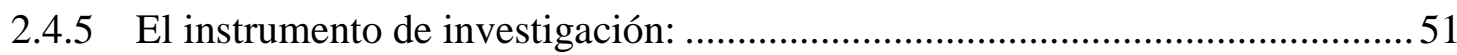

$2.5 \quad$ Procesamiento de la información: ................................................................... 51

2.5.1 Matriz de codificaciones por segmento ………………………..................... 51

2.5.2 Matriz de aspectos positivos y negativos …………………………………........5

CAPITULO 3: ANÁLISIS DE DATOS Y RESULTADOS................................................58

CAPITULO 4: DISCUSION DE RESULTADOS ............................................................ 77

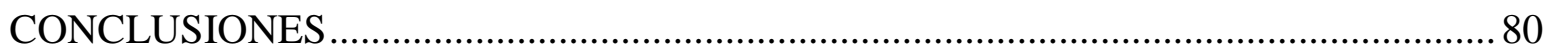

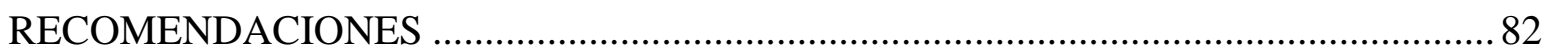

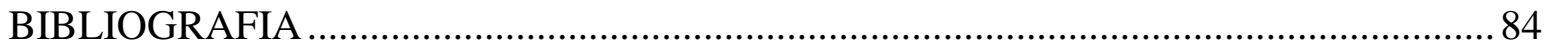




\section{INDICE DE TABLAS}

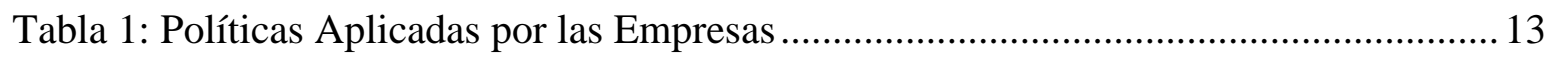

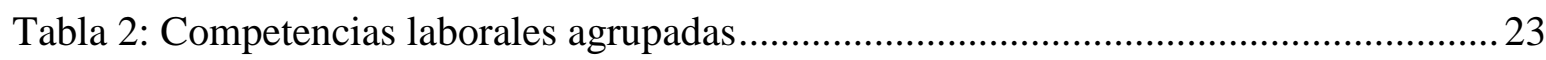

Tabla 3: Marco conceptual de competencia ética................................................................26

Tabla 4: Composición del sistema financiero peruano........................................................... 32

Tabla 3: Créditos Directos Banca Múltiple al 30 de Junio del 2015 ....................................... 38

Tabla 4: Patrimonio de la Banca Múltiple al 30 de Junio del 2015......................................... 39

Tabla 5: Proporción de ejecutivos comerciales .................................................................... 40

Tabla 6: Proporción de ejecutivos principales por cargo ...................................................... 41

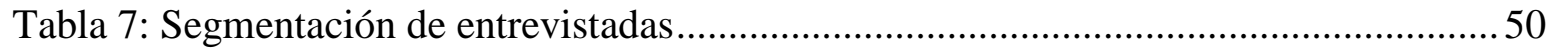

Tabla 8: Disparidad salarial en diferentes niveles de jerarquía según estado civil ...............63

Tabla 9: Sentimiento de culpa en diferentes niveles de jerarquía según estado civil............66

\section{INDICE DE FIGURAS}

Figura 1: Contribución de segmentos al aumento de créditos ................................................ 35

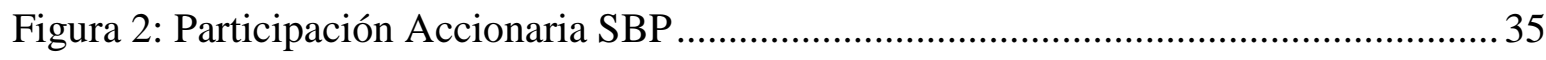

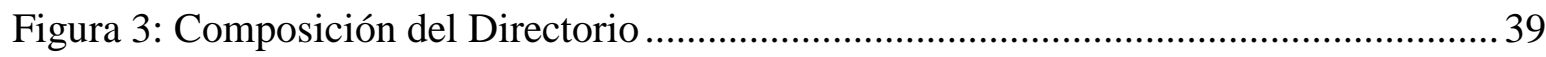




\section{INTRODUCCION}

La presencia de la mujer en el mercado laboral representa un avance para el desarrollo de la economía de un país y su participación no ha hecho más que aumentar en la última década. Según el Instituto Nacional de Estadística e Informática (INEI), en el Perú al 2015 las mujeres constituían la mitad de la población, 15 millones 545 mil 800 mujeres de las cuales el 63\% se encuentran activamente trabajando. Esta es una cifra importante para indagar cómo están representadas jerárquicamente en las organizaciones, para lo cual, se tiene como base la encuesta de GREAT PLACE TO WORK (2014) que indica que solo el 29\% de los puestos ejecutivos y de alta dirección estaba representado por mujeres. No obstante, este porcentaje se incrementa a un $46 \%$ en el rubro de supervisores. Además, en una nueva publicación realizada por el INEI en marzo de 2016 se informa que el 49,7\% de las mujeres egresadas han obtenido su título profesional, cifra mayor en 13,3 puntos porcentuales a los hombres $(36,4 \%)$.

Por lo tanto, surge la pregunta: ¿Qué hay de aquellas mujeres que buscan y persiguen sus metas profesionales? Para responderla, se analizó un estudio realizado por la Universidad del Pacífico (2011) sobre las estrategias usadas por las mujeres ejecutivas para ser exitosas, se determinó tras revisar los perfiles de las entrevistadas, que una cualidad principal es la perseverancia, en donde, el esfuerzo que realizan las presentan como personas muy trabajadoras y responsables. Otra estrategia es definir los objetivos claros, puesto que, crear una visión de adonde se desea llegar ayuda a tener claridad y a mantener una actitud positiva. Además, el apoyo en casa es de suma importancia, según el estudio, tener esa base de apoyo sirve de impulso para poder dedicar más horas al trabajo y desarrollarse profesionalmente. Por ello, una segunda estrategia mencionada es el encontrar el balance entre la vida laboral y privada, es decir, aprovechar oportunidades laborales con flexibilidad de horarios y gestionar su tiempo para cada ámbito de su vida. Asimismo, la preparación y estudios tiene su propia formula, donde las mujeres se han dado cuenta que se necesita más que tener una carrera profesional, sino, además, deben capacitarse y especializarse constantemente para ser competitivas. Finalmente, destaca también, la adaptación a un 
entorno masculino, no sólo por las barreras que se presentan para las mujeres al escalar dentro de los puestos de una compañía y aprender de su entorno si no entender que se convertirán en un profesional exitoso sin importar el sexo.

Sé decidió revisar la realidad de las mujeres ejecutivas de países latinos para lo cual se seleccionó entre ellos el estudio realizado por Suárez Battán \& Asociados (2017), en Argentina, donde destaca que un $34 \%$ considera la banca como industria que facilita su desarrollo y en su mayoría pertenece a la generación X, entre los 35 y 55 años de edad. Respecto a experiencias anteriores para alcanzar su éxito lo más relevante fue la automotivación hacía la excelencia $80 \%$ y haber tenido un mentor en su carrera un $45 \%$. Con lo cual concluyen que las mujeres buscan la independencia económica y alguien (pareja) que la respalde en sus proyectos.

Esto se complementa con el análisis de Serna realizado en México, enfocado en la capital federal. En donde, a inicios del año 2000, sólo el 11.87 \% de mujeres del total de la PEA llevaban puestos directivos. Sin embargo, en comparación a los hombres con los mismos cargos en el sector financiero, el $49 \%$ de mujeres se desempeñaban como funcionarios y sólo $8.32 \%$ de las mujeres ocupaban cargos ejecutivos en el sector financiero. Por lo que, es muy importante recalcar que, el soporte familiar y la red de contactos lograda a través de buenas relaciones con sus allegados forman un punto de impulso para las mujeres de hoy en su camino a altos cargos directivos. "Algunas de estas mujeres ejecutivas se incorporaron al mundo del trabajo, en ocasiones, gracias a las redes de su familia de origen, en donde los amigos y conocidos desempeñaron un papel importante para lograr vincularse a alguna compañía que requería el perfil profesional que ellas tenían”. (Serna: 2003).

En el Perú, según ASBANC (Asociación de Bancos del Perú) al cierre del 2017, el 52.5\% del total de empleos en el rubro financiero son ocupados por mujeres, cifra que ha venido incrementando durante los últimos cinco años (2.2\% porcentuales). Destacando así, la importante labor del sector financiero en la igualdad de género. Con lo cual, surge la pregunta ¿Qué competencias han desarrollado las mujeres ejecutivas del banco Scotiabank para alcanzar los resultados actuales? y así más mujeres puedan desarrollarse en este sector que es el que más ha destacado en el tiempo disminuyendo la brecha de género. 
La hipótesis en la cual se basa el presente estudio es las competencias críticas que tienen las mujeres ejecutivas en el Banco Scotiabank en Lima Metropolitana son: la ética e integridad, la orientación al cliente, la resolución de problemas y el trabajo en equipo.

En ese sentido el objetivo general de esta investigación es analizar las competencias críticas que tienen las mujeres ejecutivas del Banco Scotiabank en Lima Metropolitana. Se plantean los siguientes objetivos específicos:

- Analizar la situación actual de la mujer ejecutiva en el banco Scotiabank en Lima Metropolitana.

- Identificar las principales barreras que enfrentan las mujeres ejecutivas en el Banco Scotiabank en Lima Metropolitana.

- Identificar las competencias críticas de la mujer ejecutiva en el Banco Scotiabank en Lima Metropolitana.

Esta investigación es relevante porque a la fecha del presente documento, la cantidad de mujeres en el sector bancario privado representa el 52.5\% según ASBANC cifra que evidencia un incremento en los últimos años de la presencia femenina en el rubro, sin embargo, a nivel ejecutivo sólo ocupan el 35.6\%, es por ello que se eligió indagar sobre las competencias críticas de la mujer ejecutiva en el banco Scotiabank en Lima metropolitana, ya que a la fecha no hay estudios precedentes. Además, se justifica la realización de la presente investigación desde las siguientes perspectivas: social, práctica y económica.

Desde una perspectiva social, este trabajo busca servir como una guía dando a conocer las competencias laborales necesarias que tienen las mujeres ejecutivas en el banco Scotiabank para impulsar el desarrollo profesional de las mujeres que quieran seguir una línea laboral para ascender. Como lo menciona Inés Temple "Tener ejemplos de mujeres que cumplen su carrera con satisfacción y al mismo tiempo tienen familias ayuda mucho. Esas líderes ayudan a las más jóvenes a cambiar los paradigmas que expresan 'no se puede', 'estás pidiendo mucho".

Desde una perspectiva práctica, esta investigación se justifica porque permitirá a las empresas de la banca comercial, identificar las competencias laborales necesarias para la mujer ejecutiva, cuya participación en el mercado laboral va en aumento en los últimos 
años, y con lo cual puedan desarrollar modelos de gestión por competencias que incrementen su competitividad y empleabilidad en el mercado. Según un estudio de la consultora Mercer en el 2013, se revelan datos que señalan la presencia de mujeres en altos cargos es muy baja (9\%), mientras que, la posibilidad de escalar a rangos superiores es de tan sólo $4 \%$.

Desde una perspectiva económica, el presente trabajo se justifica dado que a una mayor inclusión de mujeres a nivel ejecutivo permite ampliar la cantidad de talento, lo cual se ve reflejado en el rendimiento de negocio. Esto, es respaldado por varios estudios, como el de Catalyst en USA el 2007, cuyo resultado mostró que las empresas con 3 a 4 mujeres directoras tenían $83 \%$ más rendimiento sobre la rentabilidad propia, $73 \%$ mejor rendimiento de ventas y $112 \%$ mayor rendimiento del capital invertido. Otro estudio realizado en Estados Unidos el 2004 se llevó a cabo por Hay Group a 163 ejecutivos, dando como resultados que aquellas mujeres ejecutivas sobresalientes, en comparación a su contraparte masculina, generaron una mayor participación directa y mejor rendimiento de sus empleados.

Se decidió analizar el banco Scotiabank como estudio del caso, debido a que es el 3er banco con mayor participación de mercado peruano luego del BCP y banco Continental y en cuanto a patrimonio ocupa el 2do lugar sobre el banco Continental. Además, se trata de un banco con presencia internacional con raíces en Canadá y cuyas políticas se rigen a las de su casa matriz y cuenta con un comité de inclusión social desde el 2007 que desarrolla políticas de empoderamiento de la mujer ejecutiva en la organización.

Por ello, esta investigación se basa en el caso de la mujer ejecutiva en el banco Scotiabank en Lima Metropolitana; y contribuye a conocer mejor sus características para su desarrollo laboral. 


\section{CAPITULO 1: MARCO TEORICO}

\subsection{La Mujer Ejecutiva}

\subsubsection{Definición de mujer ejecutiva}

Para precisar el significado de la persona ejecutiva y en que consiste su posición. Se consultó diferentes autores empezando por Mercado \& Salgado (2008), quienes definen al ejecutivo de la siguiente manera: El rol del ejecutivo se caracteriza por enfrentar luchas permanentes para alcanzar los objetivos de la empresa, por tomar decisiones de peso que repercuten en la vida, o muerte, de la organización y hasta reflejan el comportamiento del nivel de empleo y desempleo del país. En otras palabras, la primera responsabilidad de un ejecutivo es ser eficaz y, la segunda, mantener esa eficacia. (p. 25)

Además, de acuerdo con la definición de Drucker (2013), se define a la persona ejecutiva como: Todo trabajador cerebral, en una moderna empresa, es un ejecutivo si, en virtud de su posición y conocimientos, es responsable de un aporte que gravita materialmente en el funcionamiento y resultados de la organización. (...) dicho hombre o mujer, debe adoptar decisiones y no concretarse a cumplir órdenes. (p. 13).

Pero más que eso, Mitch McCrimmon (2017) se refiere al ejecutivo como aquella persona que ocupa una posición a cargo de varias personas y recursos en una organización. Entonces, al hacer mención de las mujeres ejecutivas, se refiere a aquellas profesionales que alcanzaron cargos de mando en su centro laboral, y que tienen a cargo a un cierto número de colaboradores, así como también tienen metas, las cuales se basan en los objetivos de su organización. 


\subsubsection{Perfil de la mujer ejecutiva en Latinoamérica}

En un estudio realizado por la revista Incae Business Review en el año 2013, publicado en la Revista Conexión ESAN, el perfil de la mujer ejecutiva latinoamericana es:

- La edad de las mujeres ejecutivas es entre los 25 y 55 años.

- El 96\% poseen estudios universitarios.

- El 65\% estudió ciencias económicas y administrativas o ingeniería

- El 79\% cuenta con estudios de posgrado.

- El 85\% tiene hijos.

- El 38\% realizó sus estudios en el extranjero.

Avolio \& otros (2013), realizó un estudio de la mujer ejecutiva en el Perú concluyendo que:

- La mayoría de mujeres ejecutivas tiene entre 30 y 39 años.

- La mayoría son casadas con hijos.

- El 60\% de estas mujeres ha estudiado administración o ingeniería.

- El 67\% cuenta con una maestría.

- El 53\% trabaja en el área de servicios.

- El 67\% de las ejecutivas entrevistadas son gerentes.

- Todas las ejecutivas participantes destacaron que han trabajado de manera constante a lo largo de su carrera y que iniciaron su actividad profesional inmediatamente después de culminar sus estudios de pregrado, o incluso mientras cursaban los dos últimos años.

Según los estudios afirmados anteriormente, se afirma que la mujer ejecutiva es una persona joven, con estudios universitarios y de posgrado, soltera o casada, que dedican mucho tiempo a su trabajo y que su experiencia y estudios son factores claves para su ascenso en las organizaciones.

\subsubsection{Barreras que enfrentan las mujeres ejecutivas}

En los últimos años, las instituciones públicas y privadas han demostrado preocupación frente a la desigualdad que existe en cuanto a la presencia de la mujer a los altos cargos 
dentro de las empresas. Sin embargo, los obstáculos para las mujeres en el mercado laboral aún persisten. En ese sentido, en un informe publicado el 2013 por parte de la Comisión Económica para América Latina y el Caribe (CEPAL), Organización de las Naciones Unidas para la Alimentación y la Agricultura (FAO), ONU Mujeres, Programa de las Naciones Unidas para el Desarrollo (PNUD) y la Organización Internacional del Trabajo (OIT) se señala que el empleo y las condiciones de vida de las mujeres son dos variables fundamentales hacia el desarrollo equitativo y sostenible.

Por ello, a pesar de los avances de las mujeres en el ámbito laboral, persisten barreras que generan brechas de desigualdad de género en la participación laboral. Estas barreras, señala el informe, se evidencian también en las diferencias salariales entre hombres y mujeres, las cuales, constituyen un fenómeno mundial que persiste actualmente asociado a pautas culturales de género, prejuicios y estereotipos tradicionales de género. Como señala (CEPAL et al. 2013) "la desigualdad que enfrentan las mujeres en el ámbito laboral está estrechamente relacionada a la presencia de actitudes y conductas discriminatorias en el mercado de trabajo, enraizadas en el complejo sistema de relaciones de género en la sociedad" (p. 90)

Otra barrera que afecta a las mujeres en su vida laboral es el sentimiento culpa que surge del balance Familia-Trabajo. Esta culpa surge como resultante de hacer una elección entre el trabajo y la familia o cuando se permite que el trabajo interfiera con la vida familiar (Glavin et al. 2011). Asimismo, se define ese sentimiento de culpa como la discrepancia entre las preferencias de cada persona y el nivel del rol de participación en casa versus el rol de participación en el trabajo (Hochwarter et al. 2007). De la misma manera, Karen Korabik \& McElwain (2005) se refieren a esta barrera como un hecho desafortunado en la vida de la mayoría de mujeres trabajadoras ya que se trata de un sentimiento negativo que afecta su bienestar físico y mental.

Según la Dirección del Trabajo (2013) del Gobierno de Chile, una de las barreras principales también son los prejuicios y estereotipos vigentes en las empresas sobre la capacidad de las mujeres para desempeñar puestos de responsabilidad, lo cual trata de ser explicado por la falta de mujeres con estudios y experiencias, pero esto no es cierto, pues según la realidad chilena hace varios años, tanto hombres como mujeres en el acceso, permanencia y egreso de la educación superior es similar. Asimismo, la cultura 
organizacional puede volverse una barrera importante, especialmente en cuanto a los procesos de promoción, asignación de cargos, puestos diferenciados, entre otros. Por último, pero no menos importante, la barrera de la maternidad y la familia, pues se piensa que una mujer al tener esposo y carga familiar, no podría asumir cargos con mayores responsabilidades.

Ahora, centrándose en el Perú, según un artículo realizado por Great Place to Work (2014), una de las barreras más importantes que enfrenta la mujer ejecutiva peruana es el famoso "techo de cristal", el cual se da por la cultura organizacional, es decir, se asume que en las áreas directivas predomina la presencia de ejecutivos del sexo opuesto. Y también se debe a que las mujeres que tienen hijos, necesitan un horario flexible, que les permita hacerse cargo de ellos. El techo de cristal, entonces, representa paradigmas y barreras que en la mayoría de casos aún persisten en la sociedad.

Existe otra barrera denomina "techo de cemento" que se refiere a las propias limitaciones que se imponen las mujeres a la hora de decidir ir tras un ascenso o conseguir una promoción laboral. En ese sentido, la revista IESE Insight (2012) de la Universidad de Navarra, en España, define en un artículo que no solo existe un 'techo de cristal' sino también está el 'techo de cemento' y se define como una barrera autoimpuesta por la mujer al momento de decidir desarrollar su línea de carrera incluso en niveles ejecutivos debido a las nuevas responsabilidades que conllevan lo que puede derivar en un alto costo familiar y también personal. Además, se indica también, que uno de los factores más importantes a considerar por las mujeres al limitarse el ascenso laboral es la flexibilidad de tiempo, puesto que en la alta dirección se programan reuniones en horarios no adecuados, se trabaja hasta muy tarde o no existen medios que faciliten su trabajo como videoconferencias, etc.

Además, entre las barreras más relevantes que afrontan las mujeres peruanas son, según Álvarez, Bullón, Silva, y Huamán (2014), "El cuidado de los hijos, seguido por la falta de tiempo conyugal, la responsabilidad de cumplir con los quehaceres del hogar, la demanda de trabajo y las discusiones conyugales, entre otros" (p. 58) las cuales generan estrés y problemas relacionados afectando la actividad laboral de las mujeres ejecutivas. 
En una encuesta realizada por la empresa reclutadora 'Trabajando Perú' (2011) aproximadamente el $70 \%$ de los participantes consideran que el machismo en el país es el primer obstáculo que tienen las mujeres para alcanzar cargos gerenciales puesto que las mujeres tienen que aguantar una carga adicional a la carga laboral, la cual tiene que ver con sus obligaciones familiares y lo que se espera de ellas. De esta manera, según Suárez (2008) es importante señalar que el conflicto de roles que tienen las mujeres surge cuando las mujeres buscan acceder a mejores oportunidades profesionales. Esto se debe a que las mujeres sienten dificultades para desarrollarse profesionalmente desde unos modelos discriminatorios de familia, en donde la mujer tiene rol de cuidadora. Según Martha Nussbaum (2009). "Las mujeres son las principales, y usualmente las únicas, cuidadoras de aquellas personas cuyas desventajas físicas o mentales les impiden vivir con la relativa independencia que caracteriza la llamada vida humana normal" (p. 92). Todo esto, hace difícil que las mujeres puedan realizar actividades que desean en otras áreas de la vida como en el mercado laboral.

\subsubsection{Situación actual de la mujer ejecutiva}

\subsubsection{Situación actual de la mujer ejecutiva internacional}

En una investigación realizada por la consultora internacional Grant Thornton (2015) revela una importante relación entre la diversidad en la toma de decisiones con los prospectos de crecimiento de las empresas comparando compañías similares de Estados Unidos, India e Inglaterra. Es decir que, para organizaciones con presencia femenina en la cadena de mando el costo de oportunidad en cuanto a retorno de inversión es mejor que el de aquellas empresas cuyos cargos directivos constan solamente de hombres. En síntesis, se evidencia que contar con mujeres en cargos con poder de decisión supera el rendimiento esperado dando importancia a que la presencia femenina es relevante y debe ser tomada en cuenta en la alta jerarquía de una organización.

La Organización internacional de Trabajo, OIT (2017), indica que hasta el 2015, un 17\% de posiciones ejecutivas, eran ocupadas por mujeres, y se espera que para el año 2025, esta cifra crezca hasta el $44 \%$. Esto se proyecta, principalmente, debido a las tasas actuales de contratación de nuevos empleados, ascensos y retención de personal. 
Asimismo, según otro estudio realizado a compañías de todo el mundo por la misma OIT (2015) se compiló una lista de las políticas organizacionales a favor de la igualdad laboral que son aplicadas, por lo general, por las grandes empresas, corporaciones e instituciones públicas. Estas políticas se presentan en la siguiente tabla:

Tabla 1: Políticas Aplicadas por las Empresas

Tabla 1: Políticas Aplicadas por las Empresas

\begin{tabular}{clc}
\hline Ítem & \multicolumn{1}{c}{ Política } & $\%$ \\
\hline 1 & Licencia de maternidad & 84 \\
2 & Acceso a la capacitación profesional & 74 \\
3 & Contratación, retención y ascenso & 70 \\
4 & Acceso a una formación profesional de alto nivel & 66 \\
5 & Equilibrio de la vida laboral & 62 \\
6 & Orientación & 59 \\
7 & Horarios flexibles & 56 \\
8 & Objetivos de equilibrio de género en la contratación & 52 \\
9 & Licencia de los padres & 52 \\
10 & Acoso sexual & 50 \\
11 & Licencia de paternidad & 44 \\
12 & Cuidado de los hijos & 44 \\
13 & Horarios de jornada parcial & 44 \\
14 & Cuidado de los miembros de la familia enfermos & 44 \\
15 & Patrocinio & 44 \\
16 & Programas de reinserción & 40 \\
17 & Interrupciones de la carrera profesional & 38 \\
18 & Formación de alto nivel especial para las mujeres & 33 \\
19 & Trabajo a distancia & 30 \\
20 & Cuidado de las personas de edad & 28 \\
\hline
\end{tabular}

Tabla 1: "La Mujer en la Gestión Empresarial: Cobrando Impulso (Versión Resumida del Informe Mundial)," por la Organización Internacional del Trabajo (OIT), 2015, p. 109. Ginebra, Suiza: OIT.

En cuanto al entorno latinoamericano, se tiene que, en Ecuador, según Deloitte (2017), se afirma que las áreas donde se destacan las mujeres ejecutivas son: marketing (26\%), finanzas (24\%) y recursos humanos (21\%). En cuanto a oportunidades laborales, solamente el $51 \%$ de personas consideran que las mujeres tienen las mismas oportunidades que los hombres. De esta manera, se evidencia la disparidad laboral en los diversos rubros del país 
vecino, donde la mayor presencia de las mujeres ejecutivas se encuentra en el área de marketing.

\subsubsection{Situación actual de la mujer ejecutiva en Perú}

En el reporte internacional anual de la firma Gran Thornton (GT) en el 2013 sobre la presencia en puestos de alta dirección, señala que la presencia de mujeres en puestos de dirección en el Perú es del 27\%. Este porcentaje es mayor a la media mundial de la presencia de mujeres ejecutivas (24\%), sin embargo, es menor a la media mundial de la presencia de mujeres en relación a la población activa (35\%).

Además, según un estudio, Avolio (2013), el 33\% de mujeres ejecutivas en el país estudiaron Administración, dichas mujeres estudiaron en Perú y cuentan con formación universitaria completa. Esto evidencia que la cantidad de mujeres egresadas en la carrera de administración se ha ido incrementando en los últimos años, lo cual incrementara la inserción laboral de estas profesionales en mando intermedios, quienes podrán alcanzar cargos gerenciales a mediano plazo.

En un sondeo publicado en la revista 'SEMANA económica' (2015) a gerentes generales y cargos que reportan directamente a gerencia general, en Latinoamérica, realizado por la consultora INAC (International Network Associated Consultants) se encontró que para nuestro país el $56 \%$ considera que no hay políticas organizacionales en su organización que respalde la igualdad de género a niveles directivos. Sin embargo, el $86 \%$ piensa que la presencia femenina en altos cargos es muy importante y hasta necesario. En ese sentido, se valora la diversidad de género en niveles de alta jerarquía puesto que según consideran la perspectiva de la mujer afecta positivamente a la organización en donde laboran.

Por otra parte, en el informe Brechas de Género 2017 publicado por el INEI se reporta que las mujeres en nuestro país obtienen de ingresos aproximadamente el $29 \%$ menos que hombres en condiciones laborales similares en el sector privado. Asimismo, la disparidad salarial incrementa mucho más en zonas rurales llegando alrededor del 50\%. Sin embargo, es importante señalar que esta brecha ha disminuido respecto a la última década y, además, es mucho menor en el sector público llegando hasta un $16 \%$ de diferencia. En ese sentido, 
según indica el estudio 'Total Remuneration Survey 2017' por la consultora internacional Mercer, la brecha salarial en niveles ejecutivos es mucho menor, siendo del 12\% para Perú, y que, además, esta cifra se ha ido reduciendo en $15 \%$ en los últimos 3 años indicando una mejora en la situación económica de las mujeres que se desempeñan en altos cargos.

\subsubsection{Normas legales de apoyo para mujeres en Perú}

De manera general, es importante señalar que en el Perú se cuenta con la Ley de Igualdad de Oportunidades entre Hombres y Mujeres (Ley No 28983). Esta ley establece un marco normativo, institucional, y de políticas públicas para garantizar la igualdad de derechos entre hombres y mujeres.

Sin embargo, en un estudio del INEI denominado: Brechas de igualdad de género (2015), se evidencia que en el país aún persiste la discriminación de género y exclusión social en la mayoría de ámbitos para las mujeres, por lo que, a finales del 2015 se emitió la ley para prevenir, sancionar y erradicar la violencia contra las mujeres y los integrantes del grupo familiar (Ley $N^{o}$ 30364). Esta ley es relevante para la mujer ejecutiva, puesto que, en su artículo 11 se establecen 4 nuevos derechos laborales para proteger la actividad productiva de las mujeres, y brindar las facilidades laborales necesarias de ser víctimas de violencia. Más recientemente a finales del 2017, se emitió la ley que prohíbe la discriminación remunerativa entre varones y mujeres (Ley $N^{\circ}$ 30709) mediante categorías, funciones y salarios que permitan la ejecución del principio de igual remuneración por igual trabajo.

De forma más concreta, las mujeres trabajadoras en el país cuentan con derechos específicos. Estos son: Descanso Pre y Post natal (Ley N²6644), Permiso por lactancia materna (Ley $\mathrm{N}^{\mathrm{o}}$ 27240), Implementación de lactarios (Ley $\mathrm{N}^{\mathrm{o}}$ 29896), Protección a la mujer gestante (Ley No 28048), Subsidios por maternidad y lactancia (Ley No 28791) y la protección contra el despido nulo (D. Legislativo $\mathrm{N}^{\circ} 728$ y Ley $\mathrm{N}^{\mathrm{o}} 27185$ ).

\subsubsection{Situación de la mujer ejecutiva en la banca comercial internacional}

Masías (2013), indica que, en el sistema financiero de México, la mujer ejecutiva ha ido escalando posiciones con el tiempo, es así que en el 2006 el 43\% de la clasificación de las 500 Empresas más importantes de México, contaban con mujeres en sus direcciones, en el 
2011 la cifra había aumentado en un 9\%, es decir al 52\%, según la revista Expansión en su lista Las 50 mujeres más poderosas.

Por otro lado, la ONU MUJER (2015) sostiene que el empoderamiento económico en la mujer es un buen negocio, pues las empresas se benefician al agregar a mujeres en puestos de liderazgo, lo que ha logrado el aumento en la eficacia organizacional. Y por consecuencia, se estima que en las empresas donde 3 o más mujeres ejercen puestos ejecutivos, registran un desempeño más alto en todos los aspectos de la eficacia organizacional.

En una publicación realizada por Álvarez (2016) en la página del BBVA, se puede ver como la mujer ejecutiva lidera altos puestos en las finanzas globales. Así, es el caso de Janet Yellen, quien en el 2014 llegó a ser la primera presidenta de la Reserva Federal de los EE.UU., colocándola como la cuarta mujer más poderosa del mundo según Forbes. También se tiene a Christine Lagarde, quien fue reelegida para su segundo mandato como directora gerente del Fondo Monetario Internacional (FMI). Por último, es importante hacer mención a Danièle Noui, quien ocupa actualmente la presidencia del Consejo de Supervisión del Mecanismo Único de Supervisión, es decir, del organismo encargado de centralizar la regulación y supervisión de la banca europea.

\subsubsection{Situación de la mujer ejecutiva en la banca comercial en el Perú.}

En un estudio realizado por ASBANC a finales del 2017 sobre la generación de empleos en la banca comercial, se puede observar que los cargos gerenciales estaban ocupados principalmente por hombres, un $64.4 \%$ ocupaba dichos puestos, y solo un $35.6 \%$ de puestos gerenciales era ocupado por mujeres. Pero también en este estudio se logra resaltar que, en cuanto a funcionarios, la brecha se acorta considerablemente, pues este puesto era ocupado por el $50.6 \%$ de hombres y el $49.4 \%$ de mujeres. Entonces se puede considerar que, estas mujeres con cargos de funcionario pueden, eventualmente, escalar hacia cargos gerenciales tomándose en consideración el incremento de 4.8 puntos porcentuales en puestos ejecutivos respecto a los últimos 5 años.

Asimismo, según el informe para las mujeres de Great Place to Work (2018) sobre el ranking de las mejores organizaciones para trabajar, dentro del top 20 se encuentran 4 
empresas financieras de las cuales 3 son bancos (Banco Cencosud, Interbank y Scotiabank) consolidando el sector bancario como un escenario ideal para el desarrollo laboral de las mujeres con miras a alcanzar cargos directivos. El informe señala que estas empresas destacan en el ranking por implementar programas de flexibilidad de horarios, orientación familiar y que además brindan oportunidades de crecimiento e inclusión a altos cargos independientemente del género de sus colaboradores.

\subsection{Competencias}

\subsubsection{Definición de competencias}

Martha Alles (2016) indica que las competencias son características de una persona, convertidas en comportamientos, los cuales logran éxito en un puesto de trabajo. De la misma manera, Sevilla García (2009) dice que:

Una competencia supone valores, actitudes y motivaciones, además de conocimientos, capacidades, habilidades y destrezas, todo formando parte del ser integral que es la persona, una persona inserta en un determinado contexto, en el que participa e interactúa, considerando también que aprende de manera constante y progresiva a lo largo de toda su vida.

Asimismo, para Spencer (1993) indica que:

"Una competencia es una característica subyacente de un individuo que está causalmente relacionada a un criterio referenciado como efectico y/o desempeño superior en un trabajo o en una situación" (Spencer 1993: 9)

\subsubsection{Competencias Laborales}

Según Spencer (1993), en el mundo laboral las competencias son la base fundamental para un desempeño superior, dado que, permiten responder positivamente ante dificultades o tareas desafiantes. Por ello, no sólo son necesarias las habilidades y actitudes adecuadas 
para una determinada tarea, sino también el conocimiento, es decir, los saberes que el individuo comprende sobre la tarea en cuestión.

Mertens, L. (2000) indica que las competencias laborales son un punto de encuentro entre los sectores educativo y productivo. Además, como señala la Organización de Estados Iberoamericanos (OEI) en el 2003: La competencia laboral es una pieza central de un enfoque integral de formación que debe conectar al mundo laboral y la sociedad con la educación, con el fin de mejorar el capital humano, puesto que las personas son la fuente principal de innovación, conocimiento, diferenciación y competitividad. (p. 7)

Acorde con lo anterior, Sagi-Vela (2004), indica que la competencia laboral es más un conjunto de conocimientos que habilidades y actitudes, que todas aplicadas en una determinada responsabilidad da el resultado óptimo. Mientras que, Alles (2016) explica que la competencia laboral difiere por el cargo que ocupa un colaborador, como también por la especialidad.

Además, según Martha Alles en su diccionario de competencias (2016) menciona también una relación entre motivación y las competencias laborales, siendo la motivación humana la base de los comportamientos que se observan en las competencias. Alles también señala la investigación de David McClelland sobre la motivación y gestión por competencias en la cual se define un motivo como un interés recurrente para concretar un objetivo, y dicho interés es lo que genera y determina los comportamientos de una persona ante una tarea.

\subsubsection{Componentes de una competencia laboral}

Según Spencer \& Spencer (1993), se puede explicar las competencias de una persona separándolas en dos grupos utilizando la teoría del Iceberg (propuesta por McClelland): existe una parte visible (observable) y una parte no visible (oculta en primera instancia). El primer grupo constituye las habilidades y conocimientos de una persona, mientras que, el otro grupo está constituido por aspectos más personales que determinan sus actitudes como lo son sus valores, rasgos de personalidad y motivaciones.

Además, Sagi-Vela (2004), explica las competencias como "conjunto de conocimientos (saber), habilidades (saber hacer) y actitudes (saber estar y querer hacer) que, aplicados en el desempeño de una determinada responsabilidad o aportación profesional, aseguran su buen logro" (p. 86). 
En resumen, como indica Spencer \& Spencer se puede determinar que las competencias están compuestas en los siguientes 3 elementos:

Conocimientos: Se refiere al "saber" que tienen las personas junto a los comportamientos relacionados al desempeño de una tarea. El conjunto de conocimientos requeridos dependerá del carácter del puesto de trabajo.

Habilidades: Se refiere al "saber hacer" para poner en práctica los conocimientos que posee la persona. Las habilidades pueden ser técnicas, sociales o cognitivas y su puesta en acción dependerá en la manera en que se resuelva una tarea o se resuelva un problema.

Actitudes: Se refiere al "saber estar" y "querer estar" que corresponde al desarrollo humano de la persona. El "saber estar" comprende las creencias y valores de las personas acorde al entorno organizacional y social. Por otro lado, el "querer estar" representa las motivaciones de un individuo para realizar o no los comportamientos requeridos en la culminación de una tarea.

\subsubsection{Tipos de competencias}

En la nueva edición del diccionario de competencias de Martha Alles para la gestión de competencias (2016), la autora brinda una perspectiva actualizada de las competencias laborales más relevantes para las organizaciones en donde señala las 60 competencias más utilizadas por empresas en cuanto a gestión por competencias; estas competencias se agrupan en 3 tipos: competencias cardinales, competencias específicas gerenciales y competencias específicas por área.

\section{A. Competencias Cardinales}

Estas competencias están ligadas y presentes en cada persona integrante de una organización. Las competencias cardinales reflejan los valores vinculados a la estrategia de una empresa para alcanzar su visión organizacional. Es por esto, que son competencias generales que cada miembro de la organización debe poseer y que pueden convertirse en competencias específicas cuando se adapten a un puesto o área de trabajo. Las competencias cardinales definidas por la autora son las siguientes: 


\section{COMPETENCIAS CARDINALES}

01. Adaptabilidad a los cambios del entorno

02. Compromiso

03. Compromiso con la calidad de trabajo

04. Compromiso con la rentabilidad

05. Conciencia organizacional

06. Ética

07. Ética y sencillez

08. Flexibilidad y adaptación

09. Fortaleza

10. Iniciativa

11. Innovación y creatividad

12. Integridad

13. Justicia

14. Perseverancia en la consecución de objetivos

15. Prudencia

16. Respeto

17. Responsabilidad personal

18. Responsabilidad social

19. Sencillez

20. Temple

\section{B. Competencias Específicas Gerenciales}

Son aquellas necesarias para personas con altos cargos o posiciones gerenciales. Por lo que, solamente son aplicables a un grupo limitado de personas en relación a un rol superior dentro de una organización. Estas competencias pueden segmentarse para empresas grandes que tienen numerosas áreas o niveles gerenciales, esta segmentación se puede presentar en 2 categorías: niveles ejecutivos y niveles restantes de conducción o dirección de personas. Las competencias específicas gerenciales definidas por la autora son las siguientes: 


\section{COMPETENCIAS ESPECIFICAS GERENCIALES}

21. Conducción de personas

22. Dirección de equipos de trabajo

23. Empowerment

24. Entrenador

25. Entrepreneurial

26. Liderar con el ejemplo

27. Liderazgo

28. Liderazgo ejecutivo (capacidad para ser líder de líderes)

29. Liderazgo para el cambio

30. Visión estratégica

\section{Competencias Específicas por área}

Estas competencias son todas aquellas que tienen relación directa con un puesto o familia de puestos de trabajo en un área de la organización. En ese sentido, las competencias específicas por área son competencias que actúan en función de las necesidades de cada área de una empresa (Administración, Recursos humanos, Ventas, etc.). Por lo que, estas competencias son aplicables a un determinado grupo de colaboradores dependiendo del sector $\mathrm{u}$ área en donde se encuentra su puesto de trabajo. Las competencias específicas por área definidas por la autora son las siguientes:

\section{COMPETENCIAS ESPECIFICAS POR ÁREA}

31. Adaptabilidad - Flexibilidad

32. Calidad y mejora continua

33. Capacidad de planificación y organización

34. Cierre de acuerdos

35. Colaboración

36. Competencia "del náufrago"

37. Comunicación eficaz

38. Conocimiento de la industria y el mercado 
39. Conocimientos técnicos

40. Credibilidad técnica

41. Desarrollo y autodesarrollo del talento

42. Dinamismo - Energía

43. Gestión y logro de objetivos

44. Habilidades mediáticas

45. Influencia y negociación

46. Iniciativa - Autonomía

47. Manejo de crisis

48. Orientación a los resultados con calidad

49. Orientación al cliente interno y externo

50. Pensamiento analítico

51. Pensamiento conceptual

52. Pensamiento estratégico

53. Productividad

54. Profundidad en el conocimiento de los productos

55. Relaciones públicas

56. Responsabilidad

57. Temple y dinamismo

58. Tolerancia a la presión de trabajo

59. Toma de decisiones

60. Trabajo en equipo

Para efectos del estudio se han sintetizado las 60 competencias que son las más utilizadas en 18 competencias, siguiendo los lineamientos trabajados por Martha Alles en su tesis doctoral "Influencia de las características de personalidad (competencias) en la empleabilidad de profesionales" (2006), y en su trilogía de gestión por competencias (2016), en los cuales se consideró aquellas competencias cuyos conceptos se relacionan y son análogos entre sí. La denominación de estos grupos está ligada a una representación más precisa de las competencias que comprenden. Las competencias resultantes son: 
Tabla 2: Competencias laborales agrupadas

\begin{tabular}{|c|c|c|}
\hline Síntesis & Denominación & Competencias \\
\hline 1 & $\begin{array}{c}\text { Ética e } \\
\text { integridad }\end{array}$ & $\begin{array}{l}\text { Compromiso } \\
\text { Conciencia organizacional } \\
\text { Ética } \\
\text { Ética y sencillez } \\
\text { Fortaleza } \\
\text { Integridad } \\
\text { Justicia } \\
\text { Prudencia } \\
\text { Responsabilidad personal } \\
\text { Responsabilidad social } \\
\text { Sencillez } \\
\text { Temple }\end{array}$ \\
\hline 2 & Liderazgo & $\begin{array}{l}\text { Liderar con el ejemplo } \\
\text { Liderazgo } \\
\text { Liderazgo ejecutivo (capacidad para ser líder de } \\
\text { líderes) } \\
\text { Liderazgo para el cambio }\end{array}$ \\
\hline 3 & $\begin{array}{l}\text { Calidad de } \\
\text { trabajo }\end{array}$ & $\begin{array}{l}\text { Compromiso con la calidad de trabajo } \\
\text { Calidad y mejora continua } \\
\text { Conocimientos técnicos } \\
\text { Orientación a los resultados con calidad }\end{array}$ \\
\hline 4 & $\begin{array}{l}\text { Capacidad de } \\
\text { planificación } \\
\text { y } \\
\text { organización }\end{array}$ & Capacidad de planificación y organización \\
\hline 5 & Iniciativa & $\begin{array}{l}\text { Iniciativa } \\
\text { Productividad } \\
\text { Responsabilidad } \\
\end{array}$ \\
\hline 6 & $\begin{array}{l}\text { Innovación y } \\
\text { Creatividad }\end{array}$ & $\begin{array}{l}\text { Innovación y Creatividad } \\
\text { Entrepreneurial }\end{array}$ \\
\hline 7 & $\begin{array}{l}\text { Orientación a } \\
\text { resultados }\end{array}$ & $\begin{array}{l}\text { Compromiso con la rentabilidad } \\
\text { Perseverancia en la consecución de objetivos } \\
\text { Gestión y logro de objetivos }\end{array}$ \\
\hline 8 & $\begin{array}{l}\text { Delegación y } \\
\text { dirección de } \\
\text { personas }\end{array}$ & $\begin{array}{l}\text { Conducción de personas } \\
\text { Dirección de equipos de trabajo } \\
\text { Empowerment } \\
\text { Entrenador } \\
\end{array}$ \\
\hline 9 & $\begin{array}{l}\text { Adaptación al } \\
\text { cambio }\end{array}$ & $\begin{array}{l}\text { Adaptabilidad a los cambios del entorno } \\
\text { Flexibilidad y adaptación } \\
\text { Adaptabilidad - Flexibilidad }\end{array}$ \\
\hline
\end{tabular}




\begin{tabular}{|c|c|c|}
\hline & & Dinamismo - Energía \\
\hline 10 & $\begin{array}{l}\text { Pensamiento } \\
\text { estratégico }\end{array}$ & $\begin{array}{l}\text { Visión estratégica } \\
\text { Pensamiento estratégico } \\
\text { Toma de decisiones }\end{array}$ \\
\hline 11 & $\begin{array}{l}\text { Influencia y } \\
\text { negociación }\end{array}$ & $\begin{array}{l}\text { Cierre de acuerdos } \\
\text { Influencia y negociación }\end{array}$ \\
\hline 12 & $\begin{array}{c}\text { Trabajo en } \\
\text { equipo }\end{array}$ & $\begin{array}{l}\text { Colaboración } \\
\text { Trabajo en equipo }\end{array}$ \\
\hline 13 & $\begin{array}{l}\text { Capacidad de } \\
\text { comunicación }\end{array}$ & $\begin{array}{l}\text { Comunicación eficaz } \\
\text { Respeto }\end{array}$ \\
\hline 14 & $\begin{array}{l}\text { Orientación al } \\
\text { cliente interno } \\
\text { y externo }\end{array}$ & $\begin{array}{l}\text { Conocimiento de la industria y el mercado } \\
\text { Orientación al cliente interno y externo } \\
\text { Profundidad en el conocimiento de los productos }\end{array}$ \\
\hline 15 & $\begin{array}{l}\text { Desarrollo y } \\
\text { autodesarrollo } \\
\text { del talento }\end{array}$ & Desarrollo y autodesarrollo del talento \\
\hline 16 & $\begin{array}{c}\text { Pensamiento } \\
\text { analítico }\end{array}$ & $\begin{array}{l}\text { Pensamiento analítico } \\
\text { Pensamiento conceptual }\end{array}$ \\
\hline 17 & $\begin{array}{l}\text { Resolución de } \\
\text { problemas }\end{array}$ & $\begin{array}{l}\text { Competencia "del náufrago" } \\
\text { Credibilidad técnica } \\
\text { Manejo de crisis } \\
\text { Temple y dinamismo } \\
\text { Tolerancia a la presión de trabajo }\end{array}$ \\
\hline 18 & $\begin{array}{l}\text { Relaciones } \\
\text { públicas }\end{array}$ & $\begin{array}{l}\text { Habilidades mediáticas } \\
\text { Relaciones públicas }\end{array}$ \\
\hline
\end{tabular}

Tabla 2: Elaboración propia. Adaptado de la tesis doctoral "Influencia de las características de personalidad (competencias) en la empleabilidad de profesionales" (2006) de Martha Alles.

\subsubsection{Competencias Críticas}

\subsubsection{Definición de competencias críticas}

Para Goleman (1998), las competencias necesarias para el éxito también pueden variar en la medida en que una persona asciende de categoría laboral, debido a que, en las organizaciones más grandes, los directivos de alto rango requieren más competencias que los mandos intermedios. Además, el autor señala "ciertas profesiones exigen competencias muy concretas o particulares como, por ejemplo, el sentido del humor en el caso de las enfermeras, el respeto a la confidencialidad de los clientes en el de los banqueros y 
proporcionar la retroalimentación adecuada a los padres y a los maestros en el de los directores de escuela".

Se refiere como competencias críticas a aquellas que no sólo son las más relevantes, sino también, representan un compás de éxito profesional. Martha Alles (2016) señala que este tipo de competencia está dirigido a un grupo de personas, como a un área en una organización o a un nivel como el gerencial. En ese sentido la autora señala que existen determinadas competencias para personal de nivel ejecutivo.

En resumen, a niveles ejecutivos, las competencias observadas en personas con posiciones de mando varían según el cargo; puesto que, las competencias requeridas deben alinearse al rol que ejercen, definiendo así las particularidades necesarias (competencias críticas) para cada puesto y asegurar el éxito. Para tales efectos, se consideran como las competencias más relevantes y con un mayor impacto para la mujer ejecutiva en la banca comercial de Lima, las siguientes: la ética e integridad, la orientación a los clientes, el trabajo en equipo y la resolución de problemas.

En primer lugar, la ética e integridad fue considerada como crítica debido a que el banco es una organización que por su naturaleza de trabajar con dinero de los ahorristas es supervisada por la SBS y es sensible a temas de fraude, es por ello que Scotiabank cuenta con un código de ética que mide la conducta y comportamiento del personal en la organización y al tener personal a su cargo la ética resulta influenciable en el equipo. En segundo lugar, la orientación al cliente se consideró debido a que es la razón de ser del banco lo cual está reflejado en la misión y visión con un enfoque orientado hacia el público. En tercer lugar, se tiene a la resolución de problemas porque a un nivel ejecutivo es el día a día enfrentar distintos tipos de contratiempos en lo cual prima el nivel de resolución tanto del área como del personal que tienen los ejecutivos a su cargo. Por último, el trabajo en equipo debido a que el banco es una organización con procesos descentralizados que requiere de la relación y cooperación constante entre áreas para lograr los resultados, así como también, la cooperación entre colaboradores de una misma área.

\section{A. La ética e integridad}

Para Kavathatzopoulos, Kostrzewa \& Berg (2008) la competencia ética se define como la capacidad de una persona para usar una solución de problemas y método adecuado de toma 
de decisiones cuando se enfrenta un problema moral y la capacidad de una organización construir, mantener y utilizar procesos, herramientas y mecanismos adecuados para el manejo de problemas morales.

Por otro lado, Martha Alles (2016) se refiere a la ética e integridad como la capacidad de realizar tareas, guiándose de los valores morales, las buenas costumbres y prácticas profesionales, respetando siempre las políticas organizacionales. Por esto se refiere a la ética como una competencia cardinal que toda persona debe desarrollar, ya que esto, debe aplicarse no sólo en el ámbito laboral, sino también en la vida privada. Debido a que, los valores morales y las buenas costumbres son las que rigen a esta persona, sin importar su propio beneficio.

Sin embargo, en un análisis más reciente, Terry L. Cooper (2015) plantea un diferente marco conceptual para la ética como competencia laboral a través de los tres componentes que constituyen una competencia (Conocimientos, habilidades y aptitudes) en los cuáles presenta 4 filas de sub-competencias para cada componente, como se muestra en el cuadro siguiente, presentado por el autor:

Tabla 3: Marco conceptual de competencia ética

\begin{tabular}{|c|c|c|c|}
\hline & Conocimientos & Habilidades & Actitudes \\
\hline $\begin{array}{l}\text { Acatamiento } \\
\text { de reglas }\end{array}$ & $\begin{array}{l}\text { Leyes, código de ética, } \\
\text { reglas y procedimientos }\end{array}$ & Aplicación de reglas & $\begin{array}{l}\text { Importancia de las } \\
\text { reglas }\end{array}$ \\
\hline $\begin{array}{l}\text { sensibilidad } \\
\text { moral }\end{array}$ & \begin{tabular}{|lrr}
$\begin{array}{l}\text { Posición } \\
\text { organización }\end{array}$ & en & la \\
sociedad & y & la \\
\end{tabular} & $\begin{array}{l}\text { Define una situación } \\
\text { como persona ética }\end{array}$ & Empatía y perspectiva \\
\hline $\begin{array}{l}\text { Razonamiento } \\
\text { moral }\end{array}$ & $\begin{array}{l}\text { Argumentos morales: } \\
\text { Consecuencias para otros } \\
\text { y consecuencias propias }\end{array}$ & $\begin{array}{l}\text { Usa distintos } \\
\text { argumentos morales }\end{array}$ & $\begin{array}{lll}\text { actitud flexible: } & \text { No } \\
\text { solo reglas, no } & \text { solo } \\
\text { consecuencias } & \text { para } \\
\text { otros y no } & \text { solo } \\
\text { consecuencias propias }\end{array}$ \\
\hline $\begin{array}{l}\text { Motivación y } \\
\text { carácter moral }\end{array}$ & $\begin{array}{l}\text { Las reglas } \\
\text { consecuencias para otros } \\
\text { son más importantes que } \\
\text { las consecuencias propias }\end{array}$ & $\begin{array}{l}\text { Prioriza las reglas y } \\
\text { sus consecuencias en } \\
\text { las decisiones que } \\
\text { toma }\end{array}$ & Autonomía \\
\hline
\end{tabular}

Tabla 3: Marco conceptual de competencia ética. Adaptado de Terry L. Cooper (2015) 
Es importante mencionar que las empresas si tienen una responsabilidad ética y enfrentan las consecuencias de sus acciones. El record histórico de una compañía y la percepción de su ética afectan su reputación y garantiza su éxito o fracaso a largo plazo. En ese contexto, la Revista Internacional de Investigación Científica y Educación Moderna "IJSRME”, por sus siglas en inglés, señala en una investigación el 2016 sobre la ética empresarial en la industria bancaria que el bienestar de los clientes para un banco es de gran preocupación para su propuesta comercial, puesto que estos, dependen de las personas para dirigir su negocio y que la responsabilidad de un banco se extiende al gobierno, clientes, accionistas y a la comunidad.

Además, el estudio muestra que las personas sienten que la ética empresarial no afecta la rentabilidad de manera negativa, sino más bien, llevar un comportamiento ético ayuda a un banco a llegar a las personas. Por último, el estudio concluye que, la integridad, los valores humanos y la honestidad son las principales cualidades que las personas asocian con un ejecutivo quién es ético en su enfoque o trato.

\section{B. La orientación hacia el cliente interno y externo}

Sobre esta competencia, Martha Alles (2016) señala que la orientación de clientes involucra el interés de ayudar y servir a los clientes, de comprender sus necesidades y cumplir sus expectativas. Comprende trabajar duro para conocer y resolver los problemas del cliente. Además, la autora se refiere a que esta competencia comprende el apoyo tanto al cliente final como los clientes de sus clientes y a todos aquellos que cooperen en la relación empresa - cliente, como lo son proveedores y colaboradores de la organización.

Además, de acuerdo al diccionario de competencias publicada por la universidad de Harvard (2014) para procesos de gestión del rendimiento, define a la orientación hacia los clientes como aquellas acciones clave que toman las necesidades de los clientes como el foco principal de las propias acciones, para así, poder conservar y desarrollar relaciones productivas con los clientes. Para esto, de acuerdo al mismo documento, se establece que las acciones claves para el desarrollo de esta competencia son: buscar entender a los

clientes, educarlos, desarrollar relaciones de colaboración, tomar medidas para satisfacer las necesidades e inquietudes de los clientes y establecer sistemas de retroalimentación. 
Por último, en el estudio "Tendencias del sector financiero en España", realizado por la Escuela de Organización Industrial (EOI) y la consultora especializada en comercial y marketing, TATUM afirma que:

Según la opinión de las 64 entidades estudiadas, que representan el 84\% del total del beneficio obtenido por el mercado financiero en España, el futuro de la banca comercial estará marcado por aspectos que supondrán la diferencia entre el éxito y el fracaso de las mismas. Entre los que destacan factores como: La orientación al cliente, la eficiencia y la multicanalidad entre otras. (EOI: 2006)

Entonces, se puede concluir que, si el futuro de la banca comercial tiene como uno de sus factores a la orientación al cliente, esto quiere decir que los colaboradores, entre ellos, las mujeres ejecutivas, también deben contar con esta competencia.

\section{El trabajo en equipo}

Escoto (2007) dice lo siguiente:

Para llevar a cabo las tareas propias de cada actividad, los bancos requieren de una adecuada división del trabajo, para asegurar la eficiencia operacional. Esto, en la organización se refleja en la formación de áreas, para cubrir determinada función: finanzas, administración, operaciones, contabilidad, etcétera. (p. 139)

En su diccionario de competencias, Alles (2012) afirma que el trabajo en equipo no sólo es trabajar con las personas de tu área, sino, significa trabajar con cualquier área de la organización, con el fin de alcanzar los objetivos de la organización, dejando de lado las metas u objetivos personales. Asimismo, esta competencia implica que se debe mantener y generar un buen ambiente de trabajo, comprender a los demás y tener expectativas positivas de las personas que formarán el equipo.

Cristina Torrelles, J. Coiduras, S. Isus \& otros (2011), docentes de las universidades de "Leida" y "Rovira i Virgili de Tarragona" en España, concluyen en un estudio que la competencia de trabajo en equipo se trata de una "competencia viva" pues tiene naturaleza multidimensional debido a la complejidad que representa el uso efectivo de esta 
competencia. Por lo que, tras un análisis de diversos modelos propuestos anteriormente, los autores proponen un modelo que defina y categorice las dimensiones del trabajo en equipo. En ese sentido, los autores concluyen que, son 4 las dimensiones que componen el trabajo en equipo como competencia, las cuales son: identidad, comunicación, ejecución y regulación

- Identidad: Esta dimensión trata de la forma de ser propia que se establece de la vinculación de todos los integrantes de un equipo y de su pertinencia al mismo. También se refiere al compromiso y cuánto se involucra cada miembro del equipo en las actividades que se desarrollan.

- Comunicación: Comprende la práctica de interacciones que realizan los integrantes de un equipo con el fin de compartir información, proceder correctamente y alcanzar un funcionamiento óptimo.

- Ejecución: Se refiere a la realización de las acciones en la práctica, haciendo uso de las estrategias que el equipo ha planificado en relación a sus objetivos.

- Regulación: Esta dimensión trata de los ajustes que el equipo de trabajo debe realizar permanentemente para cumplir sus objetivos, a través de la incorporación de nuevos elementos en el proceso y resolviendo las dificultades que se presentan en el camino.

Para complementar, según el diccionario de competencias de la Universidad de Harvard (2014) para procesos de gestión del rendimiento, el trabajo en equipo se trata de participar activamente como miembro de equipo en la persecución de los objetivos, alineando el trabajo individual y el desempeño con el equipo para alcanzar resultados mutuos que involucren a todos los participantes del equipo.

Entonces, se consigue afirmar que el trabajo en equipo es importante en la banca comercial, pues es cierto que existen diferentes áreas de trabajo que realizan ciertas funciones, pero también es cierto que cada área debe realizar un trabajo en conjunto para llegar a las metas de la organización. 


\section{Resolución de problemas}

Para esta competencia, Alles (2012) indica que la resolución de problemas es la capacidad de encaminar las acciones propias al logro deseado, a través de un sentido de urgencia ante decisiones importantes necesarias para cumplir o superar a los competidores, las necesidades del cliente o para mejorar la organización. La experta define esta competencia como la tendencia al logro de resultados, fijando metas que resulten desafiantes, mejorando los niveles de rendimiento, en el marco de las estrategias de la organización.

Según el diccionario de competencias de la Universidad de Harvard (2014). La resolución de problemas comprende hacer uso de un juicio lógico para detectar y analizar problemas que amenacen el desarrollo de las actividades. Esta competencia se evidencia al identificar proactivamente problemas e identificando soluciones sopesando las alternativas disponibles para implementar soluciones lógicas que contribuyan al interés de la organización.

\subsubsection{Importancia de las competencias críticas}

Martha Alles (2015) en su libro de Dirección Estratégica de R.R.H.H explica lo siguiente: comprender la motivación humana lleva a una definición del término motivo, entendido como el interés recurrente para el logro de un objetivo basado en un incentivo natural; un interés que energiza, orienta y selecciona comportamientos (p. 86). En ese contexto, estudiar las competencias que tienen un impacto importante en las organizaciones permitirá formular modelos de gestión que den lugar a una relación ganar-ganar entre los trabajadores y su empleador. La autora, también agrega, en su DICCIONARIO DE COMPETENCIAS (2012) una vez que se han medido las competencias de las distintas áreas (integrantes) se podrán determinar las brechas entre el nivel de competencias de cada colaborador con lo requerido en su perfil de trabajo.

Estudiar e identificar las competencias críticas en el contexto actual implica, para organizaciones y sus líderes, una medida importante para alcanzar el éxito (Hopkins \& Bilimoria 2008). Señala también que, la importancia de reconocer dichas competencias para una empresa le sirve para optimizar la gestión de su personal, identificando a la persona adecuada para un puesto determinado. En contraste, para un ejecutivo, la relevancia que tienen las competencias críticas es más significativa, puesto que, su impacto 
evidencia un efecto más trascendental. Es decir, el autoconocimiento, para así poder desarrollarse adecuadamente en su formación de líder.

En síntesis, la capacidad para reconocer las distinciones en la demostración de competencias entre ejecutivos más exitosos y ejecutivos regulares contribuye al desarrollo del liderazgo para quienes buscan alcanzar a cargos más altos. Y sirve de base para las organizaciones en gestionar el talento a su disposición.

\subsection{Sistema Financiero}

\subsubsection{Definición del sistema financiero}

Se describe al sistema financiero al conjunto de instituciones encargadas de captar, administrar e invertir recursos financieros de personas naturales y jurídicas, tanto nacionales como extranjeras. El sistema abarca también, distintas regulaciones e instrumentos que median e intervienen en el mercado financiero a través de organizaciones reguladoras. (Dueñas 2008)

Para profundizar en este concepto, Calvo, Parejo, Rodríguez y Cuervo (2014) definen al sistema financiero como el conjunto de instituciones, medios y mercados cuyo propósito es la canalización de ahorro de los agentes superavitarios hacia los agentes deficitarios. Este propósito es fundamental en la economía de mercado debido a dos razones: la primera la no coincidencia, en general los agentes superavitarios son distintos a los deficitarios y la segunda que las necesidades de los agentes superavitarios tampoco coinciden con las necesidades de los deficitarios respecto a retorno de la inversión reflejado en liquidez, seguridad y rentabilidad en el tiempo.

Es por ello que, Rodríguez (2012) indica la importancia de las instituciones financieras como mediadores estables y aceptados quienes se encargan de reducir los costos de las transacciones de manera que se facilite la comercialización. Asimismo, ofrecen activos financieros con retornos atractivos que estimulan la conducta de ahorro en una entidad financiera.

En nuestro país, realizando un enfoque a la intermediación financiera, se puede ver su clasificación a través de dos clases de mercado: Sector Bancario conformado por el banco 
de la nación, junto a los principales bancos BCP, BBVA, Scotiabank entre otros; y el Sector no bancario conformado por las cajas municipales, financieras, edpyme entre otros. Siendo ambos mercados supervisados por la Superintendencia de banca seguros y AFP. (Rodríguez 2012). Como se puede observar en la tabla inferior, la banca comercial (definida en la tabla como Banca Múltiple) representa más del $90 \%$ del sistema financiero del país en cuanto a participación conformada por 16 entidades.

Tabla 4: Composición del sistema financiero peruano

Composición del sistema financiero peruano

\begin{tabular}{lccc}
\hline & & \multicolumn{2}{c}{ Activos a Abril 2017 } \\
\cline { 3 - 4 } Empresas de Operaciones Múltiples & $\begin{array}{c}\text { Número de } \\
\text { Empresas }\end{array}$ & $\begin{array}{c}\text { Monto } \\
\text { (S/ Millones) }\end{array}$ & $\begin{array}{c}\text { Participación } \\
\text { (\%) }\end{array}$ \\
\hline Banca Múltiple & 16 & 354868 & 90,38 \\
Empresas financieras & 11 & 12339 & 3,14 \\
Cajas municipales (CM) & 12 & 21962 & 5,59 \\
Cajas rurales de ahorro y crédito (CRAC) & 6 & 1439 & 0,37 \\
Entidades de desarrollo de la pequeña & 10 & 2018 & 0,51 \\
y microempresa (Edpyme) & & & $\mathbf{1 0 0}$ \\
\hline TOTAL & $\mathbf{5 5}$ & $\mathbf{3 9 2 6 2 6}$ & \\
\hline
\end{tabular}

Tabla 4. Recuperado de Superintendencia de Banca, Seguros y AFP.

\subsubsection{Definición de la banca comercial}

La banca comercial se refiere a los integrantes del sistema bancario del país que intervienen como intermediarios entre ahorradores e inversionistas a través de la captación y préstamo de recursos financieros, según Roxana Escoto (2001). Las entidades bancarias, por tanto, pueden captar fondos del público y brindar otros servicios financieros.

Entonces, al describirse a la banca comercial se le refiere como el conjunto de bancos, tanto organizaciones estatales como privadas, que representan el sector más importante dentro del sistema financiero, debido a que, estas entidades son el actor principal en la canalización de fondos y ahorros hacia la inversión. La banca comercial se encarga de esto mediante depósitos y transferencias, a través de la concesión de préstamos y créditos (García, Martínez y Fernández 2014).

Para efectos del estudio es importante señalar a las instituciones financieras según su funcionalidad; y de esta manera, diferenciar las entidades que conforman la banca comercial. Para ello, como señalan Lopez Aliaga y David Ambrosini (2011) en su libro, 
Sistema Financiero Peruano, en el marco legal vigente, Ley № 26702 (Ley General del Sistema Financiero y del Sistema de Seguros y Orgánica de la Superintendencia de Banca y Seguros) la empresa bancaria se define de la siguiente manera:

Es aquella cuyo negocio principal consiste en recibir dinero del público en depósito o bajo cualquier otra modalidad contractual, y en utilizar ese dinero, su propio capital y el que obtenga de otras fuentes de financiación en conceder créditos en las diversas modalidades, o a aplicarlos a operaciones sujetas a riesgos de mercado. (p. 38)

En ese sentido, la banca se diferencia de la generalidad de otras entidades financieras que operan dentro del sistema financiero por la naturaleza de sus operaciones, así como por su estructura financiera y operativa. Siendo su funcionalidad principal: la administración de ahorros, transformación de ahorros en créditos y la administración del sistema de pagos (Muela 2009). De esta manera se puede diferenciar la banca, en comparación a otras entidades, como, por ejemplo, cajas rurales y municipales cuya especialidad se trata en operaciones de financiamiento a pequeñas y micro empresas.

\subsubsection{Importancia de la banca comercial}

La banca comercial, según el economista ecuatoriano Sandro Muela (2009), es considerada el sector clave en la economía de un país, debido principalmente a que la mayor parte del ahorro, la inversión y el financiamiento se canaliza a través de las instituciones que conforman la banca. Por esta razón, este sector es objeto de una mayor y extensa regulación para un funcionamiento apropiado que se refleje en un desarrollo sano de la actividad económica.

Para agregar, según Benito Solis (2015), la función de la banca comercial es ser intermediaria del ahorro entre quienes lo generan y aquellos que lo invierten o consumen. Refiriéndose al ahorro como aquel ingreso no consumido, y por tanto ahorrar por medio de estas entidades beneficia el desarrollo económico de un país, ya que dichos recursos reingresan al sistema económico. Por tanto, señala que el negocio de los bancos está en el 
rendimiento del préstamo y recuperar el dinero del mismo, que no es del banco sino de los ahorradores.

Por otro lado, Muela (2009) sostiene que las entidades bancarias también juegan un rol fundamental en la dirección de las políticas monetarias y crediticias que los gobiernos establecen a través de las actividades de depósito y préstamos que realizan. Por lo que, es importante señalar que el impacto en las políticas económicas de un país no recae solamente en los bancos centrales, quienes constituyen el centro financiero del país donde operan. Dado que, su rol principal consiste en preservar la estabilidad monetaria del país donde operan. Asimismo, las instituciones bancarias, ya sean privadas o públicas, ejecutan diferentes metas de la política económica de cada país, impactando en su desarrollo económico.

\subsubsection{Situación actual de la banca comercial}

En su informe, ASBANC (2017) indica que la morosidad bancaria en febrero del 2017 era de $2.98 \%$. Sin embargo, esta cifra ha continuado en aumento cerrando así en $3.04 \%$ a finales de mismo año, siendo la más alta en un periodo de 12 años. Esto se debe a los diversos factores que afectaron la economía del país durante el 2017, como los fenómenos climáticos y la desaceleración de la demanda interna causando estragos en el segmento de préstamos cuya mayor tasa de incumplimiento proviene mayormente por parte de las pequeñas empresas.

En ese sentido, el Banco Central de Reserva (BCR) emitió un enunciado en su reporte de estabilidad financiera en noviembre 2017: "Este deterioro [de los créditos] ha ocurrido en un contexto de menor actividad económica, debido a la evolución desfavorable de la inversión privada y pública, y por los efectos del fenómeno de El Niño, que afectó principalmente la zona norte del país".

Adicionalmente, se presenta el consumo de créditos del sector bancario y la contribución de cada segmento al cierre del año 2017. 
Figura 1: Contribución de segmentos al aumento de créditos

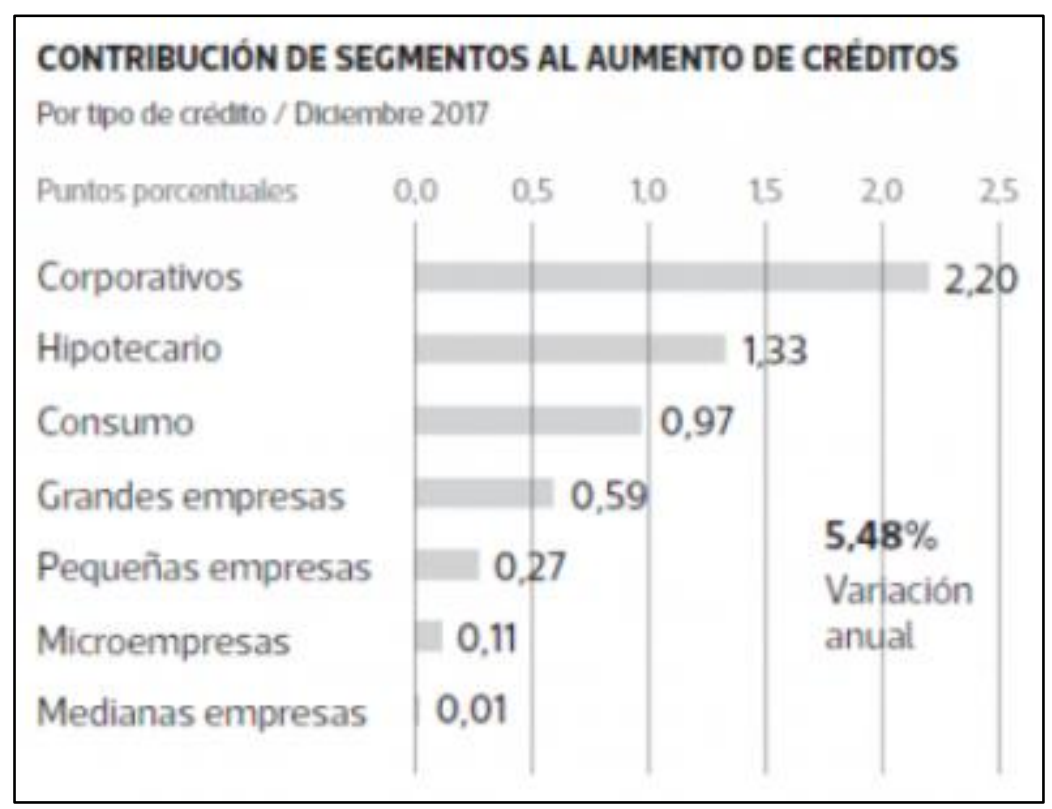

Fuente: ASBANC

\subsection{Banco Scotiabank}

\subsubsection{Situación general:}

Scotiabank Perú forma parte del grupo Bank of Nova Scotia (BNS), banco internacional con sede en Toronto fundado en 1832. Es el banco canadiense con mayor presencia a nivel internacional con un equipo alrededor de 80 mil empleados según la memoria anual de Scotiabank 2016.

El grupo Scotiabank se encuentra conformado por las siguientes entidades en el Perú:

Figura 2: Participación Accionaria SBP

\begin{tabular}{|c|c|}
\hline PARTICIPACIÓN ACCIONARIA (\%) & \\
\hline Empresa & \\
\hline CrediScotia Financiera S.A. & 100.00 \\
\hline Servicios, Cobranzas e Inversiones S.A.C.- SCI & 100.00 \\
\hline Scotia Sociedad Agente de Bolsa S.A. & 100.00 \\
\hline Scotia Fondos Sociedad Administradora de Fondos S.A. & 100.00 \\
\hline Scotia Sociedad Titulizadora S.A. & 100.00 \\
\hline Promociones de Proyectos Inmobiliarios y Comerciales S.A. & 100.00 \\
\hline
\end{tabular}

Fuente: Memoria anual Scotiabank 2016 
Según las memorias anuales de los últimos años, Scotiabank Peru ha logrado distintos premios recientes entre los que destacan:

$>$ Premio Focus Economics Analyst Forecast Awards 2016: 1er puesto en mejores proyecciones, balance fiscal y 2do lugar en inflación.

América Economía: Distinción como la mejor entidad Financiera en el Perú ocupando el puesto 6 en el ranking de los 25 mejores bancos de América Latina.

Revista Global Finance: Se reconoció como el Mejor Banco para operaciones de cambio en el país.

Great Place to work: En el 2014 alcanzó el 5to lugar en el Ranking de las mejores empresas para trabajar en el Perú y top 25 en el ranking de mejores empresas para trabajar en América Latina y en el mundo. Actualmente se encuentra en la posición 19 del ranking en Perú, y asimismo, SBP se ha mantenido dentro del ranking por 9 años consecutivos.

Asociación de buenos empleadores: Premio ABE a la responsabilidad Social Laboral (mejor programa de reconocimiento a sus trabajadores, programa Scotiabank Applause.

$>$ Índice de buen gobierno corporativo: Otorgado por la bolsa de valores de Lima "buenas prácticas en buen gobierno corporativo"

Ranking Merco Talento 2016: Scotiabank Perú fue reconocida en el puesto 11 en el ranking merco talento.

Ministerio de Trabajo: Premio Buenas prácticas laborales en dos categorías: Programa de recompensa total y Scotiabanker Beneficios. 
Recientemente, Scotiabank Perú inició un programa piloto 'FLEX TIME' para una mejor organización y flexibilidad de horarios a favor de sus ejecutivos de la sede principal y, además, la organización emplea tecnología VPN que les brinda la posibilidad de trabajar desde casa en situaciones que lo ameriten como beneficio a sus gerentes que requieran una mejor planificación ante alguna eventualidad.

\subsubsection{Planeamiento estratégico}

En la página oficial del banco Scotiabank en Perú, se constata el propósito de la organización, el cual dice lo siguiente:

Hoy hemos renovado nuestro propósito porque "Creemos que cada cliente tiene el DERECHO a estar mejor". Consideramos que no es un simple deseo, es más que eso, es un derecho de todas las personas y empresas que confían en nosotros.

Con este propósito renovado, continuamos colocando a nuestros clientes en el centro de todo lo que hacemos, como nuestra máxima prioridad, constituyéndose la base para nuestros objetivos.

Por eso, en Scotiabank seguimos esforzándonos por hacer posible el éxito de nuestros clientes; trabajando con respeto, integridad, pasión y responsabilidad.

Así mismo, en su página oficial, se puede encontrar la siguiente información:

Visión:

Ser los mejores en ayudar a nuestros clientes a mejorar su situación financiera, comprometiéndonos a proporcionarles soluciones relevantes a sus necesidades específicas. Misión:

Atender a nuestros clientes con una cultura de servicio total, enfocada en la persona, utilizando nuestra experiencia y conocimiento para ofrecerles soluciones financieras que los ayuden a alcanzar sus metas.

Valores:

Respeto, valora orígenes y experiencias diversas, tratando a todos con dignidad. 
Integridad, actuamos con integridad para merecernos la confianza de nuestros clientes y colegas.

Pasión, brindamos servicio a nuestros clientes con entusiasmo y orgullo, con el valor de escuchar, aprender innovar y ganar.

Responsabilidad, somos responsables de nuestro trabajo, compromisos y acciones ante nuestro clientes y colegas.

Entonces, según su planeamiento estratégico, el banco Scotiabank tiene como principal protagonista al cliente, pues tanto su propósito como sus objetivos giran en torno a él. Pero también, menciona a "los colegas", los cuales son los colaboradores de la empresa, y son importantes para el banco Scotiabank.

\subsubsection{Posicionamiento dentro de la banca comercial en el Perú}

Scotiabank a nivel de participación de mercado, según la siguiente tabla adaptada del Boletín Estadístico de Banca Múltiple por la SBS al 2015 ocupaba el 3er lugar con un 16.2\% siendo sus principales competidores el Banco de crédito que ocupa el ler lugar con un $33.25 \%$ seguido del Banco Continental con un $22.39 \%$.

Tabla 3: Créditos Directos Banca Múltiple al 30 de Junio del 2015

Créditos Directos Banca Múltiple al 30 de junio del 2015 en Miles de Soles

\begin{tabular}{clcc}
\hline & \multicolumn{1}{c}{ Empresas } & Monto & Participación \% \\
\hline 1 & B. de Crédito del Perú & $70,007,626$ & 33.25 \\
2 & B. Continental & $47,139,346$ & 22.39 \\
3 & Scotiabank Perú & $34,122,580$ & 16.2 \\
4 & Interbank & $23,621,330$ & 11.22 \\
5 & Mibanco & $7,450,480$ & 3.54 \\
6 & B. Interamericano de Finanzas & $7,362,177$ & 3.5 \\
7 & Otros & $20,875,207$ & 9.91 \\
Total Banca Múltiple & $210,578,746$ & 100 \\
\hline Nota. Adaptado de "Boletin Estadístico de Banca Múltiple," [Archivo de datos] por Superintendencia de Banca, Seguros y \\
AFP (SBS), 2015. Recuperado de http://www.sbs.gob.pe/app/stats/EstadisticaBoletinEstadistico.asp?p=1\#
\end{tabular}

Si se procede a detallar la composición del patrimonio, se logra apreciar que Scotiabank ocupa el 2do lugar con una participación de 18.37\%, muy similar al Banco Continental con una participacion de $17.74 \%$ y el BCP que mantiene el liderazgo con un $33.84 \%$ de 
participación patrimonial. Lo cual significa para Scotiabank una oportunidad de poder incrementar sus colocaciones y alcanzar al Continental.

Tabla 4: Patrimonio de la Banca Múltiple al 30 de Junio del 2015

Patrimonio de la Banca Múltiple al 30 de Junio del 2015 en Miles de Soles

\begin{tabular}{llrc}
\hline \multicolumn{1}{c}{ Empresas } & \multicolumn{1}{c}{ Monto } & Participación \% \\
\hline 1 B. de Crédito del Perú & $10,605,661$ & 33.84 \\
2 & Scotiabank Perú & $5,757,106$ & 18.37 \\
3 & B. Continental & $5,558,515$ & 17.74 \\
4 & Interbank & $3,184,629$ & 10.16 \\
5 & Mibanco & $1,202,033$ & 3.84 \\
6 & Citibank & 931,825 & 2.97 \\
7 Otros & $4,097,994$ & 13.08 \\
Total Banca Múltiple & $31,337,763$ & 100.00 \\
\hline Nota. Adaptado de "Boletín Estadistico de Banca Múltiple," [Archivo de datos] por Superintendencia de Banca, Seguros y
\end{tabular}

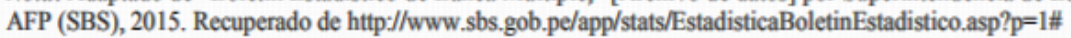

\subsubsection{Estructura organizacional}

A continuación, se presenta la estructura del directorio y la composición del Banco Scotiabank:

Figura 3: Composición del Directorio

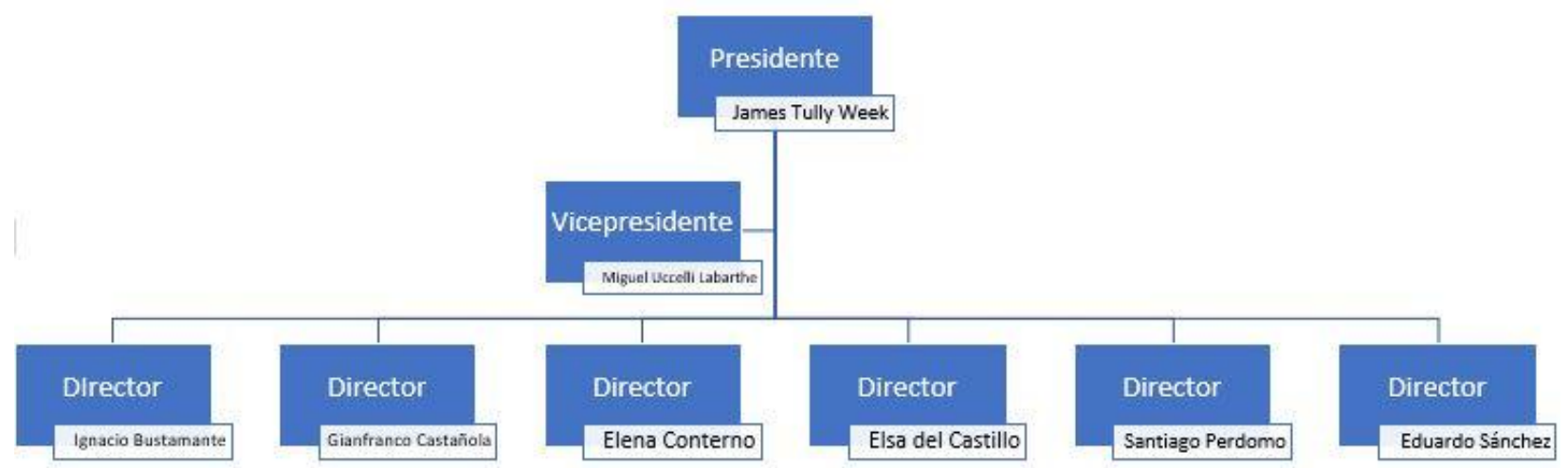

Fuente: Elaboración Propia. Recuperado de Banco Scotiabank. 
Scotiabank, cuenta con un total de 134 agencias en la capital del país, divididas en 2 territorios. A su vez, cada territorio está conformado por varias zonas que abarcan partes de la ciudad.

El territorio 1 consta de 74 agencias conformadas por las siguientes 5 zonas:

- Zona Lima Cercado (13 agencias)

- Zona Lima Norte (14 agencias)

- Zona Lima Sur Este (18 agencias)

- Zona Lima Centro (15 agencias)

- Zona Callao (14 agencias)

El territorio 2 consta de 60 agencias conformadas por las siguientes 4 zonas:

- Zona La Molina (14 agencias)

- Zona San Isidro (15 agencias)

- Zona Surco (14 agencias)

- Zona Miraflores (17 agencias)

A nivel de red (área comercial) se observa que la proporción de mujeres ejecutivas comerciales de las 134 agencias, sólo el $35 \%$ es ocupado por mujeres frente al $65 \%$ que es ocupado por su contraparte masculina en Lima Metropolitana.

Tabla 5: Proporción de ejecutivos comerciales

Proporción de ejecutivos comerciales

\begin{tabular}{c|cc}
\hline Cargo & Hombres & Mujeres \\
\hline $\begin{array}{c}\text { Gerencia } \\
\text { Comercial }\end{array}$ & $65 \%$ & $35 \%$ \\
\hline \multicolumn{2}{c}{ Fuente: Elaboración propia }
\end{tabular}

A nivel de Gerencias principales, y en adelante, la distribución entre hombres y mujeres es como se muestra en el siguiente cuadro: 
Tabla 6: Proporción de ejecutivos principales por cargo

Proporción de ejecutivos principales por cargo

\begin{tabular}{c|cc}
\hline Cargo & Hombres & Mujeres \\
\hline Vicepresidencia (VPs) & $82 \%$ & $18 \%$ \\
Directores & $69 \%$ & $31 \%$ \\
Gerencias Principales & $59 \%$ & $41 \%$ \\
\hline \multicolumn{2}{c}{ Fuente: elaboración propia }
\end{tabular}

Siendo un total de 640 ejecutivos entre las 3 categorías indicadas en el cuadro, la cantidad de mujeres ejecutivas en total son 147 representando por el $23 \%$.

Las áreas de mayor presencia femenina a niveles ejecutivos son principalmente las áreas de soporte (Operaciones, Producto, Marketing, Recursos humanos, Administración) y las áreas comerciales. 


\section{CAPITULO 2:}

\section{METODOLOGIA DE INVESTIGACIÓN}

\subsection{Planteamiento de la investigación}

\subsubsection{Propósito de la investigación:}

El presente trabajo de investigación tiene como propósito identificar y posteriormente analizar las competencias críticas de la mujer ejecutiva en el banco Scotiabank en Lima Metropolitana. Los resultados obtenidos de este estudio constituirán un aporte relevante tanto para la gestión del capital humano en los bancos comerciales de la capital como para aquellas mujeres que se encuentran en la búsqueda de alcanzar altos cargos dentro de su organización.

\subsubsection{Tipo de investigación}

La presente investigación es cualitativa del tipo descriptivo porque permitirá analizar cómo es la situación actual de la mujer ejecutiva a través de un acercamiento a la realidad que afrontan para tener un panorama claro de las principales barreras y así poder responder dos de los objetivos específicos. Además del tipo explicativo porque no sólo se trata de describir la situación y el problema sino explicar las causas sobre que competencias laborales son críticas para que las mujeres puedan alcanzar posiciones más altas dentro de la banca comercial.

La metodología de investigación aplicada está basada en el estudio del caso Scotiabank porque permite abordar la problemática de manera más focalizada e intensamente. Así como se manifiesta en la Enciclopedia Sage de Métodos de Investigación Cualitativa (Blatter, 2008, 68) en donde se define al estudio de casos como "un enfoque de investigación en el que se estudian en profundidad una o algunas dimensiones de un caso". Asimismo, Villareal y Landeta (2007) lo considera el método más apropiado para aprender 
sobre la realidad de una situación en la que se requiere explicar relaciones causales, realizar descripciones de perfil y generar teorías explicativas.

\subsubsection{Preguntas de la investigación:}

Las preguntas que se buscan responder a través de esta investigación son las siguientes:

- ¿Cuál es la situación actual de la mujer ejecutiva en el banco Scotiabank de Lima Metropolitana?

- ¿Cuáles son las principales barreras que enfrentan las mujeres para alcanzar puestos ejecutivos del Banco Scotiabank en Lima Metropolitana?

- ¿Qué competencias criticas poseen las mujeres ejecutivas del banco Scotiabank en Lima Metropolitana?

\subsection{Contexto}

\subsubsection{Descripción del contexto interno y externo}

A continuación, se presenta la matriz de análisis del contexto interno y externo donde se incluye las observaciones realizadas durante el trabajo de campo. Estas observaciones fueron hechas antes, durante y después de las entrevistas realizadas a los 5 segmentos identificados para la presente investigación. 


\begin{tabular}{|c|c|c|c|c|c|c|}
\hline SEGMENTOS & & $\begin{array}{l}\text { MUJERES EJECUTIVAS DE } \\
\text { SCOTIABANK }\end{array}$ & $\begin{array}{c}\text { ESPECIALISTA } \\
\text { RRHH EMPRESA } \\
\text { PRIVADA } \\
\end{array}$ & $\begin{array}{c}\text { GERENTE RRHH BANCA } \\
\text { COMERCIAL }\end{array}$ & $\begin{array}{l}\text { GERENTE RRHH } \\
\text { SCOTIABANK }\end{array}$ & $\begin{array}{l}\text { REPRESENTANTE } \\
\text { WOMEN CEO }\end{array}$ \\
\hline 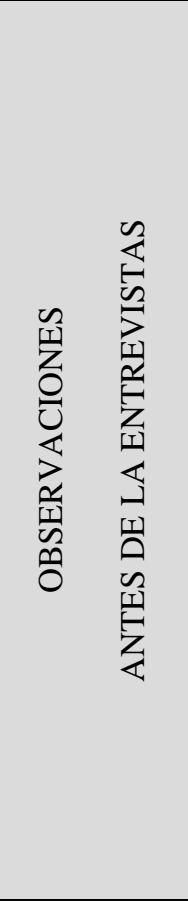 & $\frac{O}{\varrho}$ & $\begin{array}{l}\text { Las entrevistas se fijaron con cita } \\
\text { previa en un 95\%, ya que al ser } \\
\text { cargos gerenciales tienen } \\
\text { programadas sus actividades por } \\
\text { semana. Todas las entrevistas se } \\
\text { realizaron en las oficinas de las } \\
\text { entrevistadas, al tener ya una cita } \\
\text { previa, las entrevistas iniciaron } \\
\text { puntualmente, todas cerraron la } \\
\text { puerta de su oficina para evitar el } \\
\text { ruido externo y poder enfocarse en la } \\
\text { entrevista, adicional pusieron sus } \\
\text { celulares en vibración y silencio para } \\
\text { evitar desconcentrarse. Se les } \\
\text { menciono que, si tenían una llamada } \\
\text { importante que contestar se podía } \\
\text { interrumpir la entrevista, sólo sucedió } \\
\text { con } 2 \text { gerentes y la interrupción fue } \\
\text { breve solo para informar que estaban } \\
\text { ocupadas. Las entrevistadas son todas } \\
\text { profesionales con una trayectoria } \\
\text { profesional mayor a } 15 \text { años dentro } \\
\text { del banco, muy interesadas en el tema } \\
\text { de la investigación y con una edad } \\
\text { promedio de } 37 \text { años a } 65 \text { años. }\end{array}$ & $\begin{array}{lrr}\text { Esta } & \text { entrevista } & \text { se } \\
\text { realizó previa cita, } & \text { pra } \\
\text { debido a la agenda } \\
\text { ocupada } & \text { de } & \text { la } \\
\text { entrevistada y su buena } \\
\text { disposición de } & \text { poder } \\
\text { colaborar } & \text { con } & \text { la } \\
\text { investigación, } & \text { se } \\
\text { acordó realizarla en su } \\
\text { centro de labores el día } \\
\text { sábado como algo } \\
\text { excepcional, } & \text { La } \\
\text { entrevistada rambién } \\
\text { era profesional con } \\
\text { buena trayectoria en la } \\
\text { industria. }\end{array}$ & $\begin{array}{l}\text { Esta entrevista también fue } \\
\text { complicada ya que los } \\
\text { gerentes de recursos } \\
\text { humanos son las personas } \\
\text { con más talleres y reuniones } \\
\text { programadas, el primer } \\
\text { contacto con la entrevistada } \\
\text { no fue positivo ya que se } \\
\text { encontraba ocupada, la } \\
\text { reunión se logró concretar } \\
\text { debido a que se entrevistó a } \\
\text { otras dos gerentes del banco } \\
\text { financierorang quienes } \\
\text { casualmente eran cercanas y } \\
\text { pudieron realizar el contacto } \\
\text { para finalmente concretar la } \\
\text { entrevista a realizarse en la } \\
\text { torre principal en Miraflores } \\
\text { durante el transcurso de la } \\
\text { tarde. }\end{array}$ & $\begin{array}{llr}\text { Está fue } & \text { una de } & \text { las } \\
\text { entrevistas } & \text { más difícil } & \text { de } \\
\text { conseguir } & \text { debido a } & \text { las } \\
\text { muchas } & \text { actividades } & \text { y } \\
\text { reuniones que tienen en esta } & \\
\text { área, gracias a } & \text { una } \\
\text { recomendación de } & \text { otra } \\
\text { gerente se pudo contactar a } \\
\text { la gerente de recursos } \\
\text { humanos quien formaba } \\
\text { parte del comité de inclusión } \\
\text { social. Se pactó la cita para } \\
\text { realizar la entrevista en la } \\
\text { oficina de la entrevistada en } \\
\text { San Isidro durante el horario } \\
\text { de la mañana. }\end{array}$ & $\begin{array}{l}\text { Esta entrevista, si bien en } \\
\text { un inicio fue } \\
\text { recomendada por una de } \\
\text { las gerentes de Scotiabank } \\
\text { para poder concretar la } \\
\text { cita, se contactó a través } \\
\text { de la web de la } \\
\text { organización WOMEN } \\
\text { CEO quienes me } \\
\text { proporcionaron el correo } \\
\text { de la presidenta y fue así } \\
\text { como a través de un } \\
\text { correo se logró pactar la } \\
\text { entrevista. Debido a las } \\
\text { reuniones que tenía se } \\
\text { decidió que la entrevista } \\
\text { se realice en la cafetería } \\
\text { Balthazar en la tarde. }\end{array}$ \\
\hline
\end{tabular}




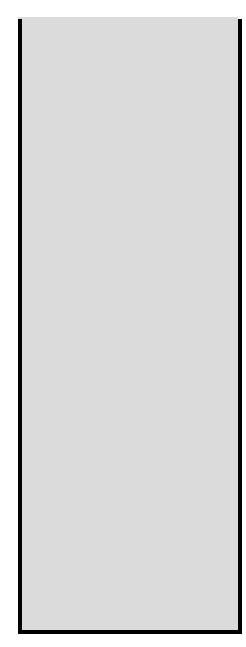

\begin{tabular}{|l|}
\hline Las entrevistas se realizaron en las \\
oficinas de las gerentes las cuales se \\
encontraban en diferentes distritos: \\
Ate, San Isidro, Miraflores y Jesús \\
María. En el caso de las gerentes de \\
la red que se encontraban en oficinas \\
dentro de una agencia, si se podía \\
apreciar la concurrencia de las \\
actividades, lo cual se minimizo \\
bastante bien al cerrar las puertas de \\
la oficina, en el caso de las gerentes \\
de la torre principal si contaban con \\
oficinas en pisos superiores, así que \\
no hubo interferencia del ambiente \\
externo.
\end{tabular}

La entrevista se realizó

en la oficina de su centro de labores a las 8am, ya que se encontraba fuera de horario, pero se eligió el día para que no haya interrupciones por et ruido de los alumnos. También empezó a la hora acordada y puso su celular en vibrador para poder tener mayor enfoque en

la

El ambiente de la oficina era amplio y personalizado, al ser un día viernes en la tarde no hubo mayor ruido por entrevistada era amplio, si parte de los colaboradores bien había otras personas en del área ya del área mayoría estaban enfocados en terminar sus labores, la entrevista también empezó a bocado a sus quehaceres sin generar mayor ruido que encontrarse en la torre principal también se me $\begin{array}{llr}\text { principal también se me } & \text { armonioso. La entrevista } \\ \text { pidió identificarme } & \text { y } & \text { empezó puntual porque ya }\end{array}$

entrevista. El ambiente era bastante amigable entrevista. para acceder ya que son de agenda de la entrevistada.

uso exclusivo para el personal del banco. 


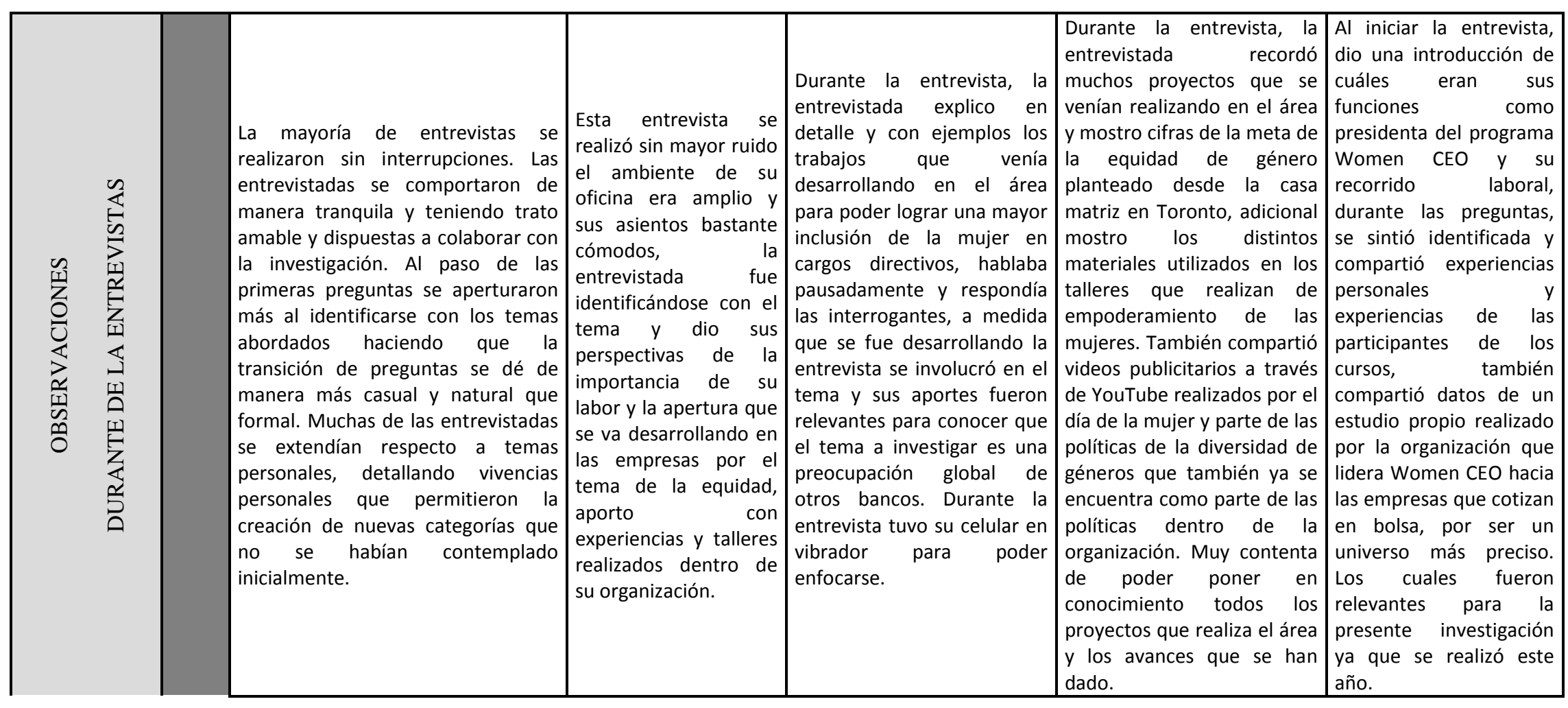




\begin{tabular}{|c|c|c|c|c|c|c|}
\hline 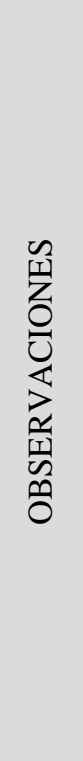 & 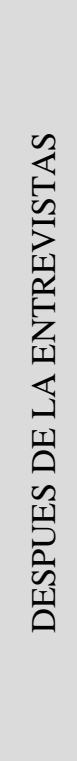 & $\begin{array}{l}\text { Buen trato al finalizar la entrevista, } \\
\text { de manera amigable. En algunos } \\
\text { casos se mostraron dispuestas a } \\
\text { apoyar la investigación refiriendo el } \\
\text { estudio a colegas que conocían más } \\
\text { del tema por haber participado } \\
\text { dentro del banco en el comité de } \\
\text { integración de la mujer y con ello se } \\
\text { lograron más entrevistas que } \\
\text { enriquecieron la investigación. Una } \\
\text { gerente en particular comentó sobre } \\
\text { la agrupación Women CEO que } \\
\text { representa a mujeres ejecutivas en } \\
\text { el país, y se contactó con la } \\
\text { presidente generando un segmento } \\
\text { más de entrevistadas a realizar. En } \\
\text { su mayoría, las entrevistadas se } \\
\text { mostraron interesadas en conocer } \\
\text { los resultados de la investigación al } \\
\text { finalizarla. }\end{array}$ & $\begin{array}{l}\text { Al finalizar la } \\
\text { entrevista, la } \\
\text { entrevistada se mostró } \\
\text { agradecida por haber } \\
\text { sido elegida, pidió } \\
\text { disculpas por no poder } \\
\text { conversar más al } \\
\text { respecto ya que tenía } \\
\text { otra reunión, sin } \\
\text { embargo dijo que se le } \\
\text { podía contactar por } \\
\text { WhatsApp rrara } \\
\text { cualquier r para } \\
\text { adicional a la } \\
\text { entrevista. }\end{array}$ & 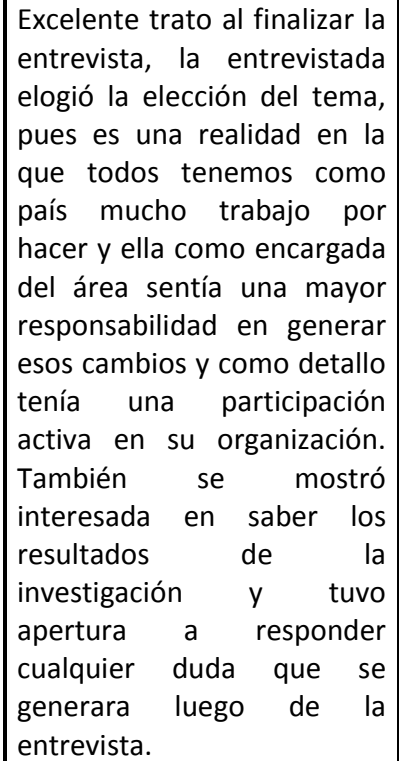 & 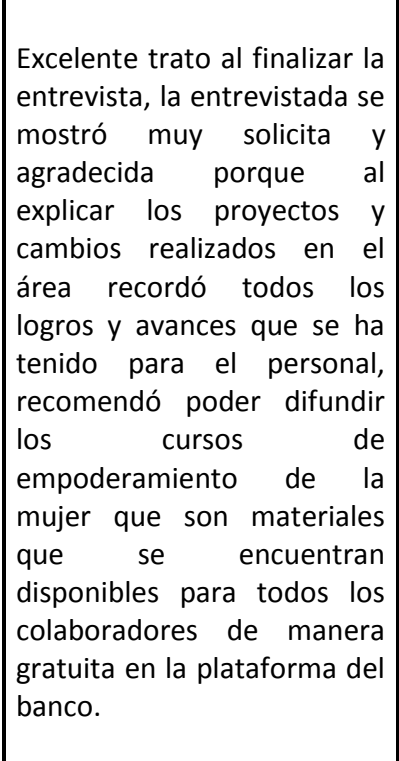 & $\begin{array}{l}\text { Excelente trato al } \\
\text { finalizar la entrevista, se } \\
\text { mostró agradecida y } \\
\text { resalto el tema de la } \\
\text { tesis, solicitando conocer } \\
\text { las conclusiones, para } \\
\text { poder tomarlo de } \\
\text { referencia y profundizar } \\
\text { en posteriores estudios } \\
\text { dentro de su } \\
\text { organización ya que } \\
\text { considero relevante el } \\
\text { tema abordado, enfatizo } \\
\text { que ahora estas barreras } \\
\text { deben ser abordadas } \\
\text { como generacionales, ya } \\
\text { que las nuevas } \\
\text { generaciones de líderes } \\
\text { tienen más apertura. }\end{array}$ \\
\hline
\end{tabular}




\begin{tabular}{|c|c|c|c|c|c|}
\hline 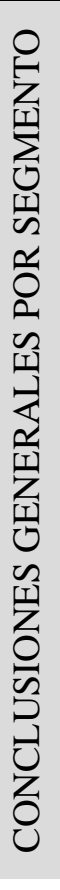 & $\begin{array}{l}\text { Las entrevistas realizadas a las } \\
\text { mujeres ejecutivas de la red y las } \\
\text { altas gerencias dentro del banco, } \\
\text { han sido muy gratificantes ya que } \\
\text { me ha permitido contrastar dos } \\
\text { realidades de percepciones muy } \\
\text { diferentes, en el caso de las } \\
\text { gerentes de la red sus experiencias } \\
\text { van acorde a lo publicado por la SBS } \\
\text { que cada vez hay mayor apertura de } \\
\text { mujeres en cargos ejecutivos en la } \\
\text { banca comercial. Sin embargo, en el } \\
\text { caso de las altas gerentes se permite } \\
\text { contrastar información que el nivel } \\
\text { de penetración en la alta gerencia es } \\
\text { todavía reducido y que las barreras } \\
\text { como el techo de cristal sigue } \\
\text { existiendo. Lo cual es una situación } \\
\text { que el banco al ser internacional } \\
\text { está dando un giro en sus políticas y } \\
\text { todas perciben esas intenciones de } \\
\text { cambio. }\end{array}$ & $\begin{array}{l}\text { Esta entrevista ha } \\
\text { permitido saber cómo } \\
\text { en otra industria ajena } \\
\text { al sector bancario, } \\
\text { también se percibe la } \\
\text { ausencia de una } \\
\text { equidad de género en } \\
\text { los altos cargos } \\
\text { ejecutivos. Hay } \\
\text { coincidías en algunas } \\
\text { barreras que enfrentan } \\
\text { las mujeres, aunque el } \\
\text { tema de balance } \\
\text { familia-trabajo es más } \\
\text { manejable en esta } \\
\text { industria debido a los } \\
\text { horarios más flexibles. } \\
\text { También perciben que } \\
\text { existe un cambio } \\
\text { gradual y que en parte } \\
\text { depende de un cambio } \\
\text { de conciencia de la } \\
\text { misma mujer. }\end{array}$ & $\begin{array}{l}\text { Esta entrevista fue también } \\
\text { muy complicada de obtener, } \\
\text { debido a lo recargado que es } \\
\text { la agenda de actividades en } \\
\text { esta área. Para lograr } \\
\text { concretar la entrevista se } \\
\text { tuvieron dos intentos de } \\
\text { contacto, el primer contacto } \\
\text { fue a través de una llamada } \\
\text { telefónica y por correo que } \\
\text { la entrevistadar no } \\
\text { respondió, el segundo } \\
\text { intento fue a través de una } \\
\text { referencia de otra gerente } \\
\text { del mismo banco, de esta } \\
\text { manera la entrevistada } \\
\text { accedió a la entrevista. La } \\
\text { información recabada ha } \\
\text { sido muy útil y concuerda } \\
\text { con la teoría expuesta sobre } \\
\text { los distintos roles de la } \\
\text { mujer. }\end{array}$ & $\begin{array}{l}\text { Esta entrevista ha brindado } \\
\text { excelentes aportes, a la } \\
\text { cuestión que el banco como } \\
\text { organización se ha } \\
\text { planteado metas en equidad } \\
\text { de género y ahora es parte } \\
\text { de sus políticas que en la } \\
\text { terna final de cualquier } \\
\text { proceso de postulación a un } \\
\text { cargo gerencial siempre se } \\
\text { deba considerar a una mujer } \\
\text { que cumpla los requisitos, } \\
\text { adicional en el panel de } \\
\text { evaluadores también es } \\
\text { política que tiene que haber } \\
\text { participación femenina para } \\
\text { que la evaluación tenga una } \\
\text { opinión más integral. }\end{array}$ & $\begin{array}{l}\text { Esta entrevista ha } \\
\text { brindado una gran } \\
\text { contribución al estudio, } \\
\text { ya que de fuente de la } \\
\text { entrevistada se ha } \\
\text { logrado en conjunto con } \\
\text { el ministerio de trabajo } \\
\text { que a partir de la fecha, } \\
\text { se solicite a las empresas } \\
\text { no sólo información } \\
\text { sobre la cantidad de } \\
\text { mujeres en la } \\
\text { organización sino } \\
\text { también saber cuántas } \\
\text { han sido ascendidas y } \\
\text { han seguido líneas de } \\
\text { carreras, para poder } \\
\text { tener cifras si la empresa } \\
\text { maneja prácticas de } \\
\text { promoción del empleo. }\end{array}$ \\
\hline
\end{tabular}




\subsection{Muestra}

\subsubsection{Descripción de la muestra:}

Para el presente estudio, se trata de aislar a un pequeño grupo de estudio al tratarse de una población en particular. El caso a estudiar se centra en el banco Scotiabank en Lima Metropolitana, y por esta razón la muestra son las mujeres ejecutivas del banco. En ese sentido, la muestra final contará con 16 entrevistas, que permitirá responder a los objetivos. Se tuvo en consideración alcanzar el nivel de saturación para considerar la muestra presente. Las entrevistas se realizarán con la finalidad de identificar y analizar las competencias críticas que influyen en la mujer ejecutiva del banco Scotiabank en Lima Metropolitana. Para tales efectos la muestra cuenta con 12 mujeres gerentes del banco Scotiabank en Lima Metropolitana, 1 Especialista de recursos humanos de empresas privadas en Lima Metropolitana, el Gerente de recursos humanos del Scotiabank, 1 Gerente de recursos humanos de la banca comercial de Lima Metropolitana y 1 representante de la organización de Mujeres ejecutivas y directivas.

\subsection{Diseño o abordaje principal}

\subsubsection{Identificación de la estructura de la entrevista.}

En la siguiente investigación se hará uso de una guía de preguntas semiestructurada debido a que además se plantean preguntas abiertas para abordar los temas más relevantes que permitirán al entrevistador tener un panorama más amplio sobre el tema. También se toma en consideración la formulación de preguntas que no se habrían tomado en cuenta inicialmente. De este modo, ampliar la cantidad y calidad de información recopilada.

\subsubsection{Guía de preguntas}

La elaboración de la guía de preguntas se basó en los objetivos establecidos para la presente investigación. Con ese fin, se determinó los segmentos que serán entrevistados los cuales apoyarán a tener diferentes puntos de vista de la problemática y las categorías 
correspondientes a cada segmento. Posteriormente, se consideró como referencia las categorías para formular las preguntas a través de una lluvia de ideas.

\subsubsection{Segmentos:}

Los segmentos de los cuales se recopila la información a través de las entrevistas semiestructuradas con preguntas abiertas son 5, como se detallan a continuación:

Tabla 7: Segmentación de entrevistadas

\begin{tabular}{|l|c|}
\hline \multicolumn{1}{|c|}{ UNIDADES PARA LA ENTREVISTA } & $\begin{array}{c}\text { CANTIDAD DE } \\
\text { ENTREVISTADOS }\end{array}$ \\
\hline $\begin{array}{l}\text { Mujeres gerentes del Banco Scotiabank en } \\
\text { Lima Metropolitana }\end{array}$ & 12 \\
\hline $\begin{array}{l}\text { Especialistas de recursos humanos de empresas } \\
\text { privadas en Lima Metropolitana }\end{array}$ & 1 \\
\hline $\begin{array}{l}\text { Gerentes de recursos humanos de la banca } \\
\text { comercial de Lima Metropolitana }\end{array}$ & 1 \\
\hline Gerente de recursos humanos del Scotiabank & 1 \\
\hline $\begin{array}{l}\text { Representante de WOMEN CEO Asociación de } \\
\text { mujeres empresarias y directivas }\end{array}$ & 1 \\
\hline
\end{tabular}

Fuente: trabajo de campo. Elaboración propia

En cuanto a los segmentos elegidos, se consideró entrevistar a un especialista de recursos humanos de empresas para tener una perspectiva de la situación, barreras y competencias de las mujeres en otra industria. Además, se tomó en cuenta a un Gerente de recursos humanos de la banca comercial para tener una perspectiva de la mujer ejecutiva en otros bancos. De la misma manera, se consideró al Gerente de recursos humanos de Scotiabank puesto que es relevante para contrastar con las competencias generales que tiene el banco. Por último, la representante de la asociación de mujeres empresarias y directivas 'WOMEN CEO' brinda un gran aporte debido a su programa dirigido a mujeres ejecutivas de distintos sectores y el cual está enfocado en poder desarrollar sus competencias y empoderar a las mujeres que tienen altos cargos. 


\subsubsection{Categorías:}

A partir de la revisión de la literatura y al tratarse de una investigación cualitativa empleando el método de entrevista a profundidad se consideró que los temas pertinentes al estudio se encuentran mejor definidos en las siguientes categorías:

- Categoría 1: Situación actual de la mujer ejecutiva

- Categoría 2: Barreras para las mujeres ejecutivas

- Categoría 3: Perfil de la mujer ejecutiva

- Categoría 4: Competencias laborales

- Categoría 5: Motivaciones (aspiraciones y motivos)

\subsubsection{El instrumento de investigación:}

En cuanto al instrumento para este estudio se recurrió a las entrevistas a profundidad. Estas entrevistas están formadas por una guía de preguntas semiestructurado que permita recopilar información amplia y confiable para poder identificar indicadores que validen la hipótesis de esta investigación. Estas preguntas buscan responder los cuestionamientos que surgieron del presente estudio y conocer, a través de un lente más amplio, el contexto de las mujeres ejecutivas del banco Scotiabank. Adicional, se elaboró una ficha de datos que se entregó a las participantes de este estudio antes de iniciar la entrevista para conocer sus datos como nombre, cargo, edad y estado civil. Esta ficha fue de mucha utilidad para orientar nuestras preguntas al abordar temas de maternidad, conciliación vida familiar trabajo y motivaciones.

\subsection{Procesamiento de la información:}

\subsubsection{Matriz de codificaciones por segmento}

Para la elaboración de esta matriz se sintetizó la información obtenida durante el trabajo de campo de la investigación a través de 5 temas asignando códigos a las respuestas de las entrevistadas de cada uno de los 6 segmentos. Durante dicho proceso surgieron 2 nuevos 
temas: Beneficios que percibe la mujer ejecutiva de Lima Metropolitana y Estrategias para el desarrollo profesional de las mujeres ejecutivas de Lima Metropolitana. A continuación, se detalla la Matriz de codificación para cada segmento con la información resultante de la agrupación de códigos para cada tema:

TEMA 1: Situación actual de la mujer ejecutiva de la banca comercial de Lima Metropolitana.

\begin{tabular}{|c|c|c|c|c|c|c|}
\hline & & $\begin{array}{c}\text { MUJERES } \\
\text { EJECUTIVAS } \\
\text { SCOTIABANK } \\
\end{array}$ & $\begin{array}{c}\text { ESPECIALISTA } \\
\text { RECURSOS } \\
\text { HUMANOS } \\
\end{array}$ & $\begin{array}{c}\text { GERENTE } \\
\text { R.R.H.H } \\
\text { OTROS } \\
\text { BANCOS } \\
\end{array}$ & $\begin{array}{c}\text { GERENTE } \\
\text { R.R.H.H. } \\
\text { SCOTIABANK } \\
\end{array}$ & $\begin{array}{c}\text { PRESIDENTA } \\
\text { ASOSIACION } \\
\text { MUJERES } \\
\text { EJECUTIVAS } \\
\end{array}$ \\
\hline \multirow{16}{*}{ 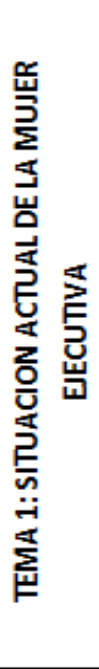 } & SA-GQT & 3 & - & - & - & - \\
\hline & SA-MBR & 4 & 1 & - & - & - \\
\hline & SA-P2030 & 4 & - & 1 & - & 1 \\
\hline & SA-P3040 & 7 & 1 & - & 1 & - \\
\hline & SA-OC & 7 & - & 1 & - & 1 \\
\hline & SA-MT & 10 & 1 & 1 & 1 & 1 \\
\hline & SA-PAC & 4 & - & - & 1 & - \\
\hline & SA-PAS & 7 & 1 & 1 & 1 & 1 \\
\hline & SA-IO & 8 & - & - & - & - \\
\hline & SA-NIO & 2 & - & - & - & - \\
\hline & SA-PME & 4 & - & - & - & - \\
\hline & SA-EMC & - & 1 & - & - & - \\
\hline & SA-ECMI & 1 & - & - & 1 & 1 \\
\hline & SA-CGA & 4 & 1 & - & - & 1 \\
\hline & SA-SDS & 4 & - & - & 1 & - \\
\hline & SA-NDS & 6 & 1 & 1 & - & 1 \\
\hline
\end{tabular}

TEMA 2: Barreras que enfrenta la mujer ejecutiva de la banca comercial de Lima Metropolitana

\begin{tabular}{|c|c|c|c|c|c|c|}
\hline & & $\begin{array}{l}\text { MUJERES } \\
\text { EJECUTIVAS } \\
\text { SCOTIABANK }\end{array}$ & $\begin{array}{c}\text { ESPECIALISTA } \\
\text { RECURSOS } \\
\text { HUMANOS }\end{array}$ & $\begin{array}{l}\text { GERENTE } \\
\text { R.R.H.H } \\
\text { OTROS } \\
\text { BANCOS }\end{array}$ & $\begin{array}{c}\text { GERENTE } \\
\text { R.R.H.H. } \\
\text { SCOTIABANK }\end{array}$ & $\begin{array}{c}\text { PRESIDENTA } \\
\text { ASOSIACION } \\
\text { MUJERES } \\
\text { EJECUTIVAS }\end{array}$ \\
\hline \multirow{10}{*}{ 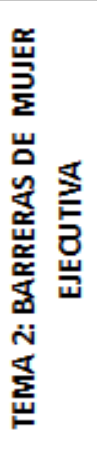 } & B-CM & 11 & 1 & - & 1 & 1 \\
\hline & B-FTVP & 4 & - & - & - & - \\
\hline & B-ARAC & 4 & - & 1 & 1 & 1 \\
\hline & B-MSDD & 1 & - & - & - & - \\
\hline & B-MNDD & 9 & - & 1 & 1 & 1 \\
\hline & B-PCCG & 2 & - & - & - & - \\
\hline & B-EEM & 1 & - & - & - & 1 \\
\hline & В-TCH & 3 & - & - & - & - \\
\hline & B-BGDA & 1 & 1 & 1 & - & 1 \\
\hline & B-SCVL & 6 & - & - & - & 1 \\
\hline
\end{tabular}


TEMA 3: Perfil de la mujer ejecutiva de la banca comercial de Lima Metropolitana

\begin{tabular}{|c|c|c|c|c|c|c|}
\hline & & $\begin{array}{l}\text { MUJERES } \\
\text { EJECUTIVAS } \\
\text { SCOTIABANK }\end{array}$ & $\begin{array}{c}\text { ESPECIALISTA } \\
\text { RECURSOS } \\
\text { HUMANOS }\end{array}$ & $\begin{array}{l}\text { GERENTE } \\
\text { R.R.H.H } \\
\text { OTROS } \\
\text { BANCOS }\end{array}$ & $\begin{array}{c}\text { GERENTE } \\
\text { R.R.H.H. } \\
\text { SCOTIABANK }\end{array}$ & $\begin{array}{c}\text { PRESIDENTA } \\
\text { ASOSIACION } \\
\text { MUJERES } \\
\text { EJECUTIVAS }\end{array}$ \\
\hline \multirow{16}{*}{ 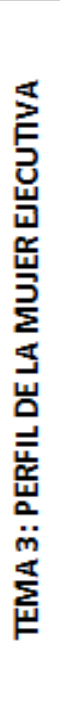 } & P-E3040 & 8 & 1 & 1 & - & - \\
\hline & P-E4150 & 4 & - & - & 1 & 1 \\
\hline & $\mathrm{P}-\mathrm{CCH}$ & 6 & - & - & - & 1 \\
\hline & P-CSH & 1 & 1 & - & - & - \\
\hline & P-DCH & 2 & - & - & - & - \\
\hline & P-CONH & 2 & - & - & - & - \\
\hline & P-SSH & 1 & - & - & 1 & - \\
\hline & P-EX1020 & 3 & 1 & 1 & - & - \\
\hline & P-EXM20 & 9 & - & - & - & 1 \\
\hline & P-NAL & 5 & 1 & - & - & - \\
\hline & P-NAM & 6 & - & - & - & 1 \\
\hline & P-NAD & 1 & - & - & - & - \\
\hline & P-TAP & 6 & - & 1 & - & - \\
\hline & P-TAC & 2 & - & - & - & - \\
\hline & Р-ТАH & 1 & - & - & - & - \\
\hline & P-TAE & 4 & - & - & - & 1 \\
\hline
\end{tabular}

TEMA 4: Competencias Críticas de la mujer ejecutiva de la banca comercial de Lima Metropolitana

\begin{tabular}{|c|c|c|c|c|c|c|}
\hline & & $\begin{array}{l}\text { MUJERES } \\
\text { EJECUTIVAS } \\
\text { SCOTIABANK }\end{array}$ & $\begin{array}{c}\text { ESPECIALISTA } \\
\text { RECURSOS } \\
\text { HUMANOS }\end{array}$ & $\begin{array}{l}\text { GERENTE } \\
\text { R.R.H.H } \\
\text { OTROS } \\
\text { BANCOS }\end{array}$ & $\begin{array}{c}\text { GERENTE } \\
\text { R.R.H.H. } \\
\text { SCOTIABANK }\end{array}$ & $\begin{array}{c}\text { PRESIDENTA } \\
\text { ASOSIACION } \\
\text { MUJERES } \\
\text { EJECUTIVAS }\end{array}$ \\
\hline \multirow{18}{*}{ 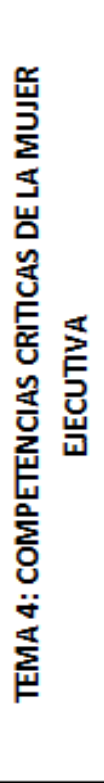 } & CC-EI & 9 & 1 & 1 & 1 & 1 \\
\hline & CC-LID & 12 & 1 & 1 & 1 & 1 \\
\hline & CC-CT & 4 & 1 & - & 1 & - \\
\hline & CC-CPO & 7 & 1 & 1 & - & - \\
\hline & CC-INI & 8 & 1 & - & - & - \\
\hline & CC-IC & 6 & - & 1 & 1 & - \\
\hline & CC-OR & 9 & 1 & 1 & 1 & 1 \\
\hline & CC-DDP & 6 & 1 & 1 & 1 & 1 \\
\hline & CC-AC & 10 & 1 & - & 1 & - \\
\hline & CC-PE & 6 & 1 & 1 & 1 & 1 \\
\hline & CC-INEG & 6 & 1 & 1 & - & 1 \\
\hline & CC-TE & 10 & 1 & 1 & - & - \\
\hline & CC-CC & 9 & 1 & 1 & 1 & - \\
\hline & CC-OCIE & 3 & 1 & 1 & 1 & - \\
\hline & CC-DAT & 7 & 1 & 1 & - & - \\
\hline & CC-PA & 4 & 1 & 1 & - & 1 \\
\hline & CC-RP & 9 & 1 & 1 & 1 & - \\
\hline & CC-RPUB & 1 & 1 & - & - & - \\
\hline
\end{tabular}


TEMA 5: Motivaciones de la mujer ejecutiva de la banca comercial de Lima Metropolitana

\begin{tabular}{|c|c|c|c|c|c|c|}
\hline & & $\begin{array}{c}\text { MUJERES } \\
\text { EJECUTIVAS } \\
\text { SCOTIABANK }\end{array}$ & $\begin{array}{c}\text { ESPECIALISTA } \\
\text { RECURSOS } \\
\text { HUMANOS }\end{array}$ & $\begin{array}{l}\text { GERENTE } \\
\text { R.R.H.H } \\
\text { OTROS } \\
\text { BANCOS }\end{array}$ & $\begin{array}{c}\text { GERENTE } \\
\text { R.R.H.H. } \\
\text { SCOTIABANK }\end{array}$ & $\begin{array}{l}\text { PRESIDENTA } \\
\text { ASOSIACION } \\
\text { MUJERES } \\
\text { EJECUTIVAS }\end{array}$ \\
\hline \multirow{6}{*}{ 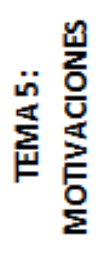 } & M-AR & 5 & 1 & 1 & 1 & 1 \\
\hline & M-AT & 8 & - & 1 & - & 1 \\
\hline & M-AF & 6 & - & - & - & 1 \\
\hline & M-AP & 4 & - & - & - & 1 \\
\hline & M-LOG & 7 & - & - & - & 1 \\
\hline & M-REC & 4 & - & 1 & - & 1 \\
\hline
\end{tabular}

TEMA 6: Beneficios que percibe la mujer ejecutiva en su organización de la banca comercial de Lima Metropolitana

\begin{tabular}{|c|c|c|c|c|c|c|}
\hline & & $\begin{array}{l}\text { MUJERES } \\
\text { EJECUTIVAS } \\
\text { SCOTIABANK }\end{array}$ & $\begin{array}{c}\text { ESPECIALISTA } \\
\text { RECURSOS } \\
\text { HUMANOS }\end{array}$ & $\begin{array}{l}\text { GERENTE } \\
\text { R.R.H.H } \\
\text { OTROS } \\
\text { BANCOS }\end{array}$ & $\begin{array}{c}\text { GERENTE } \\
\text { R.R.H.H. } \\
\text { SCOTIABANK }\end{array}$ & $\begin{array}{l}\text { PRESIDENTA } \\
\text { ASOSIACION } \\
\text { MUJERES } \\
\text { EJECUTIVAS }\end{array}$ \\
\hline \multirow{4}{*}{ 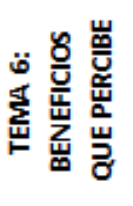 } & B-FH & 7 & - & 1 & 1 & - \\
\hline & B-CV & 4 & - & - & - & - \\
\hline & B-TD & 5 & - & 1 & 1 & 1 \\
\hline & B-CS & 2 & - & - & - & - \\
\hline
\end{tabular}

TEMA 7: Estrategias para el desarrollo de la mujer ejecutiva de la banca comercial de Lima Metropolitana

\begin{tabular}{|c|c|c|c|c|c|c|}
\hline & & $\begin{array}{l}\text { MUJERES } \\
\text { EJECUTIVAS } \\
\text { SCOTIABANK }\end{array}$ & $\begin{array}{c}\text { ESPECIALISTA } \\
\text { RECURSOS } \\
\text { HUMANOS }\end{array}$ & $\begin{array}{l}\text { GERENTE } \\
\text { R.R.H.H } \\
\text { OTROS } \\
\text { BANCOS }\end{array}$ & $\begin{array}{c}\text { GERENTE } \\
\text { R.R.H.H. } \\
\text { SCOTIABANK }\end{array}$ & $\begin{array}{l}\text { PRESIDENTA } \\
\text { ASOSIACION } \\
\text { MUJERES } \\
\text { EJECUTIVAS }\end{array}$ \\
\hline \multirow{4}{*}{ 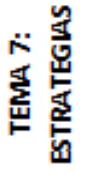 } & E-CING & 1 & 1 & - & - & 1 \\
\hline & E-EOV & 8 & - & 1 & 1 & 1 \\
\hline & E-NING & 5 & - & - & - & 1 \\
\hline & E-DAC & 2 & 1 & 1 & - & 1 \\
\hline
\end{tabular}




\subsubsection{Matriz de aspectos positivos y negativos}

\begin{tabular}{|c|c|c|c|}
\hline \multicolumn{2}{|r|}{ ASPECTOS POSITIVOS } & & ASPECTOS NEGATIVOS \\
\hline \multicolumn{4}{|c|}{ SEGMENTO 1: MUJERES EJECUTIVAS DE SCOTIABANK } \\
\hline 1 & $\begin{array}{l}\text { Perciben mejoras en el tiempo, como la } \\
\text { inclusión de la mujer a cargos ejecutivos }\end{array}$ & 1 & $\begin{array}{l}\text { Falta de tiempo para la vida privada se } \\
\text { evidencia más en las gerentes de la red, ya } \\
\text { que por la posición frente al cliente externo } \\
\text { requieren jornadas más extensas }\end{array}$ \\
\hline 2 & $\begin{array}{l}\text { Consideran que dentro de la organización se } \\
\text { dan las mismas oportunidades sin importar } \\
\text { el género }\end{array}$ & 2 & $\begin{array}{l}\text { Algunas gerentes de altos cargos, consideran } \\
\text { que existe disparidad salarial en la } \\
\text { organización }\end{array}$ \\
\hline 3 & $\begin{array}{l}\text { Sus motivaciones en el trabajo son la } \\
\text { autonomía y autorrealización }\end{array}$ & 3 & $\begin{array}{l}\text { Hay pocos cupos para ascender a cargos } \\
\text { ejecutivos ( se evidencia en las gerentes de } \\
\text { la red) }\end{array}$ \\
\hline 4 & \begin{tabular}{|l}
$\begin{array}{l}\text { Expresan su opinión en las reuniones } \\
\text { directivas. }\end{array}$ \\
\end{tabular} & 4 & $\begin{array}{l}\text { Auto limitarse a ejercer responsabilidades } \\
\text { para asumir posiciones directivas }\end{array}$ \\
\hline 5 & $\begin{array}{l}\text { Las mujeres gerentes de la red y algunas } \\
\text { gerentes de altos cargos consideran que no } \\
\text { existe disparidad salarial que está basado en } \\
\text { la meritocracia }\end{array}$ & 5 & $\begin{array}{l}\text { Los tópicos de convers } \\
\text { hombres, limita la participació }\end{array}$ \\
\hline 6 & Existen beneficios & 6 & $\begin{array}{l}\text { Sentimiento de culpa por pr } \\
\text { profesional, limita a algunas g } \\
\text { mayores cargos }\end{array}$ \\
\hline 7 & $\begin{array}{l}\text { Las gerentes de alto cargo que no trabajan } \\
\text { de cara al cliente externo, gozan de } \\
\text { beneficios como el Flex time y el trabajar } \\
\text { desde casa, todo eso de acuerdo con sus } \\
\text { superiores }\end{array}$ & 7 & $\begin{array}{l}\text { Algunas consideran que la elección de ser } \\
\text { mamá afecta el desempeño laboral, ya que le } \\
\text { dedicas menos horas extras. }\end{array}$ \\
\hline 8 & $\begin{array}{l}\text { En su mayoría consideran que el ser mamá } \\
\text { no afecta su desempeño laboral }\end{array}$ & 8 & Estereotipos de rol de ama de casa \\
\hline & $\begin{array}{l}\text { Hay gerentes que quieren y prefieren } \\
\text { trabajar con mujeres }\end{array}$ & 9 & sta del país \\
\hline
\end{tabular}

\begin{tabular}{|l|l|l|l|}
\hline \multicolumn{2}{|c|}{ ASPECTOS POSITIVOS } & \multicolumn{2}{|c|}{ ASPECTOS NEGATIVOS } \\
\hline \multicolumn{2}{|c|}{ SEGMENTO 2 : ESPECIALISTA DE RRHH DE EMPRESA PRIVADA } \\
\hline 1 & $\begin{array}{l}\text { Percibe una mayor presencia de mujeres en } \\
\text { el campo laboral principalmente en áreas } \\
\text { comerciales }\end{array}$ & 1 & $\begin{array}{l}\text { Considera que la elección de ser mamá } \\
\text { interfiere con su desempeño y crecimiento } \\
\text { laboral }\end{array}$ \\
\hline 2 & $\begin{array}{l}\text { Considera que las oportunidades están } \\
\text { presentes y que las mujeres deben atreverse } \\
\text { a ir por ellas }\end{array}$ & 2 & $\begin{array}{l}\text { Los estereotipos de como la mujer debe ser o } \\
\text { actuar en casa persisten }\end{array}$ \\
\hline 3 & $\begin{array}{l}\text { Las grandes organizaciones ya empiezan a } \\
\text { incluir políticas de inclusión de mujeres a } \\
\text { cargos más importantes }\end{array}$ & 3 & $\begin{array}{l}\text { No considera que existen las mismas } \\
\text { oportunidades para las mujeres respecto a } \\
\text { los hombres }\end{array}$ \\
\hline 4 & Las mujeres disfrutan de la autonomía que & 4 & \begin{tabular}{l} 
Hay disparidad salarial incluso en la capital \\
\hline
\end{tabular}
\end{tabular}




\begin{tabular}{|l|l|l|l|}
\hline & les da el ámbito laboral en el mundo actual & & del país \\
\hline 5 & $\begin{array}{l}\text { El apoyo familiar es fundamental para el } \\
\text { crecimiento profesional }\end{array}$ & $\begin{array}{l}\text { El machismo está presente en la oficina y en } \\
\text { casa }\end{array}$ \\
\hline 6 & $\begin{array}{l}\text { Existen diversos programas en el sector } \\
\text { privado orientado a las mujeres como } \\
\text { capacitaciones en liderazgo. }\end{array}$ & \\
\hline
\end{tabular}

\begin{tabular}{|l|l|l|l|}
\hline \multicolumn{2}{|c|}{ ASPECTOS POSITIVOS } & \multicolumn{2}{|c|}{ ASPECTOS NEGATIVOS } \\
\hline 1 & $\begin{array}{l}\text { A nivel de organización cuenta con políticas } \\
\text { e inclusión de las mujeres en cargos } \\
\text { ejecutivos. }\end{array}$ & 1 & $\begin{array}{l}\text { El tema de los estereotipos por los roles } \\
\text { asignados a la mujer como ama de casa, es un } \\
\text { tema cultural que se está superando }\end{array}$ \\
\hline 2 & $\begin{array}{l}\text { Considera que con el tiempo se ha } \\
\text { incrementado la cantidad de mujeres en } \\
\text { cargos ejecutivos }\end{array}$ & 2 & $\begin{array}{l}\text { Brecha generacional dificulta la apertura } \\
\text { hacia la mujer en cargos ejecutivos. }\end{array}$ \\
\hline 3 & $\begin{array}{l}\text { Expresa su opinión y organiza talleres de } \\
\text { liderazgo para vencer esa autolimitación a a } \\
\text { seguir desarrollándose de las mujeres }\end{array}$ & 3 & $\begin{array}{l}\text { Sentimiento de culpa por priorizar la vida } \\
\text { laboral y profesional marcada por la sociedad. }\end{array}$ \\
\hline 4 & $\begin{array}{l}\text { Sabe manejar sus prioridades familia - } \\
\text { trabajo }\end{array}$ & 4 & $\begin{array}{l}\text { Considera que existe machismo formado } \\
\text { desde casa }\end{array}$ \\
\hline 5 & $\begin{array}{l}\text { Considera que el tema salarial está en } \\
\text { función de los méritos sin importar el género }\end{array}$ & \\
\hline 6 & $\begin{array}{l}\text { Ser mamá no dificulta el desempeño laboral, } \\
\text { considera que es un tema de organización }\end{array}$ & \\
\hline
\end{tabular}

\begin{tabular}{|c|c|c|}
\hline & ASPECTOS POSITIVOS & ASPECTOS NEGATIVOS \\
\hline \multicolumn{3}{|c|}{ SEGMENTO 4: GERENTE DE RECURSOS HUMANOS DE SCOTIABANK } \\
\hline 1 & $\begin{array}{l}\text { Expresa que a nivel de organización si hay } \\
\text { una política de una cuota mínima de mujeres } \\
\text { en cargos gerenciales }\end{array}$ & \begin{tabular}{|l|l}
1 & $\begin{array}{l}\text { Considera que si existe disparidad salarial a } \\
\text { niveles de altos ejecutivos }\end{array}$
\end{tabular} \\
\hline 2 & $\begin{array}{l}\text { Considera que se ha realizado cambios en el } \\
\text { tiempo para incrementar la cantidad de } \\
\text { mujeres en cargos ejecutivos }\end{array}$ & $2 \begin{array}{l}\text { Considera que existen estereotipos sobre la } \\
\text { mujer, que se trata de mejorar pero es un } \\
\text { tema cultural }\end{array}$ \\
\hline 3 & $\begin{array}{l}\text { Expresa su opinión y realiza cursos de } \\
\text { empoderamiento de la mujer a niveles } \\
\text { ejecutivos para tener mayor presencia. }\end{array}$ & 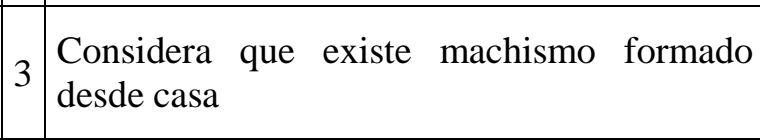 \\
\hline 4 & $\begin{array}{l}\text { Debido a la posición y funciones del puesto, } \\
\text { cuenta con beneficios como el Flex time, } \\
\text { ingresar antes al trabajo para salir antes o el } \\
\text { trabajar desde casa siempre coordinando con } \\
\text { sus superiores }\end{array}$ & $4 \begin{array}{l}\text { El rol de madre para algunas las auto limita a } \\
\text { ejercer responsabilidades para asumir } \\
\text { posiciones directivas }\end{array}$ \\
\hline 5 & $\begin{array}{l}\text { Saber manejar sus prioridades familia - } \\
\text { trabajo }\end{array}$ & \\
\hline
\end{tabular}




\begin{tabular}{|c|c|c|}
\hline & ASPECTOS POSITIVOS & ASPECTOS $\mathrm{N}$ \\
\hline \multicolumn{3}{|c|}{ SEGMENTO 5: REPRESENTANTE ASOCIACION DE MUJERES EJECUTIVAS Y DIRECTIVAS } \\
\hline 1 & $\begin{array}{l}\text { Percibe que no hay disparidad salarial desde } \\
\text { su experiencia personal y a nivel corporativo }\end{array}$ & \begin{tabular}{l|l}
1 & $\begin{array}{l}\text { Auto limitarse a ejercer responsabilidades } \\
\text { para asumir posiciones directivas }\end{array}$ \\
\end{tabular} \\
\hline 2 & $\begin{array}{l}\text { Considera que si se vienen realizando } \\
\text { cambios en el tiempo a niveles ejecutivos }\end{array}$ & $2 \begin{array}{l}\text { Brecha generacional } \\
\text { hacia la mujer en car }\end{array}$ \\
\hline 3 & $\begin{array}{l}\text { Considera que las opor } \\
\text { para todos sean hombres o } \\
\text { que estar preparados }\end{array}$ & $\begin{array}{l}3 \\
\begin{array}{l}\text { Sentimiento de culpa por priorizar la vida } \\
\text { laboral y profesional marcada por la } \\
\text { sociedad. }\end{array}\end{array}$ \\
\hline 4 & contribuido en & $4 \mathrm{M}$ \\
\hline 5 & Ser mamá no dificulta el desempeño laboral & $\begin{array}{l}5 \\
\begin{array}{l}\text { Estereotipos del rol de la mujer como ama de } \\
\text { casa, o la que se encarga de la parte operativa } \\
\text { de la mujer. }\end{array} \\
\end{array}$ \\
\hline
\end{tabular}




\section{CAPITULO 3:}

\section{ANÁLISIS DE DATOS Y RESULTADOS}

En el presente capítulo se analizarán los resultados, buscando responder las preguntas de investigación a través del análisis de las entrevistas de profundidad realizado a los diferentes segmentos. Asimismo, dicho análisis servirá para validar la hipótesis planteada para esta investigación.

\section{¿Cuál es la situación actual de la mujer ejecutiva en el banco Scotiabank de Lima metropolitana?}

La situación actual de la mujer ejecutiva se presenta en un escenario favorable ya que se ha dado un incremento del número de mujeres en cargos ejecutivos en Scotiabank Perú (SBP). Sin embargo, esto no siempre fue así, la aceptación de mujeres en cargos de alta jerarquía era muy baja y gracias a los cambios generacionales que trajo la nueva dirección de Scotiabank con la creación de un comité de inclusión social desde el 2007 que se ha trabajado en poder empoderar a la mujer ejecutiva para que se atrevan a aplicar a cargos de mayores jerarquías. Esto, en paralelo a la implementación de una cuota mínima en la terna final de una postulación a un cargo gerencial, en la que siempre debe haber al menos una mujer, al igual que en el panel de evaluadores también es requisito que tenga una conformación mixta para evitar sesgos al momento de evaluar el perfil de los postulantes a cargos gerenciales y de altos mandos. El desarrollo de estas políticas inclusivas viene de la casa matriz en Toronto por ser un banco internacional y esta mayor inclusión no sólo se da por un tema de género sino porque realmente las mujeres se encuentran tan calificadas como los hombres y es importante remarcar la importancia de la diversidad de pensamientos en una mesa de decisión. Es así que el área de recursos humanos tiene una herramienta llamada "People Report" la cual tiene una serie de métricas como: Género, edad, rotación de personal, años en la posición, entre otros en relación a la composición del 
área y permite que de manera periódica en reuniones que tiene el comité de inclusión con las vicepresidencias puedan ver de manera gráfica la composición del área y las oportunidades de tener un equipo equilibrado de hombres y mujeres que permitan tener enfoques diferentes.

(...) cuando empezamos el trabajo del comité había áreas como Marketing en donde todos los reportes eran hombres y (...) es un área donde hay mucha creatividad digamos entonces que el aporte de la mujer creo sería muy valorado (...) nosotros hicimos mucho trabajo con ese vicepresidente en especial hacerle ver que no tenía mujeres y a raíz de eso (...) creó más áreas y trajo mujeres y la verdad es que los resultados han sido mucho mejores (Gerente principal 12 SBP)

(...) a nivel de gerencias principales y VPs (Vice presidentes) parte de lo que es la selección, siempre debe haber una mujer en la terna final. (Gerente de Recursos Humanos SBP)

Además, presentan la misma apreciación de mejoría en años recientes justamente por una mayor apertura en el contexto global. Esto se ve reflejado en las declaraciones de las entrevistadas:

(...) entre al banco en el 74 pasé regular tiempo y tuve la oportunidad de participar en varias funciones donde se veía el tema del trabajo de personal femenino bastante diferenciado. Entonces, si comparamos entre esa época y todo el recorrido a la fecha pues esto se ha superado bastante, a mi parecer, todavía no del todo porque si nosotros nos movemos como pensáramos... hoy en día solamente tenemos en los cargos más altos una mujer VP y deberían dar, sí, mayores oportunidades, pero si comparamos con años anteriores si hubo bastante trabajo. (Gerente Principal 11 SBP)

(...) hemos logrado bastantes avances, en la época que yo ingrese al banco no había muchas mujeres que sean líderes ¿no? en ninguna posición alta en el banco Wiesse. (...) En el trayecto hemos ganado mayor rango...posiciones de mejor nivel banco y a nivel nacional veo mujeres que ya son líder en sus empresas (Gerente de Agencia 3 SBP)

En ese sentido, en comparación con periodos anteriores a lo largo de su experiencia en el rubro, las entrevistadas del segmento de gerentes, indica que la proporción de mujeres ejecutivas en cargos de gerencia de agencia (Red comercial del banco) está por encima del $30 \%$ pero, aún, sin llegar a la igualdad. Lo cual se asemeja a un informe de Prensa por ASBANC (Asociación de Bancos del Perú) sobre la fuerza laboral bancaria, en donde, se 
señala que el porcentaje de participación de la mujer en cargos de gerentes llega a un 35.6\% a finales del 2017 y lo confirman las siguientes declaraciones:

Yo creo que todavía estamos en un 30/70. Por ejemplo, en los gerentes aquí. Estamos maso menos en un 30/70. (Gerente de Agencia 1 SBP)

(...) yo creo que... no tengo el dato exacto, pero más o menos un 60/40 podría ser, $40 \%$ de la mujer que todavía tenemos campo para seguir desarrollando, pero creo que es algo que está evolucionando (Gerente Principal 9 SBP)

Yo creo que en la parte comercial (...) las mujeres son muy buenas para temas comerciales en ventas, sobretodo en venta de intangibles (...) Tienen mucho más poder de convencimiento (...) en los argumentos de conocer el producto y sobretodo en las ganas que tiene de cerrar algo. (Gerente de Agencia 6 SBP)

Por otro lado, frente a aquellas posiciones de Gerencia principal SBP (áreas centrales del banco) comentan que el porcentaje es menor al 30\%. Aunque este porcentaje ha ido aumentando, aún persiste el predominio masculino en cargos directivos en áreas no comerciales, esto debido a que a mayor nivel jerárgico las barreras a las que se deben enfrentar las mujeres es mayor. Es por ello, que las entidades toman consciencia y se plantean metas de inclusión para poder desarrollar estrategias que permitan una mayor apertura de las mujeres en cargos directivos.

Ya, mientras más subimos los puestos femeninos, no es que estemos a la par $50 \%$ $50 \%$, sino que estamos más o menos $30-70$, y ¿por qué? porque cada vez que suben más (...) tienen que decidir entre su familia o subir y muchas se van por subir, pero otras se dan su espacio para la familia y posteriormente que tienen su familia ya establecida cerrada, ya comienzan a subir dentro de la organización (Gerente De Recursos Humanos SBP)

(...) más o menos el $23 \%$ de todo lo que son niveles gerenciales en el banco son mujeres, de gerente principal para arriba. Esa son las últimas estadísticas que tengo a Enero de este año. (...) entre gerentes, VPs, SVPs y gerencia general son más o menos 640 gerentes y de esos 147 somos mujeres. (Gerente Principal 8 SBP)

(...) estaremos en unos 80/20, pero el banco está cambiando, nosotros hoy, en el tema de responsabilidad social, estamos trabajando mucho con todo el tema del poder y ámbito de la mujer (...) Entonces nosotros como Banco y yo como mujer de Recursos Humanos, sí estoy comprometida, de que nosotros debemos de tener más grupos de mujeres. (Gerente de Recursos Humanos Banco Financiero) 
Otro aspecto de la situación actual de las mujeres ejecutivas del banco que es importante considerar es la igualdad en oportunidades tanto para hombres como mujeres. Las mujeres gerente SBP consideran que se dan las mismas oportunidades para ambos géneros dentro de la organización, esto viene impulsado por programas de inclusión de la misma central del Banco en Canadá, y también, gracias a la implementación de programas que ayudan el itinerario de un gerente con horarios más flexibles. Asimismo, a nivel país la creación de la Ley de Igualdad de Oportunidades entre Hombres y Mujeres (Ley No 28983) ha contribuido a que la brecha de género disminuya en el país para que tanto hombres como mujeres hagan uso de sus derechos sin ningún tipo de discriminación. Esto se corrobora con el reporte "The global gap report" (2017) presentado en el Foro Económico Mundial (World Economic Forum) en donde la opinión de mujeres ejecutivas de nuestro país fue analizada en respuesta al cuestionamiento de hasta qué extensión las compañías proveen las mismas oportunidades que a los hombres para alcanzar posiciones de liderazgo dando como resultado que el avance de mujeres para roles de liderazgo en Perú fue de 0.50 (data en escala de 0 a 1 siendo $0=$ peor score, $1=$ mejor score). Entre las declaraciones que afirman esto se aprecia las siguientes:

En Scotiabank sí, (...) siento que tenemos las mismas oportunidades para competir por un mismo puesto. (...) Sí de todas maneras sobretodo (...) he visto diferentes culturas, desde la cultura cuando en el banco la dirección era peruana y luego ha sido europea, ahora es canadiense y esa cultura que viene desde la matriz es la que ha influido mucho en este cambio. (Gerente Principal 9 SBP)

Yo creo que sí, de repente estos últimos meses me han sido favorables (...) si pensé que entraba en competencias con varios, y si para mí fue muy satisfactorio ver que finalmente al margen de si era mujer o hombre vieron resultados actitud, competencias y si creo que si de alguna manera a mí si se me ha dado favorable el tema (...) y si he sentido que ha habido, este una igualdad en el tratamiento de cualquier tipo de evaluación. (Gerente Agencia 2 SBP)

En cuanto al futuro, existen oportunidades de crecimiento, estas oportunidades se presentan por cambios en la cultura organizacional, mayor apertura e inclusión orientada a la participación de las mujeres en puestos directivos como comenta la Presidenta de la Asociación WOMEN CEO Perú y hace hincapié que para que las mujeres crezcan tienen que ir a buscar esas oportunidades. Además, según un reporte de Grant Thornton "Women in business" (2018) indica que el porcentaje de empresas con por lo menos una mujer en la 
alta dirección para Latinoamérica llega a un 30\% habiéndose logrado en un incremento sustancial en toda la región respecto al año anterior cuya proporción llegaba al $20 \%$ concluyendo una relación entre estos cambios organizacionales y el incremento en la diversidad de género en cargos de gerencia. Asimismo, la mujer empieza a tener mayor presencia en áreas de soporte y no solamente el área comercial, puesto que, pueden desarrollar una línea de carrera como tomadoras de decisiones y es aquí donde las oportunidades aparecen al derribarse muros e incluir mujeres en puestos de importancia. Eso se puede encontrar en las siguientes declaraciones:

Yo creo que sí, yo creo que la cancha esta puesta, haber es como cuando tú vas a una mesa de billar y vez las bolas que las sueltan, creo que están ahí y está en ti que agarres el taco adecuado y apuntes hasta donde tú quieras y si puedes acertarla a buena hora (Presidenta Asociación WOMEN CEO PERU)

(...) yo creo que el banco está apostando con fuerza en incrementar el número de posiciones con mujeres (...) Yo creo que las oportunidades siempre están, pero hay que romper los paradigmas en la manera de pensar de las mujeres que a veces más bien no se atreven, pero yo creo que si más mujeres se atrevieran sería más fácil ocupar esos lugares. (Gerente Agencia 1 SBP)

Finalmente, se consideró relevante analizar la percepción que se tiene sobre la disparidad salarial, la cual según la Consultora Mercer al 2017 en los cargos de altos ejecutivos en el Perú la brecha salarial entre hombres y mujeres era del $12 \%$, cifra menor a otros países como Chile (18\%), México (16\%), Brasil (14\%). Además, este año entró en vigencia la ley que prohíbe la discriminación remunerativa entre varones y mujeres (Ley No 30709) mediante categorías, funciones y salarios que permitan la ejecución del principio de igual remuneración por igual trabajo. En ese sentido, según el siguiente cuadro sobre la disparidad salarial que se percibe en el sector bancario en las entrevistadas de Scotiabank se obtienen los siguientes resultados: 
Tabla 8: Disparidad salarial en diferentes niveles de jerarquía según estado civil

\begin{tabular}{|c|c|c|c|c|}
\hline & \multicolumn{4}{|c|}{ Disparidad Salarial } \\
\hline & \multicolumn{2}{|c|}{ Gerente Principal } & \multicolumn{2}{|c|}{ Gerente de Agencia } \\
\hline & $\begin{array}{l}\mathrm{Si} \\
\text { perciben }\end{array}$ & $\begin{array}{l}\text { No } \\
\text { perciben }\end{array}$ & $\begin{array}{l}\mathrm{Si} \\
\text { perciben }\end{array}$ & $\begin{array}{l}\text { No } \\
\text { perciben }\end{array}$ \\
\hline $\begin{array}{l}\text { Casada con hijo(s) } \\
\text { Convive con hijo(s) } \\
\text { Divorciada con hijo(s) }\end{array}$ & 3 & 1 & & $\begin{array}{l}1 \\
2 \\
1\end{array}$ \\
\hline $\begin{array}{l}\text { Soltera sin hijo } \\
\text { Casada sin hijo }\end{array}$ & 1 & & & 1 \\
\hline Resultados & 4 & 1 & & 5 \\
\hline
\end{tabular}

Sobre este aspecto, se aprecia que el $60 \%$ de las entrevistadas de Scotiabank no percibe disparidad salarial en sus posiciones, es importante hacer la diferenciación de puestos ya que un $90 \%$ pertenecen a las gerentes de agencia las cuales al pertenecer al área comercial tienen bonificaciones de acuerdo al logro de meta. Así los sueldos para estas posiciones están definidos por variables como: La antigüedad en la empresa, la posición, los resultados obtenidos a través de la evaluación de desempeño y una tabla de bonificaciones en las cuales es indiferente el género, es más un salario de acuerdo a los méritos Así lo expresan las siguientes entrevistadas:

Es un tema meritorio porque incluso he trabajado con varios hombres y hasta ganaba más que ellos por cumplimiento de las metas. (Gerente de Agencia 1 SBP)

Sí, es que más que todo son bandas. Tú llegas a este puesto y tienes este salario, seas hombre o mujer. Ahí no hay diferencias (Gerente de Agencia 5 SBP)

Así, también se puede contrastar con la posición de las gerentes principales quienes, si perciben disparidad salarial y tiene relación con el informe de la consultora Mercer, situación que se viene corrigiendo como manifiestan las siguientes entrevistadas:

Sí, pero esto porque viene desde hace tiempo y no se ha terminado de nivelar. Creo que faltan algunos años para que esto suceda (Gerente Principal 9 SBP) 
En la misma posición si hay muchas diferencias aun cosas que se tienen que arreglar inclusive en el banco (...), no puede pasar que tú contrates a alguien dentro del banco y le pagues menos que si trajeras a alguien de fuera. (Gerente Principal 10 SBP)

De hecho, que hay disparidad salarial, esto se llega poco a poco (...) Recién ha salido la ley igualitaria en cuanto a remuneraciones, eso es política que se tiene que manejar poco a poco. (Gerente de Recursos Humanos SBP)

\section{¿Cuáles son las principales barreras que enfrentan las mujeres para alcanzar puestos ejecutivos en el banco Scotiabank en Lima Metropolitana?}

Como se indicó en líneas anteriores se percibe un incremento del número de mujeres en cargos ejecutivos en el tiempo. Este incremento según lo explican las entrevistadas se puede acelerar si las mujeres aprenden a enfrentar y superar 3 barreras principalmente:

La primera barrera, viene por la educación machista que tiene su origen en la formación que reciben las mujeres y hombres en general desde casa, donde a las mujeres se les hace jugar con muñecas, a juegos relacionados a labores de ama de casa haciendo una diferenciación de género e inculcándole roles desde pequeños, mientras los hombres son quienes juegan con carros y ya de adultos se les sigue asignando la posición de cabeza de familia, cuando la situación actual es que la mujer también aporta a los ingresos del hogar. Resulta todavía complicado entender que el hombre también tiene que participar en los quehaceres del hogar. Las siguientes afirmaciones lo confirman:

Somos nosotras las que organizan las familias: Entonces los hombres, si bien es cierto, ayudan (...) en un trabajo están más concentrados en esa meta. En cambio, la mujer a la vez tiene que cumplir varias metas, como el rol de ama de casa, en este caso el rol de empleado y el rol principal de mamá (...) y por eso el trecho de la carrera se hace más dificultoso en mi opinión. (Gerente de Agencia 1 SBP)

Si yo creo que las mujeres de todas maneras tenemos una exigencia mayor por el hecho de que por nuestra misma naturaleza de mujer tenemos que estar más preocupadas por los hijos, más pendientes del trabajo y de la casa (...) y yo también soy ama de casa...trabajo y también tengo que ver la administración de mi casa. Esa es la mayor exigencia. (Gerente principal 9 SBP) 
El machismo (...) más que toda la idiosincrasia en nuestro país, el poco respeto que se le tiene a la mujer (...) son como consideradas menos que los hombres. Eso tiene que cambiar, es un tema de educación que en si lo tiene que mejorar el estado, estratégicamente (...) con una educación diferente no aceptas que nadie diga que "porque tú eres mujer deberías hacer esto". (Gerente de Agencia 3 SBP)

Así se puede apreciar que, en el caso de la mujer, crece pensando que debe pedir permiso si quiere abrirse un espacio o expresar algo, porque le aterra la idea que si demanda o plantea sus ideas la van a identificar como agresiva u osada, y en un mundo tan competitivo como lo es la banca comercial también se le exige demostrar que es capaz y para hacerse notar debe realizar mayor esfuerzo que sus pares masculinos como lo demuestran las siguientes declaraciones:

El tema en el Perú es que la sociedad es de machistas (...) Un hombre puede expresar más libremente y claro si el hombre habla como loco y se queja como loco esta "expresando" lo que él cree. Si una mujer lo hace " que quejona, de todo se queja". Entonces, muchas veces te hacen la broma, pero después cuando hablas con tú jefe te das cuenta (...) que es un pensamiento súper machista (Gerente principal 8 SBP)

Cuando eres mamá, "que ¿Por qué eres mamá?"; que porque probablemente tengas la mente más pensando en los hijos (...) Cuando eres soltera que entonces no tienes vida y por lo tanto puedes trabajar hasta muy tarde... y porque vivimos en una sociedad más machista los hombres se desentienden un poco de sus hijos y toda la responsabilidad se la pasan a las mujeres (Gerente principal $10 \mathrm{SBP}$ )

Por el contrario, un hombre se siente libre de expresar sus ideas sin ese prejuicio, crece y proyecta esos pensamientos en un mundo laboral que tradicionalmente ha sido manejado por hombres. Esto se relaciona a otra barrera, la brecha generacional como mencionan las entrevistadas del banco Scotiabank cuando recién ingresaron a laborar hace 10 o 20 años, el ambiente era más hostil por la predominancia masculina y porque definitivamente los gerentes de entonces eran personas mayores que habían crecido con esas ideas y prejuicios los cuales se mostraban renuentes a reconocer el rol de la mujer como trabajadora y por ello preferían trabajar con hombres.

Creo que es más generacional la gente que está entre los 50-60 (...) todavía son gente renuente al cambio, son más conservadores y se sienten más cómodos estando entre hombres porque siempre han estado entre hombres (Presidenta de la Asociación WOMEN CEO Perú) 
Estas afirmaciones concuerdan con lo expresado por Ernesto Velarde, country manager 'Trabajando Perú' en la que explica que el mundo laboral está tradicionalmente formado por valores masculino, pese a las políticas que se vienen desarrollando para promover la igualdad de oportunidades, sigue siendo la mujer quien adicional a su rol como trabajadora debe sobrellevar la carga de la vida familiar mucho más que el cónyuge en el aspecto de los quehaceres en el hogar. Al respecto, según una encuesta realizada a 2000 personas, se tuvieron que el $69 \%$ de los encuestados identifico el machismo como el mayor obstáculo para que las mujeres alcancen cargos gerenciales.

La segunda barrera, es el sentimiento de culpa por priorizar su desarrollo profesional, esto es una barrera que la propia mujer se lo genera y se da en todas aquellas que son madres, es por ello que se decidió analizar esta barrera relacionada a las ejecutivas del banco Scotiabank con su vida familiar.

Tabla 9: Sentimiento de culpa en diferentes niveles de jerarquía según estado civil

\begin{tabular}{|l|c|c|}
\cline { 2 - 3 } \multicolumn{1}{c|}{} & \multicolumn{2}{c|}{$\begin{array}{c}\text { Sentimiento de culpa priorizar vida } \\
\text { profesional }\end{array}$} \\
\cline { 2 - 3 } \multicolumn{1}{c|}{} & Gerentes Agencia & Gerente Principal \\
\hline $\begin{array}{l}\text { casada con hijo } \\
\text { convive con hijo } \\
\text { divorciada con hijo }\end{array}$ & 1 & 3 \\
\hline $\begin{array}{l}\text { soltera sin hijo } \\
\text { casada sin hijo }\end{array}$ & 2 & \\
\hline Resultados & 3 & \\
\hline
\end{tabular}

Elaboración propia

En el cuadro arriba, se logra apreciar que ambas ejecutivas identifican esta barrera en igual porcentaje, y es que cuando una mujer pasa por la etapa de ser madre no debería entrar en conflicto con sus prioridades entre el cuidado de sus hijos y su desarrollo profesional. Aquí se presentan dos escenarios: 
En el caso de las gerentes principales, lo identifican como una limitante propia de la mujer, sin ser necesariamente su caso, ya que ellas han desarrollado competencias como la planificación y organización para poder complementar sus roles de madre y trabajadora.

Asimismo, es importante señalar que un apoyo fundamental es el hecho de contar con alguien de confianza para el cuidado de sus hijos sobre todo cuando son pequeños, con ello desarrollan otra competencia el delegar responsabilidades y poder estar tranquilas sabiendo que sus hijos están en buenas manos y ellas pueden enfocarse en el trabajo y seguir su desarrollo profesional de la mano.

(...) iba a mi casa y yo nunca podía estar en el parque con ellos, pero yo me iba al parque a la una y media a dos (...) y jugábamos pelota- regresaba y me ponía de nuevo la ropa de trabajo (...) Mil sacrificios tienes que hacer, pero lo haces, hay gente que dice "Hay es el sentimiento de culpa" yo no sentía culpa- yo lo disfrutaba tanto (Gerente Principal 12 SBP)

(...) tener el mejor equipo de trabajo en mi casa, Yo nunca he hablado que tengo una empleada en mi casa (...) para mí siempre han sido mis asistentes y las he tratado lo mejor posible y (...) hemos sido mejores amigas porque cuidan lo más valioso que yo tengo: mi hogar, mi familia, mi hija (...) entonces si tú tienes una red de organización propia que te permite que eso funcione ¡maravilloso! (Presidenta Women Ceo Perú)

En cambio, en el caso de las gerentes de Agencia, se observa que, si bien han optado por desarrollarse profesionalmente, lo cual a nivel del trabajo les ha reflejado en premios si sienten esa culpa al tomar una decisión como lo señalan las siguientes declaraciones:

En mi caso por ejemplo yo tengo dos hijos y en algún momento yo me estanqué pensando en ellos, y dije no, tengo que estudiar una maestría, y dije no, estudiar una maestría implicaba no verlos un buen tiempo, dos años casi o verlos lo menos (Gerente de Agencia 2 SBP)

Yo te digo ahora en estas alturas del partido, siento que "uy nos va bien, ganando premios y todo" yo he pasado momentos difíciles con mis hijas este año (...) y amigos cercanos me dijeron "Betty ahí está, no todo es trabajo"... la mujer también tiene que entender e interiorizar que no todo es trabajo. (...) La mujer tiene que ser consciente que, si es madre, tiene que ser madre y sino la vida te pasa la factura larga (Gerente de Agencia 4 SBP)

Es importante señalar que la organización también puede influir de manera positiva a que las mujeres y hombres ejecutivos en general puedan llevar mejor esa organización a través 
de políticas de flexibilidad de horario que hacen amigable el balance familiar - trabajo y lo cual es muy apreciado. Así en el caso de Scotiabank cuenta con políticas de home - office para todos aquellos puestos ejecutivos, haciendo énfasis que esta política se da dependiendo del tipo de funciones que realicen los gerentes, así en el caso de las gerencias de agencia por tener un trato directo con el público en un horario determinado no hace posible que puedan gozar de estos beneficios. En cambio, las gerentes principales, si cuentan con estos beneficios coordinado siempre con su superior que por cualquier tema personal que se presente, es posible negociar el poder trabajar desde casa donde igual pueden avanzar sus labores sin ver afectado su rendimiento por ser posiciones que al trabajar con el cliente interno las demás áreas no requieren su presencia física en la oficina. En consecuencia, Scotiabank consciente del bienestar que genera en sus colaboradores, está realizando pilotos con las áreas de soporte que no tienen trato directo con el cliente externo para poder tener beneficios del Flex time que permita manejar las 8 horas de trabajo de manera flexible ingresando antes y saliendo antes. Como lo manifiesta una Gerente Principal:

(...) el tema de flexibilidad ayuda mucho porque es la principal razón por la cual las mujeres detienen su avance, cuando sienten que ya no pueden más, que están descuidando los hijos, y la verdad es que con una tarde a la semana o 2 tardes a la semana sin alterar las 8 horas de trabajo puede solucionar el tema, creo que hay una oportunidad allí para muchas empresas para retener y atraer talento femenino hacia la organización. (Gerente Principal 12 SBP)

(...) una estrategia es poder tener el balance familia - trabajo que la organización te la pueda brindar, más que estrategia de ella es un lineamiento que la organización te pueda brindar (Gerente de Recursos Humanos de SBP)

La tercera barrera, es la autolimitación, la cual se identificó por las entrevistadas si bien en menor medida, pero es una barrera inconsciente que se da principalmente por la falta de auto confianza. Es un cuestionamiento interno en las mujeres que se limitan a asumir más responsabilidades o funciones, así, si se encuentran estudiando y ejerciendo, no quieren ser líderes, sus principales limitaciones son tiempo, familia, tengo que trabajar o no puedo viajar. Esta barrera es otra de las causas del porque si bien se está trabajando en una mayor apertura de oportunidades para hombres y mujeres, sigue habiendo una predominancia masculina a niveles más altos, siendo la mujer la misma que frena su desarrollo. Las siguientes afirmaciones lo confirman: 
La primera razón es que la mujer por decisión propia detiene su avance profesional (...) porque siente que no va a poder hacer un adecuado balance con su vida personal, siente que al asumir mayores responsabilidades le va a traer consecuencias como tener que sacrificar tiempo con su familia, y no quiere seguir avanzando (Gerente Principal 12 SBP)

(...) la característica del hombre es "yo leo" el Job posting que tiene el banco y tengo el $60 \%$ de las calificaciones que tú pides (para el puesto) y quiero el puesto, el hombre se presenta. En cambio, la mujer si no tiene el $100 \%$ no se presenta. Es un tema de carácter, un tema de cómo lo afronto, eso de ahí si lo ves muchísimo. (Gerente Principal 8 SBP)

(...) tú le das una parte de promoción a un hombre, te va ocupar un cargo importante, el hombre dice, "Ah." gracias es lo que esperaba, en cambio a veces le das a una mujer, y te puede decir, ¿estas segura?, ¿Porque crees, que yo lo puedo hacer? (...) entonces (...) yo creo que la única limitación que nosotros tendríamos es que no me la crea (Gerente de Recursos Humanos Banco Financiero)

Finalmente, según las entrevistadas de Scotiabank y otros segmentos, en su mayoría no consideran que la maternidad sea una causa que influya en un menor desempeño dentro de la organización, por el contrario, manifiestan que les ha influido energías para poder hacer mayores esfuerzos dentro del horario laboral ya que para todo el rol de madre también es el de referente por lo tanto es importante brindarles un buen ejemplo.

(...) en mi caso este me dio más pilas para trabajar (...) luego de tener familia yo creo que triplica o cuadriplica la dosis de energía para querer hacer las cosas bien porque este, sabes que vas a ser un tema muy importante y una como mujer se valoriza más inclusive porque ya no eres tú, sino tus descendientes. (Gerente de Agencia 2 SBP)

Esta experiencia como madres para muchas gerentes les permite desarrollar una mayor empatía con aquellos miembros de su equipo que pasan por este rol para poder brindarles los derechos que tienen, además de ser más flexibles en cuanto a los permisos que podrían solicitar por un tema de salud o en fechas específicas como el día de la madre y otros eventos, quizá con una mayor apertura que aquellas mujeres que no son madres o sus pares hombres. 


\section{¿Cuáles son las competencias críticas que deben desarrollarse para alcanzar puestos ejecutivos en el banco Scotiabank en Lima Metropolitana?}

Entre las competencias críticas que se pueden observar entre las mujeres ejecutivas de Scotiabank, resalta por encima de todas las demás, el Liderazgo. Los siguientes testimonios corroboran lo mencionado:

La competencia yo creo que es el liderazgo, tienen que trabajar mucho en repotenciar su liderazgo y creérsela uno mismo para poder irradiar eso, para continuar rompiendo los estereotipos de que el líder, para algunas personas, es un varón (Gerente Agencia $1 \mathrm{SBP}$ )

(...) nosotros los jefes tenemos que ayudar o empujar el equipo para enseñarles a auto gestionar el conocimiento o inclusive enfrentarlos un poco o retarlos (...) Por eso los jefes tenemos que estar preparados para eso, y SBP nos prepara mucho a los líderes porque estamos en programas de liderazgo (Gerente Agencia $5 \mathrm{SBP}$ )

El banco se ha centrado en potenciar a los líderes (...) El banco yo creo que ahí hace un buen trabajo apoyando a los líderes en buscar esos objetivos, aparte del coaching, mentoring y de generar estas comunicaciones con otros líderes que te ayuden a crecer también. (Gerente Principal 7 SBP)

En segundo lugar, la orientación a resultados es otra competencia crítica que deben desarrollar las mujeres ejecutivas en su día a día. Esto se puede apreciar en las siguientes manifestaciones.

(...) las empresas se mueven porque necesitan resultados, necesitan una rentabilidad. Entonces, todo tu trabajo debe estar orientado a la productividad y lo que el día de hoy nos piden y que nos miden diariamente rinda frutos (Gerente de Agencia 6 SBP)

(...) siempre lograr los resultados que nos piden, (...) y que se desarrolle la organización, eso me parece gratificante y generar un impacto a nivel de la organización con mi producto. (Gerente Principal 7 SBP)

También se prioriza como competencia crítica a la adaptación al cambio, la cual es identificada por la mayoría de segmentos como lo demuestran las afirmaciones:

Yo estoy convencida de que hay que hacer cambios y que nada naces aprendiendo, pero todo se aprende. Todo te sirve y el cambio es el que te genera mayor aprendizaje. (Gerente Principal 8 SBP) 
$\mathrm{Si}$, tienes que adaptarte sí o sí en todo... en tu casa, en el tema de las computadoras, con lo electrónico, o sea, con las situaciones que se dan... hoy día estas acá de repente mañana te dicen no necesitamos esta situación hay que ajustarnos y tienes que hacerlo o sea en cualquier situación tienes que adaptarte. (Especialista en Recursos Humanos)

Luego, el trabajo en equipo también representa una competencia de vital importancia para una mujer ejecutiva con mucho personal a su cargo.

(...) es un trabajo que no es solo de la organización si no que es un trabajo que parte de cada uno de los miembros del equipo (...). Y además de ello obtener un conocimiento nuevo de la posibilidad de conectar y si una cosa que busca el banco o que promueve el banco es que efectivamente tu networking crezca. (Gerente Principal 10 SBP)

Si no trabajas en equipo no te desarrollas. Tienes que trabajar conjuntamente con toda la gente que te rodea... vas a encontrar cosas positivas como también vas a encontrar cosas negativas, las cosas negativas que nosotros encontremos nos enseña, pero tenemos que ver el lado positivo de esto (...) todos tenemos puestos importantes de alguna manera, si un engranaje se malogra no funciona la máquina (Gerente Principal 11 SBP)

(...) el trabajo en equipo, no sentirse autosuficiente, sino que dependes del trabajo de otras personas también, las relaciones que tenemos con otras personas (Especialista Recursos Humanos)

Posteriormente, la resolución de problemas es otra competencia crítica que es necesaria y que debe ser desarrollada por las mujeres ejecutivas en su línea de carrera.

(...) a pesar de que uno no tiene que saber necesariamente de todos los temas, tiene que tener criterio para ver más o menos como son las variables que te van a llevar a solucionar los problemas a partir de ahí. (Gerente Principal 7 SBP)

(...) por ejemplo con algún cliente difícil (...) voy a buscar la manera de como poder ayudar voy a apoyarme en otras personas $\mathrm{u}$ otras áreas para poder buscarle la solución (...) no le voy a mentir, no le voy a inventar información, ni le voy a decir si tengo la solución ahorita porque eso no es así, averiguo primero y me comprometo. (Gerente Agencia 5 SBP) 
Por último, la ética e integridad incorpora un valor adicional al repertorio de competencias críticas para una mujer ejecutiva. La ética debe ser un reflejo que otros puedan percibir. En esa línea se tienen las siguientes afirmaciones:

Es una competencia que no puede faltar en nuestras actividades diarias, es algo que considero es un valor. Cuando es así buscas que nuestro equipo también sea así, (...) y se les trata de explicar, en esa parte si soy radical acá es o blanco o negro. (Gerente Agencia 5 SBP)

(...) es básico no solamente para el trabajo sino también para tú vida diaria... yo creo que una persona que no es ética ni integra...si no eres así en tú vida laboral tampoco en tú vida familiar, es imposible (...) está mal aquí y en donde sea, es lo mínimo que puedo pensar y para mí la ética e integridad son básicas. (Gerente Principal 8 SBP)

Para analizar las competencias críticas identificadas anteriormente, se consideró previamente analizar las competencias laborales que las mujeres ejecutivas entrevistadas consideraron que fueron relevantes para alcanzar su posición actual. Entre estas las competencias más destacadas son 5: capacidad de comunicación, ética e integridad, liderazgo, capacidad de planificación y organización y adaptación al cambio. En contraste con otros segmentos existen similitudes que reflejan las mismas competencias. Estas competencias representan lo que ellas perciben que fueron importantes para seguir creciendo en su línea de trabajo. Esto se refleja en las siguientes transcripciones:

(...) en mi caso creo que ha sido hacer siempre movimientos laterales siempre buscar conocer algo más (...) y algunas personas les da miedo hacer ese movimiento primero porque es algo nuevo, a lo nuevo no le tienes que tener miedo (...) siempre tienes que buscar el cambio porque al final la vida es eso cambios y lo que pasa alrededor es cambio...creo que eso ha sido una de las claves que me ha funcionado (Gerente Principal 10 SBP)

La mujer tiene que tener liderazgo y un tema que debe de ser cada vez más desarrollado es la estrategia, como voy a desarrollar algo dentro de mi trabajo para poder llegar a los resultados, que estrategia voy a utilizar, esos son temas que mientras más escalas más debes tener presente comunicación y cercanía también. (Gerente Recursos Humanos \& Talent Delivery SBP)

Sin embargo, existe diferenciación respecto a un segmento donde además de la competencia de liderazgo, también se evidencia la orientación a resultados y otros 
comportamientos que reflejan inteligencia emocional y son pertenecientes a la competencia de resolución de problemas como se puede observar en el siguiente manifiesto:

Liderazgo, negociación, manejo, empatía, tolerancia, alegría, para estas condiciones necesitan ser muy alegre, muy amable, creo no tan sensible, porque tengo que despedir gente, ingresar, tomar decisiones, alguien muy eficiente y eficaz que de resultados. (Especialista en Recursos Humanos)

También es importante mencionar otras competencias que tienen las mujeres a diferencia de su contraparte masculina, en donde las mujeres ejecutivas reconocían mayormente la Innovación y Creatividad junto a la capacidad de planificación y organización como las competencias que desarrollan más en comparación a los hombres. En cuanto a los demás segmentos opinan de similar manera como se expresa en las siguientes declaraciones:

Si claro, las mujeres somos más creativas e innovadoras. Ahí sí de lejos le ganamos a los hombres y eso es importante para poder hacer nuevas cosas y generar nuevas formas de hacer las cosas para cumplir los objetivos. (Gerente de Agencia 1 SBP)

La mayor competencia para mi es la planificación y organización no es que necesariamente no la tengan los hombres, pero si las mujeres la tenemos más desarrollada. (Gerente Principal 8 SBP)

(...) por la misma formación de ser mujeres...por esa capacidad de servicio, esa preocupación por los demás... esa visión macro que no te limitas al punto (...) entonces podemos estar pensando en el reporte que tengo que presentar en este momento (...) lo puede hacer todo a la vez (...) todo lo está pensando a la vez la mujer; en cambio el hombre no. (Presidenta Asociación WOMEN CEO)

Las 6 competencias identificadas como críticas son:

El liderazgo. Esta competencia está presente en cada una de sus facetas, desde que toman el rol de gerente y ante las barreras que se les presenta terminan desarrollando esta competencia continuamente. Esto se debe al contexto actual en el cual, aunque se pudo contemplar que existe mayor apertura, las mujeres aún deben mostrarse capaces ante sus contrapartes hombres en un entorno cambiante. Entre sus respuestas las gerentes de SBP definen al liderazgo como la capacidad de poder influenciar en tu equipo y atender las necesidades de su equipo de trabajo. Además, para trabajar su liderazgo las gerentes 
participan en talleres de capacitación que ofrece Scotiabank, pero también lo hacen por su cuenta en cursos como coaching y programas similares.

En ese sentido, ambas gerentes de Recursos Humanos, tanto de Scotiabank como la gerente del Banco Financiero comentan sobre el liderazgo y su exigencia. El liderazgo sirve como herramienta para influir y sacar adelante a tu equipo:

Un puesto ejecutivo te exige conocimiento, liderazgo, porque podrías no tener conocimiento, pero si tienes liderazgo puedes llegar a las personas e influenciarlas y vas a obtener resultados. (Gerente Recursos Humanos \& Talent Delivery SBP)

(...) es saber gestionar que eso es lo más importante, (...) tú tienes que saber gestionar, tienes que saber empoderar, que es algo súper importante, alinear a la gente, comprar a la gente, remar juntos, conocer a tu equipo y conocer la parte sensible de tu equipo, (...) y saber qué es lo que motiva a tu gente, tu equipo va ser siempre sólido, en líneas generales lo que buscamos son buenos líderes. (Gerente Recursos Humanos Banco Financiero)

La orientación a resultados. Esta competencia la definen como alcanzar los objetivos trazados por la institución y realizar bien su trabajo. La orientación a resultados es sin duda una exigencia de la banca, sin embargo, a profundidad, alcanzar las metas propuestas tiene que ver también con la motivación de alcanzar logros y de superar retos que experimentan las gerentes porque esto ayuda en aumentar su autoconfianza a pesar de prejuicios o estereotipos aun presentes en la sociedad. En comparación a mujeres ejecutivas de otros bancos la orientación de resultados se presenta de igual manera, una competencia muy necesaria para empatar con las exigencias del mercado actual.

Adaptación al cambio, para las ejecutivas del banco ser renuente al cambio solo conlleva a estancarse, es decir, que para crecer tienes que salir de tu zona de confort. Sobre este punto concuerdan también varios segmentos y queda claro, además, que las nuevas tendencias y tecnologías son parte también de este proceso; y es por ello de la importancia de esta competencia.

Trabajo en Equipo, esta competencia se trata de la colaboración entre áreas y el apoyo a los trabajadores de los cuales se está a cargo. En este caso, las mujeres ejecutivas desarrollan su red de contactos para poder extender su alcance y contar con el apoyo de otras áreas del banco en conjunto. Esto es muy importante porque también les brinda visibilidad dentro del entorno. 
Resolución de Problemas, esta competencia se presenta ante retos y eventualidades que son parte de la dinámica competitiva del rubro bancario. Las mujeres ejecutivas, por lo tanto, deben poder tolerar el trabajo bajo presión y tener un manejo de crisis que son características de esta competencia. Además, según la definición para esta competencia de la Universidad de Harvard, la resolución de problemas es detectar problemas e implementar soluciones lógicas que contribuyan al interés de la organización.

Ética e integridad, ser firme e íntegra en su actuar y sobre sus decisiones les permite expresar su opinión sin miedo a quedarse calladas en defender su posición. Esta competencia está ligada con el rubro y los cargos de responsabilidad que se ejercen. En ese contexto, sobre la ética Martha Alles (2016) manifiesta que la ética e integridad no son solamente valores individuales ni valores organizacionales sino una competencia que debe reforzarse para desarrollar comportamientos adecuados en las personas y que estos sean puestos en práctica en la organización. Esta percepción la comparten las mujeres ejecutivas de varios bancos.

Además, Scotiabank Perú ha establecido 5 competencias propias que espera de sus líderes y las ha promovido a todas las áreas de la organización. Estas competencias son: Enfoque al cliente, enfoque a resultados, consciencia de sí mismo(a) y desarrollo personal, desarrollo de un equipo talentoso y curiosidad. El banco SBP se refiere a estas competencias como las características que buscan encontrar en su personal y que formen parte de la cultura organizacional. La siguiente declaración lo pone en manifiesto:

(...) tenemos 5 competencias claves en el sentido de que esas hacen que el líder pueda estar a la altura de lo que Scotiabank requiere y obviamente de tu desarrollo personal y profesional. Eso sí lo sabes: enfoque en el cliente, enfoque en resultados, consciencia de sí misma y desarrollo personal, desarrollo de un equipo talentoso y curiosidad. (Gerente Recursos Humanos \& Talent Delivery)

Para profundizar sobre el significado que Scotiabank da a estas competencias. Primeramente, se tiene al enfoque al cliente. Se refiere a identificar y satisfacer las necesidades de los clientes, para esta competencia se debe asumir la responsabilidad de asistir al cliente y orientarlo oportunamente. 
En segundo lugar, el enfoque a resultados se refiere básicamente a tener una preocupación genuina para alcanzar metas y superar el nivel de desempeño esperado. En contraste con el análisis de las competencias críticas se refiere a la orientación a resultados

Consciencia de sí mismo(a) y desarrollo personal tiene que ver con el empuje personal y la construcción del talento propio. El banco busca personal motivado y con deseo de superación capaz de poner en práctica lo aprendido y desarrollarlo.

En cuanto al desarrollo de un equipo talentoso SBP busca formar equipos de éxito. Para esto, lo que se busca es que los líderes integren al personal bajo su cargo, atienda sus solicitudes y los apoye a crecer.

Por último, la curiosidad. Esta competencia se refiere a 'ir indagando' para poder mejorar hay que indagar constantemente para aprender nuevos temas, aprender sobre tu equipo de trabajo y para poder ayudarlo es necesario indagar. Es decir, se espera encontrar a los líderes en una posición proactiva.

Finalmente haciendo un contraste entre las competencias críticas encontradas en las mujeres ejecutivas y las competencias que Scotiabank requiere, resalta solamente una competencia: el enfoque a resultados. La orientación a resultados es una competencia distintiva del rubro financiero, en este caso la banca comercial. No hay mayor similitud entre las competencias críticas y las competencias que ha establecido SBP debido a que el banco ha determinado dichas competencias pensando en un perfil de líder para puestos ejecutivos indiferentemente del género de su personal. 


\section{CAPITULO 4: DISCUSION DE RESULTADOS}

\section{Hallazgos:}

La realidad percibida sobre su situación actual varía entre las mujeres ejecutivas entrevistadas. Esto se debe a que las gerentes de agencias, cuya labor forma parte del área comercial del banco, tienen trato directo con los clientes externos mientras que aquellas gerentes de la sede principal de Scotiabank, quienes forman parte del área de soporte de la organización, tienen funciones que no requiere interactuar con los clientes externos y sus labores son por ejemplo el desarrollo de productos, supervisión de proyectos, gestión del talento humano, etc. Ante esta diferenciación surgen distintas situaciones e incluso diferentes beneficios para ambos grupos. Por un lado, las mujeres ejecutivas con cargos de Gerentes principales, tienen beneficios como el home office, el cual bajo coordinación con su superior les permite poder realizar labores desde casa. Mientras que, las mujeres ejecutivas de la red de la banca (Gerentes de Agencia) tienen un horario establecido de trato directo al público y no pueden gozar de este beneficio, por el contrario, trabajan más horas a fin de incrementar la productividad que requiere la empresa. Por otro lado, las gerentes de agencia pueden acceder a comisiones en función de sus méritos alcanzados mensualmente, situación que no ocurre con las Gerentes Principales al no formar parte del área comercial, sus remuneraciones son diferentes.

La maternidad no es considerada una barrera que afecte el desempeño laboral de la mujer ejecutiva de la banca, y en su mayoría, se presenta como una razón más para superar obstáculos en la carrera laboral de las entrevistadas. Esto representa un hallazgo interesante, puesto que, la maternidad permite desarrollar en las mujeres una mejor capacidad de organización para poder equilibrar su vida laboral y familiar. 
En ese sentido, otro hallazgo son las estrategias que las mujeres ejecutivas han desarrollado para progresar en su carrera laboral. Esto nace en base a su experiencia y a las exigencias actuales, en donde el cambio es constante y rápido. Además, esto se presenta no solamente en las entrevistadas de SBP sino también se evidencia en los demás segmentos.

Estas estrategias son, primeramente, a manera de 'supervivencia' han aprendido a alzar su voz, es decir, las mujeres en altos cargos tienen que expresar su opinión de manera oportuna para hacerse notar y para hacer valer su punto de vista. En una cultura machista esto es muy necesario y lo han venido desarrollando cada vez más mientras ascendían escalones dentro de su organización.

Como segunda estrategia, para poder desarrollar sus equipos de trabajo y la colaboración entre áreas, las mujeres ejecutivas aprovechan cada evento y reuniones para desarrollar su red de contactos. Gracias al networking, las mujeres ejecutivas recurren a las relaciones formadas para facilitar y acelerar sus pendientes laborales.

La tercera estrategia a la que recurren es el coaching para desarrollar y direccionar al personal a su cargo, muchas de las entrevistadas se inscribieron a cursos de coaching para poder aplicarlo a su equipo de trabajo cuando alcanzaban posiciones de mayor responsabilidad.

Por último, las gerentes son conscientes de la importancia de tener confianza en sí mismas, para esto, ellas toman muy en serio su rol como ejecutivas, y así, pensar y actuar de manera consistente que refleje liderazgo. Para trabajar la auto-confianza también recurren al feedback y a los talleres que implementa la empresa, en el caso de las gerentes de Scotiabank.

\section{Barreras:}

Se presentaron barreras que dificultaron el progreso del presente estudio siendo la principal la disponibilidad de los entrevistados para conceder citas. Esto se debe a la exigencia de responsabilidad que exige sus puestos ya que las participantes de esta investigación se 
encontraban mayormente dispuestas a colaborar con las entrevistas, sin embargo, hubo ocasiones que estas reuniones fueron pospuestas generando un desbalance en la programación inicial en las que las entrevistas se llevarían a cabo. En esa misma línea fue muy difícil contactar gerentes de recursos humanos. 


\section{CONCLUSIONES}

1. La hipótesis fue validada parcialmente debido a que las competencias laborales formuladas como críticas no son todas las mismas que aquellas resultantes en el estudio. De este resultado 3 competencias de las 4 formuladas en la hipótesis si fueron validadas, siendo estas las siguientes: éticas e integridad, resolución de problemas y trabajo en equipo. Además, se encontraron 3 competencias más como críticas para el desarrollo profesional de la mujer ejecutiva en Scotiabank, estas son: Adaptación al cambio, liderazgo y orientación a resultados.

2. El escenario actual para las mujeres ejecutivas en Scotiabank es favorable debido a las políticas desarrolladas por el comité de inclusión social de incluir una mujer en la terna final como mínimo para cargos gerenciales y que parte del panel seleccionador también debe tener conformación mixta y ha contribuido al incremento del número de mujeres ejecutivas. Así se percibe una igualdad de oportunidades en años recientes que se refleja en una apertura global que favorecen como la ley que prohíbe la discriminación remunerativa entre hombres y mujeres.

3. El machismo representa la mayor barrera que enfrenta la mujer ejecutiva en Scotiabank debido a la cultura del país y la falta de educación. Esto deriva en muchas cosas que ralentiza el desarrollo profesional de las mujeres que aspiran a puestos ejecutivos, puesto que, genera prejuicios y dificulta que se tome en cuenta su opinión. Otras barreras a considerar son el sentimiento de culpa que algunas mujeres sufren al enfocarse en su desarrollo profesional y dedicar menos tiempo a su vida privada y la autolimitación para asumir responsabilidades mayores por inseguridad.

4. En cuanto a las competencias críticas encontradas, la ética e integridad es de carácter fundamental debido al rubro financiero y las regulaciones existentes. La resolución de problemas representa los retos y obligaciones que implica un cargo de alta jerarquía. 
En cuanto al trabajo en equipo, las mujeres ejecutivas han aprendido e implementado estrategias como el networking para facilitar su trabajo y relación con otras áreas de la organización y clientes externos. La adaptación al cambio tiene que ver con el contexto actual, en un entorno altamente competitivo respecto a los otros bancos y también con el cambio e implementación de políticas que provienen de la casa matriz. Para el liderazgo, las mujeres ejecutivas recurren a otras estrategias como el coaching y actividades que desarrollen su autoconfianza para creerse capaz de alcanzar sus objetivos, esta competencia es fundamental para manejar a un gran número de personas y representar al banco. Finalmente, la orientación a resultados tiene que ver con la razón de ser del banco y es un factor muy importante para poder escalar posiciones dentro de la organización. 


\section{RECOMENDACIONES}

De acuerdo con los resultados y conclusiones de la investigación, se describen las siguientes recomendaciones:

1. Se recomienda a las mujeres ejecutivas de la banca comercial de Scotiabank poder llevar el programa de Women CEO Perú dirigido para mujeres, el cual está orientado a poder desarrollar y potenciar las competencias para alcanzar cargos de alta dirección, asimismo les permitirá incrementar su red de contactos y conocimientos, ya que, a niveles ejecutivos el dominio de las competencias se vuelven requisitos indispensables más que los requisitos técnicos.

2. Se recomienda al banco Scotiabank evaluar la viabilidad de desarrollar beneficios de flexibilidad de horarios que también se puedan adaptar a la posición comercial que tiene trato directo al público. Estas políticas deberían ayudar al equilibrio entre el trabajo y la familia y mejore el clima laboral en las agencias.

3. Se recomienda al banco Scotiabank realizar programas sobre cómo enfrentar y superar las barreras que limitan el desarrollo profesional de las mujeres hacia cargos de alta dirección. Por ejemplo, es importante incluir casos de mujeres líderes referentes del entorno para así impulsar su crecimiento, incentivar su participación activa para incrementar su red de contactos con distintas áreas dentro de la organización.

\section{RECOMENDACIONES PARA FUTURAS INVESTIGACIONES}

De acuerdo con los resultados y conclusiones de la investigación, se describen las recomendaciones para futuras investigaciones: 
1. Se recomienda realizar una investigación sobre las principales barreras inconscientes y conscientes que enfrentan las mujeres ejecutivas de la banca comercial de Lima Metropolitana debido a que representan una realidad que complica y frena el desarrollo profesional de las mujeres.

2. Durante la investigación las gerentes entrevistadas mencionaron recibir apoyo por parte de sus cónyuges en cuanto a la carga familiar. Sin embargo, el machismo está muy arraigado en la cultura del país y los hombres manejan la situación familiar de manera muy diferente a las mujeres. En ese sentido, se recomienda realizar una investigación sobre qué estrategias utilizan los hombres para lograr un balance familia - trabajo cuando ocupan cargos ejecutivos en la banca comercial. 


\section{BIBLIOGRAFIA}

Aliaga R. \& Ambrosini D (2011). SISTEMA FINANCIERO PERUANO. Lima, Perú: Universidad de Piura. (Consulta: 10 de diciembre de 2017) (Recuperado de: http://rafaellopezaliaga-dambrosini.com/archivos/SFP-Completo.pdf)

ALLES, MARTHA (2006). Influencia de las características de personalidad (competencias) en la empleabilidad de profesionales. Buenos Aires: Universidad de Buenos Aires. Facultad de Ciencias Económicas. (Consulta: 12 de diciembre de 2017) (Recuperado de: http://bibliotecadigital.econ.uba.ar/download/tesis/15011181_AllesMA.pdf)

ALLES, MARTHA (2015). Dirección Estratégica de Recursos Humanos, Gestión por competencias Vol. I. Editorial Granica: Buenos Aires, Argentina.

ALLES, MARTHA (2016) Diccionario de Competencias. La Trilogía. Vol. 1. Editorial Granica: Buenos Aires, Argentina.

ALVAREZ, Carmen (2016) Tres mujeres para liderar la regulación financiera global. En: BBVA. 08 de marzo (consulta: 12 de diciembre de 2017) (https://www.bbva.com/es/3-mujeres-para-liderar-las-finanzas-globales/)

Álvarez, Y. R., Bullón, C. A., Silva, T. C., \& Huamán, T. D. (2014). Estrés en la mujer ejecutiva (Tesis de maestría, CENTRUM Católica, Lima, Perú)

Arango, L. y Viveros, M. (1995). GÉNERO E IDENTIDAD: Ensayos sobre lo femenino y lo masculino. Primera edición. Tercer mundo, Colombia. (Consulta: 01 de diciembre de 2017) (Recuperado de: http://www.bdigital.unal.edu.co/1384/2/01PREL01.pdf)

ASOCIACIÓN DE BANCOS DEL PERÚ (ASBANC) (2016). Más de 62,000 empleos adecuados generó la banca en el 2015. [Informe de prensa] (Consulta: 02 de Diciembre de 2017) (Recuperado de: http://www.asbanc.com.pe/Informes\%20de\%20Prensa/ESTAD\%C3\%8DSTICA\%2 OLABORAL_Diciembre_2015.pdf)

ASOCIACIÓN DE BANCOS DEL PERÚ (ASBANC) (2017). MOROSIDAD BANCARIA ASCENDIÓ A 2.96\% EN ENERO DE 2017. [Informe de prensa] (Consulta: 12 de marzo de 2017) (Recuperado de: http://www.asbanc.com.pe/Informes\%20de\%20Prensa/MOROSIDAD_Enero_2017. pdf\#search=morosidad $\% 20$ bancaria) 
ASOCIACIÓN DE BANCOS DEL PERÚ (ASBANC) (2018) Las mujeres representan el $52.5 \%$ de la fuerza laboral bancaria. [Informe de prensa] (Consulta 21 de mayo de 2017) (Recuperado de: http://www.asbanc.com.pe/Informes\%20de\%20Prensa/ESTAD\%C3\%8DSTICA\%2 OLABORAL_Diciembre_2017.pdf)

Avolio, B. \& otros. (2013) Mujeres ejecutivas en grandes empresas. Lima: Santillana.

Behrensen, Celina (2017) La mujer ejecutiva; un nuevo modelo a tener en cuenta. (Consulta: 06 de diciembre de 2017) (https://es.linkedin.com/pulse/la-mujerejecutiva-un-nuevo-modelo-tener-en-cuenta-behrensen)

Blatter, J.; "Case Study". En The Sage Encyclopedia of Qualitative Research Methods. Given, L. (Edit.) Sage Publications Ltd., London, 2008.

Calvo, Parejo, Rodríguez, Cuervo y Alcalde (2014). Manual del sistema financiero español (26 edición). España: ARIEL.

Cerda, Hugo (1993) Los elementos de la investigación: como reconocerlos, diseñarlos y construirlos. Santa Fe de Bogotá: El Buho Ltda.

Comisión Económica para América Latina y el Caribe [CEPAL], Organización de las Naciones Unidas para la Alimentación y la Agricultura [FAO], ONU Mujeres, Programa de las Naciones Unidas para el Desarrollo [PNUD], \& Organización Internacional del Trabajo [OIT]. (2013). Trabajo decente e igualdad de género: Políticas para mejorar el acceso y la calidad del empleo de las mujeres en América Latina y el Caribe (Informe regional). Santiago de Chile, Chile: Autor. (Recuperado de: $\quad$ http://www.ilo.org/wcmsp5/groups/public/---americas/---ro-lima/---srosantiago/documents/publication/wcms_233161.pdf)

Cooper, T. \& Menzel, D. (2015). Achieving Ethical Competence for Public Service Leadership, Routledge: United States.

Daeren, L., (2000). Mujeres empresarias en América latina: el difícil equilibrio entre dos mundos de trabajo. Desafíos para el futuro.

Debeljuh, P. (2012) Qué le aporta la mujer a la nueva empresa. En: MBA \& Educación Ejecutiva, 21 de febrero (consulta: 12 de diciembre de 2017) (Recuperado de: https://mba.americaeconomia.com/articulos/columnas/que-le-aporta-la-mujer-lanueva-empresa)

Deloitte Touche Tohmatsu Limited (DELOITTE) (2017) Mujeres 2017 Una radiografía de las ejecutivas ecuatorianas. (Consulta: 7 de diciembre) (Recuperado de: https://www2.deloitte.com/content/dam/Deloitte/ec/Documents/deloitteanalytics/Estudios/Mujeres\%202017.pdf) 
DIARIO GESTIÓN (2011) Machismo, primer obstáculo de mujeres al optar por cargo gerencial. En: Diario Gestión, 07 de marzo (Consulta: 1 de junio) (https://archivo.gestion.pe/noticia/724099/machismo-principal-obstaculo-mujeresal-optar-cargo-gerencial?ref=gesr)

DIARIO GESTIÓN (2014) 125 años: La historia del Banco de Crédito en imágenes. En: Diario Gestión, 09 de abril (consulta: 8 de enero) (https://gestion.pe/tendencias/125anos-historia-banco-credito-imagenes-57076?foto=1)

DIARIO GESTIÓN (2017) Brecha salarial entre mujeres y hombres disminuyó 15\% en tres años en Perú. En: Diario Gestión, 6 de diciembre (Consulta: 1 de Junio) (https://gestion.pe/economia/management-empleo/brecha-salarial-mujeres-hombresdisminuyo-15-tres-anos-peru-222162)

DIARIO GESTIÓN (2017) En cinco años la mitad de puestos de alta dirección en Perú serán ocupados por mujeres. En: Diario Gestión, 05 de marzo (consulta: 7 de diciembre) (https://gestion.pe/tendencias/management-empleo/cinco-anos-mitadpuestos-alta-direccion-peru-seran-ocupados- mujeres-130066)

DIRECCIÓN DEL TRABAJO (OT) (2013) Actuaciones y políticas de género en empresas del sector bancario. Santiago de chile, Chile (http://www.dt.gob.cl $/ \mathrm{m} / 1620 /$ articles103031_recurso_1.pdf) Sitio web oficial de la DT. (Consulta: 13 de diciembre)

Drucker, Peter F. (2013) El ejecutivo eficaz. Barcelona: De bolsillo.

Dueñas, Ricardo (2008). INTRODUCCIÓN AL SISTEMA FINANCIERO Y BANCARIO. Politécnico Grancolombiano Institución Universitaria: Bogotá, Colombia. (Consulta: 10 de diciembre de 2017) (Recuperado de: http://crear.poligran.edu.co/publ/00008/SFB.pdf)

Escoto Roxana (2007). Banca Comercial. San José, Costa Rica: Editorial EUNED.

ESCUELA DE ORIENTACIÓN INDUSTRIAL (EOI) (200\&) EOI Y TATUM presentan el primer estudio "Tendencias del sector financiero en España" (https://www.eoi.es/es/noticias/16406/eoi-y-tatum-presentan-el-primer-estudiotendencias-del-sector-financiero-en-espana)

Fuchs, Rosa (2011). Estrategias de mujeres ejecutivas exitosas. Journal of Business, Universidad del Pacífico. Volumen 3(2): 69-78. (Consulta: 02 de diciembre de 2017) (Recuperado de: http://revistas.up.edu.pe/index.php/business/article/view/52/53

García M., Martínez F., Fernández E. \& asociados (2014). Manual del asesor financiero. Madrid, España: Ediciones Paraninfo. (Consulta: 10 de diciembre de 2017) (Recuperado de:https://books.google.com.pe/books?id=gLNsAwAAQBAJ\&printsec=frontcover $\underline{\& h l=e s \# \mathrm{v}=\text { onepage } \& q \& \mathrm{f}=\text { false) }}$ 
Glavin, P., Scheiman, S., \& Reid, S. (2011). Boundary spanning work demands and their consequences for work and psychological distress. Journal of Health and Social Behavior, 52, 43-57

Goleman D. (1998) La práctica de la inteligencia emocional. Barcelona, España: Editorial Kairós.

Grant Thornton (2015) The value of diversity. (Consulta: 30 de mayo 2017) (Recuperado de: https://www.grantthornton.global/en/insights/articles/diverse-boards-in-indiauk-and-us-outperform-male-only-peers-by-us\%24655bn/)

Grant Thornton (2018) Women in business report 2018. (Consulta 21 de mayo 2017) (Recuperado de: https://www.grantthornton.global/globalassets/1.-memberfirms/global/insights/women-in-business/grant-thornton-mujeres-directivas-2018embargo-8-march---es---web.pdf)

Great Place to Work (GTP) (2014). Mujeres y mercado laboral en el Perú. Great Place to Work Institute. (Consulta: 01 de diciembre de 2017) (Recuperado de: http://www.greatplacetowork.com.pe/storage/documents/Publications_Documents/ Mujeres_y_mercado_laboral_en_el_Peru.pdf)

Great Place to Work (GTP) (2018). Mujeres y mercado laboral en el Perú. Great Place to Work Institute. (Consulta: 30 de mayo 2017) (https://www.greatplacetowork.com.pe/los-mejores-lugares-paratrabajar/mujeres/2018)

Harvard University (2014). Competency Dictionary. Harvard Human Resources. (Consulta: 27 de diciembre de 2017) (Recuperado de: http://hr.fas.harvard.edu/files/fashr/files/competency_dictionary_fy14___final.pdf)

Hochwarter, W. A., Perrewé, P. L., Meurs, J. A., \& Kacmar, C. (2007). The interactive effects of work-induced guilt and ability to manage resources on job and life satisfaction. Journal of Occupational Health Psychology, 12, 125-135.

INSTITULO NACIONAL DE ESTADISTICA (INEI) (2017) BRECHAS DE GENERO 2017: Avances hacia la igualdad. (Recuperado de: https://www.inei.gob.pe/media/MenuRecursivo/publicaciones_digitales/Est/Lib144 4/libro.pdf)

INSTITUTO NACIONAL DE ESTADÍSTICA, (INEI) (2015) Brechas de Género 2015: Avances hacia la igualdad entre mujeres y hombres (Recuperado de: https://www.inei.gob.pe/media/MenuRecursivo/publicaciones_digitales/Est/Lib130 9/Libro.pdf)

INSTITUTO NACIONAL DE ESTADÍSTICA, (INEI) (2016) Más de 7 millones de mujeres conforman la fuerza laboral del Perú. [Informe de Prensa] (Consulta: 2 de 
diciembre de 2017) (Recuperado de: https://www.inei.gob.pe/prensa/noticias/masde-7-millones-de-mujeres-conforman-la-fuerza-laboral-del-peru-8943/)

Kavathatzopoulos I., Kostrzewa A. \& Berg K. (2008, October). Measuring ethical competence of organizacitions. Paper presented at the 21st Anual European Business Ethics Network: Antalya, Turkey. (Recuperado de: http://www.it.uu.se/research/project/ethcomp/EC-Org_sub3.pdf)

Margaret M. Hopkins, Diana Bilimoria (2008). "Social and emotional competencies predicting success for male and female executives", Journal of Management Development, Vol. 27 Issue: 1, pp.13-35. (Consulta: 05 de diciembre de 2017) (Recuperado de: https://doi.org/10.1108/02621710810840749)

Masias, Le. \& Parada, E. (2013) Mujeres, su participación económica en la sociedad. Guadalajara: Universidad de Guadalajara, México.

McElwain, A., \& Korabik, K. (2004). Work-family guilt. In M. Pitt-Catsouphes \& E. Kossek (Eds.). Work and Family Encyclopedia Online. Chestnut Hill MA: Sloan Network Encyclopedia Entry. (Recuperado de: http://workfamily.sas.upenn.edu/wfrn-repo/object/1eg649d12kw3zr8x)

Menezes, Amith (2016). Business Ethics and its importance in Banking Industry. International Journal of Scientific Research and Modern Education, 1(2), 196-201. (Recuperado de: http://ijsrme.rdmodernresearch.com/wpcontent/uploads/2016/12/139.pdf)

Mercado, P. \& Salgado, R. (2008). Estrés en ejecutivos de medianas y grandes empresas mexicanas: un enfoque de desarrollo humano organizacional. Estudios Gerenciales, 24(108), 15-36. Recuperado de http://www.sciencedirect.com/science/article/pii/S0123592308700421

Mertens, L. (2000). La Gestión por Competencia Laboral en la Empresa y la Formación Profesional. (Recuperado de: www.cinterfor.org.uy)

Muela Sandro (2009). Importancia de la banca en la economía de un país. [Mensaje en un blog]. (Consulta 10 de diciembre de 2017) (Recuperado de: http://smuela2009.blogspot.pe/)

Nussbaum, Martha. (2009). Las capacidades de las mujeres y la justicia social. Debate Feminista, 20(39), 89-129.

ONU MUJERES (2015) Hechos y cifras: Empoderamiento económico. (Consulta 10 de diciembre de 2017) (Recuperado de: http://www.unwomen.org/es/what-wedo/economic-empowerment/facts-and-figures)

Organización Internacional del Trabajo [OIT]. (2015). La mujer en la gestión empresarial: Cobrando impulso (Versión resumida del Informe Mundial). Ginebra, Suiza: OIT. 
Organización Internacional del Trabajo [OIT]. (2017). Towards a better future for women and work: Voices of women and men. Ginebra, Suiza: OIT.

Revista Conexión Esan (2013) Las claves para el ascenso de la mujer ejecutiva. En: Revista Conexión Esan, 13 de diciembre (consulta: 9 de enero) (Recuperado de: https://www.esan.edu.pe/conexion/actualidad/2013/12/13/claves-ascenso-mujerejecutiva/)

Revista IESE Insight (2012) Mujeres directivas bajo el techo de cristal. Liderazgo y dirección de personas. (Consulta: 31 de mayo 2017) (Recuperado de: http://www.ieseinsight.com/doc.aspx?id=00435\&ar=6\&idioma=1)

Revista SEMANA Económica (2014) El BCP es considerado la mejor empresa para trabajar en el país. En: Revista Semana Económica, 16 de julio (consulta: 9 de enero) (Recuperado de: http://semanaeconomica.com/article/mercados-yfinanzas/banca-y-finanzas/140360-el-bcp-es-considerado-la-mejor-empresa-paratrabajar-en-el-pais/)

Revista SEMANA Económica (2015) El ejecutivo peruano desea más mujeres en puestos directivos. (Recuperado de: http://semanaeconomica.com/factorhumano/2015/07/15/el-ejecutivo-peruano-desea-mas-mujeres-en-puestosdirectivos/)

Rodríguez Karem (2012). Sistema Financiero Peruano. Actualidad Empresarial, № 265. (Consulta: 09 de diciembre de 2017) (Recuperado de: http://aempresarial.com/servicios/revista/265_9_KLHHWEYODZXIJWLUQCGU XCBKSZOMAEPLPXSMBRAFRXNBTZVJCB.pdf)

SAGI - VELA, Luis (2004) Gestión por competencias: el reto compartido del crecimiento personal y de la organización. Editorial ESIC: Madrid, España.

Scotiabank. (2016) Reseñas institucionales: Scotiabank en el mundo. (Consulta: 27 de diciembre de 2017) (Recuperado de: https://www.scotiabank.com.pe/Acercade/Scotiabank-Peru/Scotiabank-en-Peru/resenas-institucionales)

Serna, Guadalupe. (2003). Propuestas y hallazgos preliminares para un análisis sobre mujeres ejecutivas en la Ciudad de México. Desacatos, (11), 77-96. (Consulta: 28 de noviembre de 2017) (Recuperado de: http://www.scielo.org.mx/scielo.php?script=sci_arttext\&pid=S1607050X2003000100005\&lng=es\&tlng=es.)

Sevillano García, M. L. (Dir.) (2009). Competencias para el uso de herramientas virtuales en la vida, trabajo y formación permanentes. Madrid: Pearson, Prentice Hall.

SITTERLY, Connie (1994) La mujer ejecutiva. Editorial Iberoamérica: Baja California, Estados Unidos. 
Solís Benito (24 Marzo de 2015). La importancia de la banca en el crecimiento. Diario El financiero: México. (Recuperado de: http://www.elfinanciero.com.mx/opinion/laimportancia-de-la-banca-en-el-crecimiento.html)

SPENCER, Lyle M. (1993) Competence at work, models for superior performance. USA: Wiley and Sons.

Suárez Battán \& Asociados (2017) Resultados del Primer Sondeo de "Mujeres Ejecutivas en Argentina 2017". Suárez Battán \& Asociados: Buenos Aires, Argentina. (Consulta: 28 de noviembre de 2017) (Recuperado de: http://www.sbasociados.com/files/Articulos/MujeresEjecutivas/Resultados_Mujeres_Ejecutivas_ Argentina-2017.pdf)

Suárez, Magdalena. (2008). Barreras en el desarrollo profesional femenino. Revista Española de Orientación y Psicopedagogía, 19(1), 61-72.

SUPERINTENDENCIA DE BANCA, SEGUROS Y AFP (SBS) (2017) Sistema Financiero Peruano. (Consulta: 4 de enero de 2018) [Tabla] (Recuperado de: https://intranet2.sbs.gob.pe/estadistica/financiera/2017/Abril/SF-0003-ab2017.PDF)

Torrelles, C., Coiduras, J., Isus, S. \& varios (2011). COMPETENCIA DE TRABAJO EN EQUIPO: DEFINICIÓN Y CATEGORIZACIÓN. Profesorado: Revista de Curriculum y formación de profesorado, 15 (3), 330-344.

Villarreal, O \& Landeta. (2007). La Estrategia de Internacionalización de la Empresa. Un Estudio de Casos de Multinacionales Vascas, Tesis Doctoral, Universidad del País VascoEuskalHerrikoUnibertsitatea, Bilbao. Premio Extraordinario de Doctorado de la UPV/EHU.

World Economic Forum (2017) The global gap report 2017. (Consulta 21 de mayo 2017) (Recuperado de: http://www3.weforum.org/docs/WEF_GGGR_2017.pdf) 


\section{ANEXOS}

\section{ANEXO 1: GUIA DE PREGUNTAS}

Buenos días/tardes. Mi nombre es Nadia Bullón Solis, y me encuentro realizando una investigación sobre las competencias críticas de las mujeres ejecutivas en la banca comercial en Lima Metropolitana

El objetivo principal es identificar y analizar aquellas competencias laborales que son críticas para las mujeres al ocupar cargos ejecutivos en la banca comercial en Lima Metropolitana.

Al respecto, por favor, siéntase con la libertad de opinar, brindar sus ideas y/o comentarios, no hay respuesta buena o mala, lo que nos interesa es solo conocer su opinión sincera al respecto. Es importante mencionar que toda la información proporcionada solo será usada para nuestro trabajo de investigación, estas serán unidas con otras encuestas realizadas y serán de uso confidencial, por lo que no se revelará su identidad.

Para una mejor y rápida entrevista se utilizará una grabadora de voz, ya que nos permitirá seguir una conversación más rápida y sencilla, ya que tomar apuntes implicará más tiempo en escribir sus respuestas y se tiene presente que su tiempo es importante. ¿Tiene algún inconveniente que se grabe esta conversación?

Se agradece de antemano el interés brindado y su participación en este estudio.

\section{SEGMENTO 1: Mujeres gerentes del Banco Scotiabank en Lima Metropolitana}

\section{A. Categoría: Situación actual}

1. ¿Cuál cree que es la situación actual de la mujer en puestos ejecutivos en su organización? 
2. ¿Considera que existen las mismas oportunidades para las mujeres respecto a los hombres en el sector bancario? ¿Por qué?

3. ¿Cree que esta situación ha cambiado en el tiempo? ¿Por qué?

4. ¿En qué áreas considera que la mujer ejecutiva tiene más presencia? ¿Por qué?

5. ¿Qué opina sobre las leyes acerca de la maternidad? ¿Consideras estas leyes como una brecha en el desempeño de la mujer en su trabajo? ¿Por qué?

6. ¿Qué apoyo o beneficios existen para las mujeres en donde se desempeña adicionales a los estipulados por ley? Puede mencionarlas. ¿Cree en su opinión que debería haber más beneficios para las mujeres? ¿Por qué?

7. ¿Qué cualidades debería tener, para usted, la mujer líder en la banca comercial?

8. Respecto a las relaciones laborales, el nivel académico u otros factores ¿Cuál considera que han sido los factores claves para su desarrollo profesional?

9. ¿Cuán amigable o no amigable considera que es la empresa donde trabaja con la vida familiar? (flexibilidad, horas extras, viajes, incorporación de los ritmos de las familias y sus necesidades)

\section{B. Categoría: Barreras para la mujer ejecutiva}

1. ¿Cuáles son las barreras sociales y culturales que enfrentan las mujeres ejecutivas de nuestro país para lograr el desarrollo profesional? ¿Considera que, en nuestro país, la cultura influye en el trato de hombres y mujeres desde niños? ¿Cómo ha enfrentado estas barreras?

2. Como mujer, ¿Cuáles son las principales facilidades y obstáculos que has enfrentado en tu trayectoria laboral en comparación a los hombres?

3. ¿Qué tanto cree que es una realidad en su organización? ¿Por qué?

4. ¿Cuáles cree que son los beneficios y desventajas de tener un trabajo como el suyo?

5. ¿Participa activamente en las reuniones de trabajo? ¿Expresa sus puntos de vista?

6. ¿Siente satisfacción de la imagen que transmite de Ud.?

7. ¿Cuáles son los principales obstáculos que ha enfrentado para llegar a este puesto? 
8. ¿Considera que estar casada es un reto para lograr un ascenso en la empresa? ¿Considera que tener hijos es un reto para lograr un ascenso en la empresa?

9. Según su opinión ¿Aún existe disparidad salarial respecto a hombres con el mismo cargo? ¿A qué cree que deba esto?

C. Categoría: Perfil de la mujer ejecutiva

1. ¿Cuál ha sido su "historia laboral”? ¿Cómo se acercó al mundo laboral? (prácticas, trabajos, cuántos trabajos, cambios, razones de cambios, dejó de trabajar en algún momento, retomó el trabajo) ¿por qué?

2. ¿En qué áreas de la banca comercial ha trabajado?

3. ¿Cuánto tiempo lleva en su posición actual?

4. ¿Cómo concilias tu vida profesional con la personal? ¿Tiene hijos? ¿Cuenta con apoyo para su cuidado?

5. ¿Qué nivel académico posee? ¿En qué carrera? ¿Y qué cursos han complementado su desarrollo profesional?

6. ¿Qué necesita hacer una mujer para ser bien percibida por sus pares y por su jefe?

7. Según su percepción, ¿cómo es el desempeño de las mujeres en la organización?

8. ¿Qué estrategias desarrollan las mujeres en la empresa donde Ud. trabaja para poder responder a las exigencias laborales y familiares? ¿Lo logran? ¿cómo? ¿Cree que los hombres viven la misma situación que las mujeres o usan las mismas estrategias?

D. Categoría: Competencias laborales

1. ¿Qué competencias consideras que deben desarrollar las mujeres para alcanzar tu posición actual?

2. De la siguiente lista (agrupación de 18 competencias) ¿cuáles considera las competencias críticas que le han permitido alcanzar su posición actual? 
3. ¿Se encuentra identificada con las competencias que exige su puesto? ¿Por qué? ¿Podría brindar un ejemplo de la puesta en práctica de esas competencias?

4. ¿La organización donde Ud. trabaja manifiesta explícitamente principios éticos, usted cree que se cumplen? ¿Los comparte?

5. ¿Crees que haya competencias específicas que tengan las mujeres ejecutivas y que no lo tienen la mayoría de hombres ejecutivos?

\section{E. Categoría: Motivaciones}

1. ¿Qué aspiraciones tiene en su trabajo?

2. ¿Qué significa el trabajo para usted como persona, es decir, qué valor le atribuye al trabajo (independencia /autonomía, realización personal, status, poder)?

3. ¿Qué consejo le darías a una mujer de la banca comercial que aspira a un puesto ejecutivo?

4. ¿Cuenta con referencias de mujeres que han desempeñado su profesión con eficacia?

5. ¿Cuál es el mejor consejo profesional y de quién vino?

6. ¿Cómo se visualiza en 5 años?

7. ¿Se siente reconocida profesionalmente por parte de su entorno (Familia, amistades, superiores, etc.)?

8. ¿Qué es lo que más le gusta de trabajar en el banco?

\section{SEGMENTO 2: Especialistas de recursos humanos de empresas privadas en Lima Metropolitana}

\section{A. Categoría: Situación actual}

1. ¿Cuál cree que es la situación actual de la mujer en puestos ejecutivos en su organización? 
2. ¿Considera que existen las mismas oportunidades para las mujeres ejecutivas respecto a los hombres? ¿Por qué?

3. ¿Cree que esta situación ha cambiado en el tiempo? ¿Por qué?

4. ¿En qué áreas considera que la mujer ejecutiva tiene más presencia? ¿Por qué?

5. ¿En qué sectores empresariales cree usted que hay más mujeres ejecutivas? ¿Por qué?

6. ¿En su organización cuentan con políticas específicas para el reclutamiento o línea de carrera para las mujeres?

7. ¿Existe cuota mínima de mujeres en cargos ejecutivos?

8. ¿Cuán amigable o no amigable considera que es la empresa donde trabaja con la vida familiar? (flexibilidad, horas extras, viajes, incorporación de los ritmos de las familias y sus necesidades)

9. ¿Qué apoyo o beneficios existen para las mujeres en donde se desempeña adicionales a los estipulados por ley? Puede mencionarlas. ¿Cree en su opinión que debería haber más beneficios para las mujeres? ¿Por qué?

\section{B. Categoría: Barreras para la mujer ejecutiva}

1. ¿Cuáles considera que son las barreras que más dificultan el desarrollo profesional de las mujeres para alcanzar puestos ejecutivos?

2. ¿Qué opina de los estereotipos sobre el rol de la mujer como madre, ama de casa, trabajadora y mujer? Como organización ¿Promueven el empoderamiento de la mujer ejecutiva? ¿Como?

3. Según su opinión ¿Existe disparidad salarial respecto a hombres y mujeres con el mismo cargo? ¿A qué cree que deba esto?

C. Categoría: Perfil de la mujer ejecutiva

1. ¿Cuál considera que debe ser el perfil de una gerente ejecutiva en su organización?

2. ¿Cuándo cree usted que está ante una líder? 
3. ¿Qué necesita hacer una mujer para ser bien percibida por sus pares y por su jefe?

4. Según su percepción, ¿cómo es el desempeño de las mujeres en la organización?

5. ¿Qué estrategias desarrollan las mujeres en la empresa donde Ud. trabaja para poder conciliar su vida laboral y familiar? ¿Lo logran? ¿cómo?

6. ¿Cree que los hombres viven la misma situación que las mujeres o usan las mismas estrategias?

7. ¿Qué nivel académico considera que debería como mínimo una mujer para alcanzar un cargo ejecutivo?

D. Categoría: Competencias laborales

1. ¿Qué cualidades debería tener, para usted, la mujer ejecutiva?

2. ¿Qué competencias exige el puesto de ejecutivo?

3. De la siguiente lista (agrupación de 18 competencias) ¿cuáles considera las competencias críticas para que las mujeres alcancen puestos ejecutivos?

4. ¿Existen programas para desarrollar específicamente ciertas competencias para puestos ejecutivos? ¿Cuáles?

5. ¿Crees que haya competencias específicas que tengan las mujeres ejecutivas y que no lo tienen la mayoría de hombres ejecutivos? ¿Cuáles?

\section{E. Categoría: Motivaciones}

1. ¿Cuáles son las causas más comunes de renuncia de las mujeres ejecutivas respecto a sus pares masculinos?

2. ¿Qué consejo le darías a una mujer que aspira a un puesto ejecutivo?

SEGMENTO 3: Gerentes de recursos humanos de la banca comercial de Lima Metropolitana 


\section{A. Categoría: Situación actual}

1. ¿Cuál cree que es la situación actual de la mujer en puestos ejecutivos en su organización?

2. ¿Considera que existen las mismas oportunidades para las mujeres ejecutivas respecto a los hombres en el sector bancario? ¿Por qué?

3. ¿Por qué crees que hay mayor porcentaje de mujeres ejecutivas en la banca comercial que en otros sectores?

4. ¿Cree que esta situación ha cambiado en el tiempo? ¿Por qué?

5. ¿En qué áreas considera que la mujer ejecutiva tiene más presencia? ¿Por qué?

6. ¿Cómo banco internacional tiene políticas específicas para el reclutamiento o línea de carrera para las mujeres?

7. ¿Existe cuota mínima de mujeres en cargos ejecutivos?

8. ¿Cuán amigable o no amigable considera que es la empresa donde trabaja con la vida familiar? (flexibilidad, horas extras, viajes, incorporación de los ritmos de las familias y sus necesidades)

9. ¿Qué apoyo o beneficios existen para las mujeres en donde se desempeña adicionales a los estipulados por ley? Puede mencionarlas. ¿Cree en su opinión que debería haber más beneficios para las mujeres? ¿Por qué?

\section{B. Categoría: Barreras para la mujer ejecutiva}

1. ¿Cuáles considera que son las barreras que más dificultan el desarrollo profesional de las mujeres para alcanzar puestos ejecutivos?

2. ¿Qué opina de los estereotipos sobre el rol de la mujer como madre, ama de casa, trabajadora y mujer? Como organización ¿Promueven el empoderamiento de la mujer ejecutiva? ¿Como?

3. Según su opinión ¿Existe disparidad salarial respecto a hombres y mujeres con el mismo cargo? ¿A qué cree que deba esto? 


\section{Categoría: Perfil de la mujer ejecutiva}

1. ¿Cuál considera que debe ser el perfil de una gerente ejecutiva en el banco?

2. ¿Cuándo cree usted que está ante una líder?

3. ¿Qué necesita hacer una mujer para ser bien percibida por sus pares y por su jefe?

4. Según su percepción, ¿cómo es el desempeño de las mujeres en la organización?

5. ¿Qué estrategias desarrollan las mujeres en la empresa donde Ud. trabaja para poder responder a las exigencias laborales y familiares? ¿Lo logran? ¿cómo?

6. ¿Cree que los hombres viven la misma situación que las mujeres o usan las mismas estrategias?

D. Categoría: Competencias laborales

1. ¿Qué cualidades debería tener, para usted, la mujer líder en la banca comercial?

2. ¿Qué competencias exige el puesto de ejecutivo?

3. De la siguiente lista (agrupación de 18 competencias) ¿cuáles considera las competencias críticas para que las mujeres alcancen puestos ejecutivos?

4. ¿Existen programas para desarrollar específicamente ciertas competencias para puestos ejecutivos? ¿Cuáles?

5. ¿Crees que haya competencias específicas que tengan las mujeres ejecutivas y que no lo tienen la mayoría de hombres ejecutivos? ¿Cuáles?

E. Categoría: Motivaciones

1. ¿Cuáles son las causas más comunes de renuncia de las mujeres ejecutivas respecto a sus pares masculinos?

2. ¿Qué consejo le darías a una mujer de la banca comercial que aspira a un puesto ejecutivo? 


\section{SEGMENTO 4: Gerente de recursos humanos del Scotiabank.}

A. Categoría: Situación actual

1. ¿Cuál cree que es la situación actual de la mujer en puestos ejecutivos en su organización? ¿En qué proporción? ¿Cree que se da de la misma manera en otros bancos?

2. ¿Considera que existen las mismas oportunidades para las mujeres ejecutivas respecto a los hombres en el sector bancario? ¿Por qué?

3. ¿Por qué crees que hay mayor porcentaje de mujeres ejecutivas en la banca comercial que en otros sectores?

4. ¿Cree que esta situación ha cambiado en el tiempo? ¿Por qué?

5. ¿En qué áreas considera que la mujer ejecutiva tiene más presencia? ¿Por qué?

6. ¿Cómo banco internacional tiene políticas específicas para el reclutamiento o línea de carrera para las mujeres?

7. ¿Existe cuota mínima de mujeres en cargos ejecutivos?

8. ¿Cuán amigable o no amigable considera que es la empresa donde trabaja con la vida familiar? (flexibilidad, horas extras, viajes, incorporación de los ritmos de las familias y sus necesidades)

9. ¿Qué apoyo o beneficios existen para las mujeres en donde se desempeña adicionales a los estipulados por ley? Puede mencionarlas. ¿Cree en su opinión que debería haber más beneficios para las mujeres? ¿Por qué?

B. Categoría: Barreras para la mujer ejecutiva

1. ¿Cuáles considera que son las barreras que más dificultan el desarrollo profesional de las mujeres para alcanzar puestos ejecutivos?

2. ¿Qué opina de los estereotipos sobre el rol de la mujer como madre, ama de casa, trabajadora y mujer? Como organización ¿Promueven el empoderamiento de la mujer ejecutiva? ¿Como? 
3. Según su opinión ¿Existe disparidad salarial respecto a hombres y mujeres con el mismo cargo? ¿A qué cree que deba esto?

C. Categoría: Perfil de la mujer ejecutiva

1. ¿Cuál considera que debe ser el perfil de una gerente ejecutiva en el banco?

2. ¿Qué necesita hacer una mujer para ser bien percibida por sus pares y por su jefe?

3. Según su percepción, ¿cómo es el desempeño de las mujeres en la organización?

4. ¿Qué estrategias desarrollan las mujeres en la empresa donde Ud. trabaja para poder responder a las exigencias laborales y familiares? ¿Lo logran? ¿cómo?

5. ¿Cree que los hombres viven la misma situación que las mujeres o usan las mismas estrategias?

D. Categoría: Competencias laborales

1. ¿Qué cualidades debería tener, para usted, la mujer líder en la banca comercial?

2. ¿Qué competencias exige el puesto de ejecutivo?

3. De la siguiente lista (agrupación de 18 competencias) ¿cuáles considera las competencias críticas para que las mujeres alcancen puestos ejecutivos?

4. ¿Existen programas para desarrollar específicamente ciertas competencias para puestos ejecutivos? ¿Cuáles?

5. ¿Crees que haya competencias específicas que tengan las mujeres ejecutivas y que no lo tienen la mayoría de hombres ejecutivos? ¿Cuáles?

\section{E. Categoría: Motivaciones}

1. ¿Cuáles son las causas más comunes de renuncia de las mujeres ejecutivas respecto a sus pares masculinos?

2. ¿Qué consejo le darías a una mujer de la banca comercial que aspira a un puesto ejecutivo? 


\section{SEGMENTO 5: Representante de la asociación de mujeres ejecutivas y directivas}

\section{A. Categoría: Situación actual}

1. ¿Cuál cree que es la situación actual de la mujer en puestos ejecutivos?

2. ¿Considera que existen las mismas oportunidades para las mujeres ejecutivas respecto a los hombres? ¿Por qué? ¿Qué debería hacer la mujer para conseguir esas mismas oportunidades?

3. ¿Cree que esta situación ha cambiado en el tiempo? ¿Por qué?

4. ¿En qué áreas dentro de una organización considera que la mujer ejecutiva tiene mayor presencia? ¿Por qué?

5. ¿En qué sectores empresariales cree usted que hay mayor presencia de mujeres ejecutivas? ¿Por qué?

6. En su opinión, ¿las organizaciones deberían contar con políticas específicas para el reclutamiento o línea de carrera para las mujeres? ¿por qué? ¿Y cómo influiría en su desarrollo?

7. En su opinión, ¿Existe cuota mínima de mujeres en cargos ejecutivos? ¿Qué opina al respecto?

8. ¿Cuán amigable o no amigable considera que son las empresas en general con la vida familiar? (flexibilidad, horas extras, viajes, incorporación de los ritmos de las familias y sus necesidades). Podría darme ejemplos, y como debería afrontarlo una mujer que desee hacer una línea de carrera en estas empresas.

9. En su opinión, ¿considera que existen apoyos o beneficios para las mujeres en las organizaciones adicionales a los estipulados por ley? Puede mencionarlas. ¿Cree en su opinión que debería haber más beneficios para las mujeres? ¿Por qué?

En el Perú existen leyes como el descanso pre y post natal - permiso de lactancia materna - implementación de lactarios.

10. ¿Qué opina sobre estas leyes? ¿Consideras estas leyes como una brecha en el desempeño de la mujer en su trabajo al tener que ausentarse durante el tiempo de pre y post natal? ¿por qué? 
11. ¿Qué cualidades debe tener hoy en día una mujer ejecutiva teniendo en cuenta el contexto económico, cultural y social?

12. Respecto a las relaciones laborales, nivel académico u otros factores ¿Cuáles considera que han sido los factores clave para su desarrollo profesional y laboral?

B. Categoría: Barreras para la mujer ejecutiva

1. ¿Cuáles son las barreras sociales y culturales que enfrentan las mujeres ejecutivas de nuestro país para lograr el desarrollo profesional? ¿Considera que, en nuestro país, la cultura influye en el trato de hombres y mujeres desde niños? ¿Cómo ha enfrentado estas barreras?

2. ¿Qué opina de los estereotipos sobre el rol de la mujer como madre, ama de casa, trabajadora y mujer? Como organización ¿cómo Promueven el empoderamiento de la mujer ejecutiva?

3. Como mujer, ¿Cuáles son las principales facilidades y obstáculos que ha enfrentado en tu trayectoria laboral en comparación a los hombres?

4. ¿Cómo pueden las mujeres lograr una mayor participación activamente en las reuniones de trabajo? ¿Expresa sus puntos de vista?

5. ¿Siente satisfacción de la imagen que transmite de Ud.?

6. ¿Cuáles son los principales obstáculos que ve reflejado en las mujeres ejecutivas que participan del programa de Women CEO?

7. ¿Considera que estar casada es un reto para lograr un ascenso en la empresa? ¿Considera que tener hijos es un reto para lograr un ascenso en la empresa?

8. Según su opinión ¿Aún existe disparidad salarial respecto a hombres con el mismo cargo? ¿A qué cree que deba esto?

C. Categoría: Perfil de la mujer ejecutiva

1. ¿Cuál considera que debe ser el perfil de una gerente ejecutiva?

2. ¿Qué necesita hacer una mujer para ser bien percibida por sus pares y por su jefe?

3. ¿Qué estrategias desarrollan las mujeres para poder conciliar su vida laboral y familiar? ¿Lo logran? ¿cómo? 
4. ¿Cree que los hombres viven la misma situación que las mujeres o usan las mismas estrategias?

5. ¿Qué nivel académico considera que debería como mínimo una mujer para alcanzar un cargo ejecutivo?

6. En su experiencia ¿conoce o ha tratado con ejecutivas de la banca? ¿Qué imagen tiene de ellas? ¿Qué imagen proyectan para usted?

D. Categoría: Competencias laborales

1. ¿Qué competencias desarrolla el programa WOMEN CEO para ayudar al desarrollar profesional de mujeres ejecutivas? ¿Por qué?

2. De la siguiente lista (agrupación de 18 competencias) ¿cuáles considera las competencias críticas para que las mujeres alcancen puestos ejecutivos?

3. ¿Crees que haya competencias específicas que tengan las mujeres ejecutivas y que no lo tienen la mayoría de hombres ejecutivos? ¿Cuáles?

4. En su experiencia ¿Cómo cree que deben evaluar las competencias laborales para puestos ejecutivos al contratar o ascender personal? ¿Las evaluaciones son iguales para hombres y mujeres?

\section{E. Categoría: Motivaciones}

1. ¿Qué consejo le darías a una mujer que aspira a un puesto ejecutivo?

2. Según su experiencia ¿Qué motivaciones cree que tienen las mujeres para llevar cargos ejecutivos? Y en su caso ¿Cuál es su motivación para lo que viene realizando? 


\section{ANEXO 2: LISTA DE COMPETENCIAS LABORALES}

De la siguiente lista (agrupación de 18 competencias) Marque con una $\mathrm{X}$ aquellas competencias que considera como críticas para que las mujeres alcancen un puesto ejecutivo.

$\square$ Ética e integridad

$\square$ Liderazgo

$\square$ Calidad de trabajo

$\square$ Capacidad de planificación y organización

$\square$ Iniciativa

$\square$ Innovación y creatividad

$\square$ Orientación a resultados

$\square$ Delegación y dirección de personas

$\square$ Adaptación al cambio

$\square$ Pensamiento estratégico

$\square$ Influencia y negociación

$\square$ Trabajo en equipo

Capacidad de comunicación

$\square$ Orientación al cliente interno y externo

$\square$ Desarrollo y autodesarrollo del talento

$\square$ Pensamiento analítico

$\square$ Resolución de problemas

$\square$ Relaciones públicas

$\square$ Otros: 


\section{ANEXO 3: FICHA DE DATOS}

\begin{tabular}{|l|l|}
\hline \multicolumn{2}{|c|}{ Ficha de datos de la entrevistada } \\
\hline \multicolumn{2}{|c|}{} \\
\hline Nombre completo: & \\
\hline Edad: & \\
\hline Estado civil: & \\
\hline Cargo: & \\
\hline \multicolumn{2}{|c|}{} \\
\hline
\end{tabular}




\section{ANEXO 4: CODIFICACION DE LA INFORMACIÓN}

\section{CODIGOS}

\begin{tabular}{|c|c|c|}
\hline 1 & SA-GQT & GERENTES QUIEREN TRABAJAR CON MUJERES \\
\hline 2 & SA-MBR & MUJERES DAN BUENOS RESULTADOS \\
\hline 3 & SA-P2030 & PROPORCION DE MUJERES $<30 \%$ \\
\hline 4 & SA-P3040 & PROPORCION DE MUJERES $>30 \%-50 \%<$ \\
\hline 5 & SA-OC & EXISTEN OPORTUNIDADES DE CRECIMIENTO \\
\hline 6 & SA-MT & PERCIBE INCREMENTO DEL NUMERO DE MUJERES EN EL TIEMPO \\
\hline 7 & SA-PAC & PRESENCIA EN AREA COMERCIAL \\
\hline 8 & SA-PAS & PRESENCIA EN AREA DE SOPORTE \\
\hline 9 & SA-IO & IGUAL OPORTUNIDADES PARA HOMBRES Y MUJERES \\
\hline 10 & SA-NIO & NO HAY IGUAL OPORTUNIDADES PARA HOMBRES Y MUJERES \\
\hline 11 & SA-PME & PREDOMINIO MASCULINO AREAS EJECUTIVAS \\
\hline 12 & SA-EMC & EXISTE MUCHA COMPETENCIA EN ALTOS CARGOS \\
\hline 13 & SA-ECMI & EXISTE CUOTA MINIMA DE INCLUSION PARA MUJERES A ALTOS CARGOS \\
\hline 14 & SA-CGA & CAMBIOS GENERACIONALES HAN GENERADO APERTURA \\
\hline 15 & SA-SDS & CREE QUE SI HAY DISPARIDAD SALARIAL \\
\hline 16 & SA-NDS & CREE QUE NO HAY DISPARIDAD SALARIAL \\
\hline 17 & B-CM & CULTURA MACHISTA DEL PAIS \\
\hline 18 & B-FTVP & FALTA TIEMPO PARA VIDA PRIVADA \\
\hline 19 & B-ARAC & $\begin{array}{l}\text { AUTOLIMITARSE A EJERCER RESPONSABILIDADES DE ASUMIR ALTOS } \\
\text { CARGOS }\end{array}$ \\
\hline 20 & B-MSDD & SER MAMA SI DIFICULTA EL DESEMPEÑO LABORAL \\
\hline 21 & B-MNDD & SER MAMA NO DIFICULTA DEL DESEMPEÑO LABORAL \\
\hline 22 & B-PCCG & HAY POCOS CUPOS PARA ASCENDER A CARGOS DIRECTIVOS \\
\hline 23 & B-EEM & ENVIDIA ENTRE MUJERES \\
\hline 24 & B-TCH & TOPICOS DE CONVERSACION ENTRE HOMBRES \\
\hline 25 & B-BGDA & BRECHA GENERACIONAL DIFICULTA APERTURA HACIA LA MUJER \\
\hline 26 & B-SCVL & SENTIMIENTO DE CULPA POR PRIORIZAR VIDA PROFESIONAL \\
\hline 27 & P-E3040 & EDAD ENTRE 35-45 AÑOS \\
\hline 28 & P-E4150 & EDAD DE 46 A MÁS AÑOS \\
\hline 29 & $\mathrm{P}-\mathrm{CCH}$ & CASADA CON HIJO(S) \\
\hline 30 & $\mathrm{P}-\mathrm{CSH}$ & CASADA SIN HIJO(S) \\
\hline 31 & $\mathrm{P}-\mathrm{DCH}$ & DIVORCIADA CON HIJO(S) \\
\hline 32 & P-CONH & CONVIVIENTE CON HIJO(S) \\
\hline
\end{tabular}




\begin{tabular}{|c|c|c|}
\hline 33 & & SOLTERA SIN HIJO(S) \\
\hline 34 & P-EX1020 & EXPERIENCIA EN RUBRO 10-20 AÑOS \\
\hline 35 & P-EXM20 & EXPERIENCIA EN RUBRO MAS DE 20 AÑOS \\
\hline 36 & P-NAL & NIVEL ACADEMICO LICENCIADA \\
\hline 37 & P-NAM & NIVEL ACADEMICO MAESTRIA \\
\hline 38 & P-NAD & NIVEL ACADEMICO DOCTORADO \\
\hline 39 & P-TAP & TIENE APOYO DE LOS PADRES \\
\hline 40 & P-TAC & TIENE APOYO DEL CONYUGE \\
\hline 41 & P-TAH & TIENE APOYO DE LOS HIJOS \\
\hline 42 & P-TAE & TIENE APOYO DE EMPLEADA \\
\hline 43 & CC-EI & ETICA E INTEGRIDAD \\
\hline 44 & CC-LID & LIDERAZGO \\
\hline 45 & CC-CT & CALIDAD DE TRABAJO \\
\hline 46 & CC-CPO & CAPACIDAD DE PLANIFICACION Y ORGANIZACIÓN \\
\hline 47 & CC-INI & INICIATIVA \\
\hline 48 & CC-IC & INOVACION Y CREATIVIDAD \\
\hline 49 & CC-OR & ORIENTACION A RESULTADOS \\
\hline 50 & CC-DDP & DELEGACION Y DIRECCION DE PERSONAS \\
\hline 51 & CC-AC & ADAPTACION AL CAMBIO \\
\hline 52 & CC-PE & PENSAMIENTO ESTRATEGICO \\
\hline 53 & CC-INEG & INFLUENCIA Y NEGOCIACION \\
\hline 54 & CC-TE & TRABAJO EN EQUIPO \\
\hline 55 & $\mathrm{CC}-\mathrm{CC}$ & CAPACIDAD DE COMUNICACIÓN \\
\hline 56 & CC-OCIE & ORIENTACION AL CLIENTE INTERNO Y EXTERNO \\
\hline 57 & CC-DAT & DESARROLLO Y AUTODESARROLLO DEL TALENTO \\
\hline 58 & CC-PA & PENSAMIENTO ANALITICO \\
\hline 59 & CC-RP & RESOLUCION DE PROBLEMAS \\
\hline 60 & CC-RPUB & RELACIONES PUBLICAS \\
\hline 61 & M-AR & MOTIVO DE AUTOREALIZACION \\
\hline 62 & M-AT & MOTIVO DE AUTONOMIA \\
\hline 63 & M-AF & MOTIVO DE AFILIACION \\
\hline 64 & M-AP & MOTIVO DE APRENDIZAJE \\
\hline 65 & M-LOG & MOTIVO DE LOGRO \\
\hline 66 & M-REC & MOTIVO DE RECONOCIMIENTO \\
\hline 67 & B-FH & FLEXIBILIDAD DE HORARIOS \\
\hline 68 & B-CV & CAPACITACION VIRTUAL \\
\hline 69 & B-TD & TALLERES DE DESARROLLO DE COMPETENCIAS \\
\hline
\end{tabular}




\begin{tabular}{|l|l|l|}
70 & B-CS & CAMPAÑAS DE SALUD PARA MUJERES \\
\hline
\end{tabular}

\begin{tabular}{|c|l|l|}
\hline 71 & E-CING & COACHING \\
\hline 72 & E-EOV & EXPRESAR SU OPINIÓN PARA TENER VISIBILIDAD \\
\hline 73 & E-NING & NETWORKING \\
\hline 74 & E-DAC & DESARROLLO DE AUTOCONFIANZA \\
\hline
\end{tabular}

